\title{
Room-Temperature Gas Sensors Under Photoactivation: From Metal Oxides to 2D Materials
}

Cite as

Nano-Micro Lett.

(2020) 12:164

Received: 15 May 2020

Accepted: 15 July 2020

Published online: 13 August 2020

(C) The Author(s) 2020

\author{
Rahul Kumar ${ }^{1}$, Xianghong Liu $^{2,3}$, Jun Zhang $^{2,3}{ }^{凶}$, Mahesh Kumar $^{1} \bowtie$ \\ $\triangle$ Jun Zhang, jun@qdu.edu.cn; Mahesh Kumar, mkumar@iitj.ac.in \\ 1 Department of Electrical Engineering, Indian Institute of Technology Jodhpur, Jodhpur 342037, India \\ 2 College of Physics, Center for Marine Observation and Communications, Qingdao University, \\ Qingdao 266071, People's Republic of China \\ 3 Key Laboratory of Advanced Energy Materials Chemistry (Ministry of Education), Nankai University, \\ Tianjin 300071, People's Republic of China
}

\section{HIGHLIGHTS}

- Operations of metal oxide semiconductors gas sensors at room temperature under photoactivation are discussed.

- Emerging two-dimensional (2D) materials-based gas sensors under light illumination are summarized.

- The advantages and limitations of metal oxides and 2D-materials-based sensors in gas sensing at room temperature under photoactivation are highlighted.

\begin{abstract}
Room-temperature gas sensors have aroused great attention in current gas sensor technology because of deemed demand of cheap, low power consumption and portable sensors for rapidly growing Internet of things applications. As an important approach, light illumination has been exploited for room-temperature operation with improving gas sensor's attributes including sensitivity, speed and selectivity. This review provides an overview of the utilization of photoactivated nanomaterials in gas sensing field. First, recent advances in gas sensing of some exciting different nanostructures and hybrids of metal oxide semiconductors under light illumination are highlighted. Later, excellent gas sensing performance of emerging two-dimensional materialsbased sensors under light illumination is discussed in details with proposed gas sensing mechanism. Originated impressive features from the interaction of photons with sensing materials are eluci-
\end{abstract}

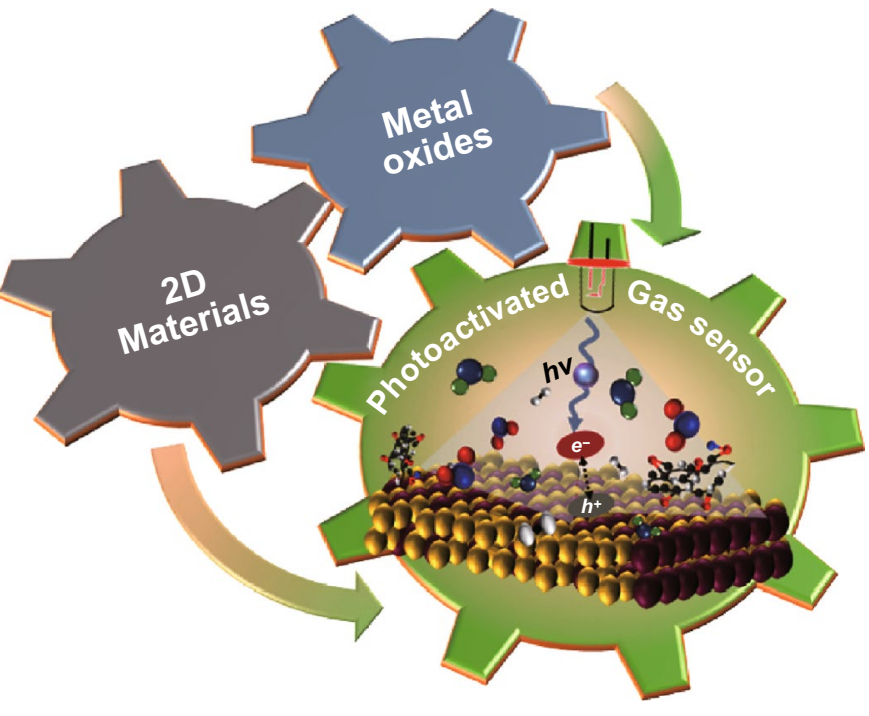
dated in the context of modulating sensing characteristics. Finally, the review concludes with key and constructive insights into current and future perspectives in the light-activated nanomaterials for optoelectronic gas sensor applications.

KEYWORDS Gas sensor; Room temperature; Photoactivation; Metal oxide; 2D materials 


\section{Introduction}

Over the past decades, room-temperature (RT) gas sensor device has been shown great research interest in the realm of advanced electronic devices. Due to detection of toxic gases and volatile organic compounds (VOCs), the sensors are exploited in many different kind of applications, such as air quality and industry processing monitoring, agriculture production, medical diagnosis and space [1, 2]. Various types of gas sensors such as electrochemical, optical, acoustic and conductometric, etc., have been explored in gas sensing field [3-7]. Among these sensors, resistive or fieldeffect transistor (FET) sensors are nowadays demanded in this nanotechnology era because of its easy fabrication, possible miniaturization, low cost and simple operation [8-12]. Moreover, different materials such as semiconducting metal oxides, carbon nanotubes (CNTs) and most emerging twodimensional (2D) materials have been employed for developing resistive gas sensors [13-16].

Metal oxide semiconductors (MOS) have been long investigated for chemiresistive gas sensors since $1960 \mathrm{~s}$ [17]. This type of gas sensors usually works at an elevated temperature in the range of $200-500{ }^{\circ} \mathrm{C}$, which requires a heater in the sensor device. Thermal energy is needed to activate the adsorption of ionized oxygen species and to overcome the barriers of sensing reactions [18-20]. However, the high working temperatures can lead to some drawbacks. It may deteriorate the working life of a sensor, increase fabrication complexity and cause decay of sensor sensitivity due to the thermally induced ripening of nanoparticles. Consequently, enormous research efforts have been dedicated to the development of gas sensors that can work at low temperature, or even RT. In this regard, light activation is a promising method as an alternative to thermal heating. The illumination of MOS with a light such as UV can change the surface electronic properties by modulating the concentration of photocarriers in MOS, hence promoting the interaction between molecules and sensing layers. It has been widely studied to improve the sensor sensitivity of various MOS at RT. In addition, light activation is also very useful to optimize the sensor selectivity and response-recovery speed. This topic has been recently discussed in some reviews and book chapters [21-23]. Here, we will summarize the most recent advances obtained in light-activated RT MOS sensors within the past few years.
On the other hand, emerging 2D materials have garnered enormous attention for developing high-performance RT chemiresistive gas sensor owing to its high surface-to-volume ratio and excellent physical or chemical properties [24-27]. First, 2D material-based chemiresistive gas sensor was fabricated using prominent $2 \mathrm{D}$ material graphene in [28]. The graphene gas sensor exhibited excellent sensitivity to gases even to detect single gas molecule at RT. This significant research has led exploitation of the increasing number of $2 \mathrm{D}$ materials in gas sensing field [24, 29-31]. Despite the RT operation with high sensitivity, slow response and incomplete recovery at RT limit its usage on commercial sensing platforms. In this regard, thermal energy was used to achieve fast response and complete recovery; however, it deteriorates the gas sensitivity of 2D material-based gas sensors [32-35]. Moreover, integration of thermal energy source with the sensor also introduces drawbacks as mentioned above for metal oxide gas sensor. On the other hand, the light source has also been utilized to address slow response/recovery kinetics of 2D materials gas sensors. Photoactivation has been improved the response/recovery time and also enhanced the gas sensitivity of the sensor at RT. Besides, it is also used for optimizing the selectivity of the 2D materials sensors. Thus, light activation is a very useful tool to optimize the sensor's figure of merits including sensitivity, selectivity, speed and stability.

In this review, we discussed RT gas sensors using photoactivated materials. This review has been divided into two sections related to sensing materials: semiconducting metal oxide, and 2D materials including graphene and layered materials ( $\mathrm{MoS}_{2}, \mathrm{MoTe}_{2}, \mathrm{WS}_{2}, \mathrm{SnS}_{2}, \mathrm{ReS}_{2}, \mathrm{MXenes}$, etc.). Firstly, we focus on recent progress in gas sensing of some exciting different nanostructures and hybrids of the metal oxide semiconductors at RT under light illumination. Secondly, we discussed the gas sensing performance of emerging 2D materials under light illumination with proposed gas sensing mechanism. Finally, we explained current constructive insights and future perspective in the exploitation of photons in gas sensing field.

\section{Considerations of Selection of Light Source}

Although light activation is an efficient method to improve the sensor performances, it is still quite difficult to tell which kind of light is most powerful towards detection of a 
particular molecule. This is reflected by the large amount of works reported so far, from which a general consent on the correlations between the light activation, sensor structure and materials selection is still missing.

Undoubtedly, the sensing properties are a complex interaction between sensor materials, gaseous molecules and light illumination. It is widely considered that the light illumination can change the surface carrier density of sensing materials by exciting electrons from the valence band of semiconductors. On the one hand, the bandgap of the semiconductors should be a matter of concern when choosing a light source. For example, $\mathrm{SnO}_{2}$ has a wide bandgap of $3.5 \mathrm{eV}$, implying this material can only be activated by light with a higher photon energy in the UV region. Probably this is why most reports of $\mathrm{SnO}_{2}$ sensors have been activated under UV light. In principle, $\mathrm{TiO}_{2}$ and $\mathrm{ZnO}$ materials with a moderate bandgap of ca. $3.2 \mathrm{eV}$ should be active under the light illumination with a wavelength shorter than $388 \mathrm{~nm}$, i.e., UV light. As reported by Kim et al. [36], the UV light $(\lambda \leq 382 \mathrm{~nm})$ was found to result in the most significant decrease in the resistance of $\mathrm{ZnO}$ films due to generation of photoexcited electrons compared to the blue $(\lambda \leq 439 \mathrm{~nm})$ and green $(\lambda \leq 525 \mathrm{~nm})$ lights. However, this does not guarantee the best sensor response to NO, which was otherwise obtained under irradiation of blue light. It is also noted that the best sensing dynamics have been achieved under UV illumination. When $\mathrm{PbS}$ with a small bandgap of $0.41 \mathrm{eV}$ is attached to $\mathrm{ZnO}$, the sensor can be activated by near-infrared light illumination $(\lambda=850 \mathrm{~nm})$ with a minimum photon energy or detection of $\mathrm{NO}_{2}$ [37]. On the other hand, the choice of light source is also related to the molecule structure. It was reported that the $\mathrm{ZnO}$ was not sensitive to benzene and toluene under $365 \mathrm{~nm}$ UV irradiation, but could be sensitive under $254 \mathrm{~nm}$ UV irradiation [38]. This is ascribed to the aromatic ring structure with a high stability, which needs a high photon energy to initiate the sensing reactions. Li et al. [39] showed that $\mathrm{ZnO}$ under UV light was very selective to formaldehyde against other molecules including methanol, acetone, toluene, benzene and ethanol. They attributed the sensitivity to the larger polarity of formaldehyde. In addition, ketone compounds change its behaviour from a weak reducing to a weak oxidizing agent under lower wavelength of $254 \mathrm{~nm}$ UV irradiation. So, the $\mathrm{MoTe}_{2}$ sensor showed different negative and positive response to ketone compounds under 365 and $254 \mathrm{~nm}$ light irradiation at RT, respectively [40].
In the following parts, we will present a detailed discussion on the sensor performances under photoactivation of gas sensors based on MOS, and 2D materials.

\section{Photoactivated Metal Oxide Semiconductors}

\section{1 $\mathrm{ZnO}$}

$\mathrm{ZnO}$ nanostructures have been reported to have improved sensor sensitivity or selectivity to multiple gases under photoactivation. For gas sensors, UV illumination was initially found to largely improve the conductance of $\mathrm{ZnO}$ nanowires in the presence of $\mathrm{O}_{2}$ due to the increased carrier density, as a result of the capture of photoexcited holes by the oxygen ions $\left(\mathrm{O}_{2}^{-}, \mathrm{O}^{-}\right.$, or $\left.\mathrm{O}^{2-}\right)$ [41]. Costello and co-workers previously demonstrated that the UV illumination successfully resulted in the RT sensitivity of $\mathrm{ZnO}$ thick film sensors for detection of VOCs [42]. It is rather impressive that the sensor was able to detect acetone and acetaldehyde at an extremely low concentration (1 ppb). According to this report, a tunable sensitivity of the sensor was obtained on the varied UV light intensity, and it is also possible to tune the sensor selectivity by changing the light intensity.

In another work, Fan et al. studied the effects of UV illumination on the hydrogen sensing performance of $\mathrm{ZnO}$ thin films at RT [43]. They found that the sensor sensitivity and the response-recovery speed were improved by UV illumination. A mechanism investigation revealed that pre-chemisorbed oxygen ions $\left(\mathrm{O}_{2}^{-}\right)$on $\mathrm{ZnO}$ surface are thermally stable at $\mathrm{RT}$ and these are unreactive in dark condition owing to its high adsorption energy. However, holes generated by UV light react with intrinsic chemisorbed oxygen ions $\left(\mathrm{O}_{2}^{-}\right)$and desorb these from $\mathrm{ZnO}$ surface. While photogenerated electrons promote the additional oxygen adsorption and formation of the new highly reactive photoinduced oxygen ions $\left(\mathrm{O}_{2}^{-}\right)$, which are responsible for the RT gas sensing through performing redox reaction with target analyte at RT. Moreover, some of the gas molecules react with photoexcited electrons/holes through direct adsorption on the sensing material surface. This sensing mechanism has been widely used to explain the sensing properties of MOS under photoactivation. 
However, a consistent general sensing mechanism of MOS under light illumination has not been appeared yet . UV illumination was also used by Duan et al. to improve the $\mathrm{NO}_{2}$ sensing performances of $\mathrm{ZnO}$ porous thin films at RT [44]. The thickness-dependent responses were demonstrated under UV irradiation. The $\mathrm{ZnO}$ porous thin film with a thickness of ca. $1500 \mathrm{~nm}$ showed the best response compared to other thickness. They claimed the thicknessdependent responses were due to the gradual decrease of photogenerated carrier concentration in the film, which is highly related to the penetration depth of the incident UV light. This finding is meaningful to the design of sensing layers with appropriate thickness in order to achieve a high response. Furthermore, Cui and co-workers studied the effect of structural properties of $\mathrm{ZnO}$ on gas sensing under UV light illumination [45]. They synthesized $\mathrm{ZnO}$ nanofibers by electrospinning, and nanoplates as well as nanoflowers of $\mathrm{ZnO}$ were synthesized by hydrothermal method, and SEM images are shown in Fig. 1a-c. It was observed that $\mathrm{ZnO}$ nanofibers exhibited about 6.7 times higher sensitivity to formaldehyde compared to $\mathrm{ZnO}$ nanoplates and about 2.5 times higher than that of $\mathrm{ZnO}$ nanoflowers, respectively, under $365 \mathrm{~nm}$ UV light (Fig. 1d). This enhanced sensitivity of $\mathrm{ZnO}$ nanofibers was attributed to their more reactive sites on surface and polycrystalline structure with large number of grain boundaries and sensing mechanism is shown Fig. 1e. In addition, Peng et al. demonstrated sensing behaviour of $\mathrm{ZnO}$ nanorods to formaldehyde under UV illumination at RT [46]. The ZnO nanorods showed about 120 times higher sensitivity under UV light compared to that without UV light illumination.

A reliable selectivity to formaldehyde with low detection limit of 1.8 ppm was because of better photocatalytic oxidation of formaldehyde through absorbed oxygen ions on nanorods surface. The photocatalytic reaction is stimulated by photogenerated charge carrier efficiency; however, this efficiency decreases with decrease in size of sensing material. So, optimized size of $\mathrm{ZnO}$ nanorods with higher surface-tovolume ratio as well as maximum photogenerated carrier efficiency showed high sensitivity to formaldehyde at RT under
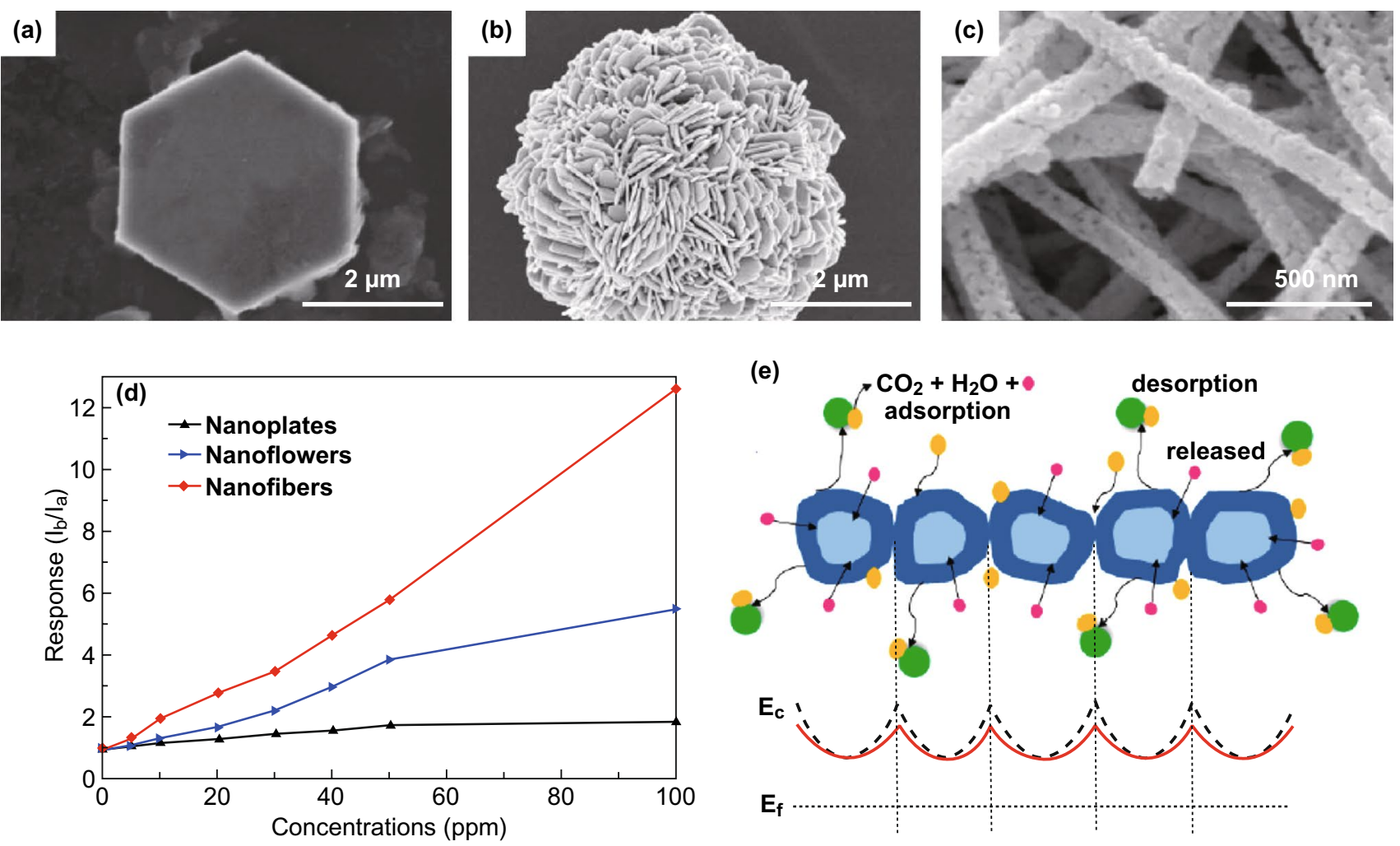

Fig. 1 SEM images of $\mathrm{ZnO}$ a nanoplates, $\mathbf{b}$ nanoflowers, $\mathbf{c}$ nanofibers. d Comparative plot of sensor responses for $\mathrm{ZnO}$ nanoplates, nanoflowers and nanofibers at RT under UV light. e Schematic sensing mechanism for the ZnO nanofibers to formaldehyde under UV irradiation. Reproduced with permission [45]. Copyright 2015, Elsevier 
UV light illumination [47]. To further enhance the photogenerated charge carrier efficiency by forming heterojunctions in sensing material, $\mathrm{Li}$ et al. demonstrated sensing characteristics of $\mathrm{SnO}_{2} / \mathrm{ZnO}$ nanofibers heterojunctions under UV light irradiation at RT [39]. The nanofibers heterojunctions increase carrier lifetime of photogenerated electron-hole pairs via avoiding recombination, which enhances the redox reaction during sensing. As a result, the $\mathrm{SnO}_{2} / \mathrm{ZnO}$ sensor exhibited higher selective sensitivity to formaldehyde at RT.

Synergic interaction between noble metal catalyst and photo-UV illumination has been explored to improve the sensor sensitivity. Kumar and co-workers achieved RT sensor performances from $\mathrm{Au}$-modified $\mathrm{ZnO}$ networks to hydrogen under UV illumination [48]. The sensor exhibited a response of $\sim 21.5 \%$ to $5 \mathrm{ppm}$ hydrogen, while no response was recorded without UV illumination. The RT sensor response was due to the UV photoactivation enhanced the adsorption of ionized oxygen species and the d-band electron transition from $\mathrm{Au}$ to $\mathrm{ZnO}$. UV light-activated flexible gas sensor based on $\mathrm{ZnO}$ materials has been reported [49, 50]. For example, nanoarrays of Au-modified $\mathrm{ZnO}$ nanorods have been shown by Joshi et al to have stable and reproducible performances for detection of $\mathrm{O}_{3}$ under UV illumination [50]. The $\mathrm{ZnO}$ nanorods arrays were hydrothermally grown on a poly (ethylene terephthalate) substrate to fabricate a flexible sensor. The $\mathrm{ZnO}$ sensor is not able to recover to its baseline resistance. The UV illumination plays a crucial role in promoting the sensor recovery. The complete recovery observed under UV irradiation is due to the accelerated reaction rate because UV light can provide sufficient energy to desorb the chemisorbed oxygen species on $\mathrm{ZnO}$ surfaces. Due to the formation of a nano-Schottky barrier at the $\mathrm{Au} / \mathrm{ZnO}$ interface and the catalytic spillover effect of $\mathrm{Au}$, the flexible $\mathrm{Au} / \mathrm{ZnO}$ exhibited a high response of 108 to $30 \mathrm{ppb}$ under UV illumination, which is much higher than that of $\mathrm{ZnO}$. The depletion layer formed on the surface of $\mathrm{ZnO}$ increases the electrical resistance of the sensor. When the sensor is illuminated by UV light, many electron-hole pairs are generated because the photon energy is higher than the bandgap of $\mathrm{ZnO}$. The reactions of photogenerated holes with oxygen species $\left(\mathrm{O}_{2}^{-}\right)$will desorb the oxygen species from the $\mathrm{ZnO}$ surface, and the surface depletion layer is narrowed. Upon exposure to $\mathrm{O}_{3}$, the adsorption of $\mathrm{O}_{3}$ molecules on $\mathrm{ZnO}$ will consume the photogenerated electrons, thus causing the expansion of the surface depletion layer and the increase of the sensor resistance (Tables 1,2,3).
In addition to UV, visible lights such as blue, green and red, as well as the mixed monochromatic, i.e., white light, are also frequently explored to enhance the sensor performances. The visible light activation provides higher energy efficiency and lager potential for gas sensors because of their wide spectrum range in the sunlight [51, 52]. Due to the different photon energy, the influence of different visible lights on the electronic properties and the sensor properties can be modulated. Kim and co-workers studied the $I-V$ curves (Fig. 2a) of $\mathrm{ZnO}$ films in dark and various wavelength light irradiation and found that higher photon energy generated the higher current, which is due to the photoexcitation of electron-hole pairs in the film [36]. However, their gas sensing measurements revealed that the blue light irradiation exhibited the highest response (Fig. 2b), combined with $\mathrm{Au}$ catalytic effect greatly enhanced the NO response rate, and it is also observed that the response-recovery speed is also highly dependent on the wavelength of the lights.

Apart from the catalytic effect of noble metals, the concept of localized surface plasmon resonance (LSPR) was also utilized to develop high-performance gas sensors at RT $[53,54]$. The introduction of LSPR effect into noble metal/ MOS hybrids greatly expands the research in photoactivated gas sensors. $\mathrm{Xu}$ et al. studied the sensing performance to ethanol of $\mathrm{Au} / \mathrm{ZnO}$ nanowires under white light illumination at RT [54]. They found light illumination and Au decoration jointly led to the enhanced gas sensing results. However, as shown in Fig. 2c, the Au nanoparticles are observed to play a dominant role in the enhanced sensing. They attributed the promotion effect to the LSPR effect of Au. The LSPR effect not only enhanced the light absorption but also suppress the recombination of photogenerated electron-hole pairs. The hot electrons in Au generated by the LSPR absorption can overcome the Schottky barrier at $\mathrm{Au} / \mathrm{ZnO}$ junctions and inject into the conduction band of $\mathrm{ZnO}$ (Fig. 2d). As a result, more surface-adsorbed oxygen species will be formed on the surface of $\mathrm{ZnO}$ to trigger more intense sensing reactions.

Tai and co-workers investigated the sensitivities of $\mathrm{Ag} /$ $\mathrm{ZnO}$ sensors to $\mathrm{NO}_{2}$ gas $(0.5-5 \mathrm{ppm})$ under various light $(365-520 \mathrm{~nm})$ illumination [55]. They also studied the loading level of $\mathrm{Ag}$ on the photoactivated sensor performance. The best response towards $\mathrm{NO}_{2}$ detection was obtained on the $3 \mathrm{~mol} \% \mathrm{Ag} / \mathrm{ZnO}$ sensor under blue-green illumination with a wavelength of $470 \mathrm{~nm}$ (Fig. 2e). It is revealed in Fig. $2 f$ that the varied light with different wavelength 
Table 1 Summary of metal oxide gas sensors to various gases under photoactivation at room temperature

\begin{tabular}{|c|c|c|c|c|c|c|}
\hline Material & Gas & Sensitivity or response & Light source & Response/ recovery time & Detection limit & References \\
\hline $\mathrm{ZnO}$ nanoparticles & Acetone & - & $400 \mathrm{~nm}$ & $-1-$ & $1 \mathrm{ppb}$ & {$[42]$} \\
\hline $\mathrm{ZnO}$ nanoline & $100 \mathrm{~m} \mathrm{H}_{2}$ & $1.5 \%$ & $365 \mathrm{~nm}$ & $>10 \mathrm{~min}$ & - & {$[43]$} \\
\hline $\mathrm{ZnO}$ & $50 \mathrm{ppm} \mathrm{NO}$ & 15 & $365 \mathrm{~nm}$ & - & - & {$[44]$} \\
\hline $\mathrm{ZnO}$ nanofiber & 100 ppm HCHO & 12.61 & $365 \mathrm{~nm}$ & $32 / 17 \mathrm{~s}$ & - & [45] \\
\hline $\mathrm{ZnO}$ nanorods & 200 ppm Formaldehyde & 16.87 & $370 \mathrm{~nm}$ & $14 / 0.5 \mathrm{~min}$ & $1.8 \mathrm{ppm}$ & {$[46]$} \\
\hline $\mathrm{SnO}_{2} / \mathrm{ZnO}$ nanofibers & 50 ppm HCHO & 2.3 & $365 \mathrm{~nm}$ & - & - & [39] \\
\hline $\mathrm{ZnO}$ & $5 \mathrm{ppm} \mathrm{H}_{2}$ & $21.5 \%$ & $365 \mathrm{~nm}$ & $4 / 24 \mathrm{~s}$ & - & {$[48]$} \\
\hline $\mathrm{ZnO}$ nanorod & $30 \mathrm{ppb}$ Ozone & $44 \%$ & $370 \mathrm{~nm}$ & $-1-$ & $30 \mathrm{ppb}$ & {$[50]$} \\
\hline Gold-ZnO & 30 ppb Ozone & $108 \%$ & $370 \mathrm{~nm}$ & $13.2 / 28.79 \mathrm{~s}$ & $30 \mathrm{ppb}$ & {$[50]$} \\
\hline $\mathrm{In}_{2} \mathrm{O}_{3}-\mathrm{ZnO}$ & 100 ppm HCHO & $419 \%$ & $460 \mathrm{~nm}$ & $-/-$ & $5 \mathrm{ppm}$ & {$[51]$} \\
\hline $\mathrm{ZnO}$ & 10 ppm NO & 14 & 439 & $-1-$ & $1 \mathrm{ppm}$ & {$[36]$} \\
\hline $\mathrm{ZnO} / \mathrm{Au} \mathrm{NP}$ & 6 ppm NOx & $78 \%$ & White & $110 / 100 \mathrm{~s}$ & $550 \mathrm{ppb}$ & {$[53]$} \\
\hline $\mathrm{Au}-\mathrm{ZnO}$ & 500 ppm Ethanol & 62 & White & $-1-$ & $1 \mathrm{ppm}$ & {$[54]$} \\
\hline $\mathrm{ZnO}-\mathrm{Ag}$ nanoparticles & $5 \mathrm{ppm} \mathrm{NO} \mathrm{N}_{2}$ & 1.545 & $470 \mathrm{~nm}$ & $150 / 50 \mathrm{~s}$ & $<500 \mathrm{ppb}$ & {$[55]$} \\
\hline $\mathrm{ZnO} / \mathrm{PbS}$ & $1 \mathrm{ppm} \mathrm{NO} 2$ & $118-122 \%$ & $850 \mathrm{~nm}$ & $3 / 4 \min$ & $26 \mathrm{ppb}$ & {$[37]$} \\
\hline $\mathrm{CdSe} / \mathrm{ZnO}$ & $0-0.5 \mathrm{ppm} \mathrm{NO} 2$ & $0.7-0.8$ & $535 \mathrm{~nm}$ & $-/-$ & - & {$[56]$} \\
\hline $\mathrm{ZnO} / \mathrm{In}_{2} \mathrm{O}_{3}$ & $0.7 \mathrm{ppm} \mathrm{NO}$ & 117 & $365 \mathrm{~nm}$ & $100 / 31 \mathrm{~s}$ & - & {$[58]$} \\
\hline $\mathrm{ZnO} / \mathrm{g}-\mathrm{C}_{3} \mathrm{~N}_{4}$ & $7 \mathrm{ppm} \mathrm{NO} \mathrm{NO}_{2}$ & 44.8 & $460 \mathrm{~nm}$ & $142 / 190 \mathrm{~s}$ & $38 \mathrm{ppb}$ & [59] \\
\hline $\mathrm{SnO}_{2}$ & $\mathrm{NO}_{2}$ & $300 \%$ & $365 \mathrm{~nm}$ & $2 / 4 \min$ & - & {$[63]$} \\
\hline $\mathrm{Pd} / \mathrm{SnO}_{2}$ & $\mathrm{NO}_{2}$ & $3.4 \times 10^{3}$ & $365 \mathrm{~nm}$ & $2.8 / 16 \mathrm{~min}$ & - & {$[65]$} \\
\hline $\mathrm{Pd} / \mathrm{SnO}_{2}$ & $5 \mathrm{ppm} \mathrm{NO} 2$ & 3000 & $365 \mathrm{~nm}$ & $-148 \mathrm{~s}$ & - & {$[66]$} \\
\hline $\mathrm{SnO}_{2}$ monolayer array & $5 \mathrm{ppm} \mathrm{NO}$ & 5 & $365 \mathrm{~nm}$ & $7 / 25 \mathrm{~s}$ & $0.1 \mathrm{ppm}$ & {$[67]$} \\
\hline $\mathrm{ZnO}-\mathrm{SnO}_{2}$ & 20 ppb Ozone & 8 & $325 \mathrm{~nm}$ & $13 / 90 \mathrm{~s}$ & $20 \mathrm{ppb}$ & {$[68]$} \\
\hline $\mathrm{SnO}_{2} / \mathrm{ZnO}$ & 30 ppm Formaldehyde & 40 & $365 \mathrm{~nm}$ & $36 / 73 \mathrm{~s}$ & $1.91 \mathrm{ppb}$ & [69] \\
\hline $\mathrm{LaOCl}-\mathrm{SnO}_{2}$ & $250 \mathrm{ppm} \mathrm{O}_{2}$ & 2.25 & $380 \mathrm{~nm}$ & $182 / 1315 \mathrm{~s}$ & - & [71] \\
\hline $\mathrm{TiO}_{2}$ microsphere & 5 ppm Formaldehyde & 40 & $365 \mathrm{~nm}$ & $40 / 50 \mathrm{~s}$ & $124 \mathrm{ppb}$ & {$[75]$} \\
\hline $\mathrm{TiO}_{2} @ \mathrm{NGQD}$ & 100 ppm NO & $31.1 \%$ & $365 \mathrm{~nm}$ & $235 / 285 \mathrm{~s}$ & - & [76] \\
\hline $\mathrm{In}_{2} \mathrm{O}_{3}$ & $4 \mathrm{ppm} \mathrm{NO}$ & 8 & $400 \mathrm{~nm}$ & - & - & {$[77]$} \\
\hline $\mathrm{In}_{2} \mathrm{O}_{3}$ & $50 \mathrm{ppm}$ NO & 40 & $365 \mathrm{~nm}$ & $10 \mathrm{~s} / 4 \mathrm{~min}$ & - & [78] \\
\hline $\mathrm{In}_{2} \mathrm{O}_{3}$ nanorod & $800 \mathrm{ppb} \mathrm{NO}$ & 14.9 & $365 \mathrm{~nm}$ & $14 / 32 \mathrm{~s}$ & - & [79] \\
\hline $\mathrm{In}_{2} \mathrm{O}_{3}$ & $50 \mathrm{ppm} \mathrm{NO}$ & 219 & $365 \mathrm{~nm}$ & $89 / 80 \mathrm{~s}$ & - & {$[80]$} \\
\hline $\mathrm{WO}_{3}$ & $160 \mathrm{ppb} \mathrm{NO} 2$ & 4 & $400 \mathrm{~nm}$ & $20 / 42.5 \min$ & - & {$[52]$} \\
\hline $\mathrm{WO}_{3}$ & $400 \mathrm{ppb} \mathrm{NO}_{2}$ & 92 & $430 \mathrm{~nm}$ & $51 / 60 \mathrm{~min}$ & - & {$[82]$} \\
\hline $\mathrm{PdO}-\mathrm{WO}_{3}$ & $40 \mathrm{ppm} \mathrm{H} \mathrm{H}_{2}$ & 8.02 & Visible & $2.1 / 5.8 \mathrm{~min}$ & $5 \mathrm{ppm}$ & [83] \\
\hline
\end{tabular}

generally improves the sensor sensitivity, but this improvement is also related to the Ag loadings.

Apart from the noble metals, another photosensitizer such as quantum dots such as PdS [37] and CdSe [56] has been also functionalized on MOS to achieve better performance under photoactivation. The quantum dots are typically narrow bandgap semiconductors, e.g., $0.41 \mathrm{eV}$ of $\mathrm{PbS}$. When attached to MOS, the quantum dots serve as a photosensitizer to shift the optical adsorption range of MOS to higher wavelengths. On photoexcitation, the free electrons in quantum dots can migrate into the conduction band of MOS [57].
Xiang et al. studied the $\mathrm{NO}_{2}$ sensing performances of $\mathrm{ZnO} /$ $\mathrm{PbS}$ nanocomposites with different $\mathrm{PbS}$ densities near-infrared light (NIR) illumination $(\lambda=850 \mathrm{~nm})$ [37]. As displayed in Fig. 3a, the $\mathrm{ZnO} / \mathrm{PbS}-2$ with medium PdS loading ( 2\%) possesses the maximum response. The enhanced $\mathrm{NO}_{2}$ sensing performances of $\mathrm{ZnO} / \mathrm{PbS}$ under NIR illumination are due to the increased carrier concentration in $\mathrm{ZnO}$ nanorods. The electron transfer from $\mathrm{PbS}$ to $\mathrm{ZnO}$ has been evidenced by the photoluminescence spectra (Fig. $3 b$ ) and $I-V$ tests.

Although quantum dots of metal chalcogenides are effective in promoting the sensor performance, they suffer from 
Table 2 Summary of graphene-based gas sensors to various gases under photoactivation at room temperature

\begin{tabular}{|c|c|c|c|c|c|c|}
\hline Material & Gas & $\begin{array}{l}\text { Sensitivity or } \\
\text { Response }\end{array}$ & Light source & Response/ Recovery Time & Detection limit & References \\
\hline Graphene & 100 ppm $\mathrm{NO}_{2}$ & $26 \%$ & $265 \mathrm{~nm}$ & $\sim 200 / 1000 \mathrm{~s}$ & $42.18 \mathrm{ppb}$ & [87] \\
\hline Graphene & $10 \mathrm{ppt}$ NO & $1.4 \%$ & UV & $-1-$ & $158 \mathrm{ppq}$ & [89] \\
\hline Graphene & $40 \mathrm{ppt} \mathrm{NO}_{2}$ & $1 \%$ & UV & $-1-$ & $2.06 \mathrm{ppt}$ & [89] \\
\hline Graphene & $0.1 \mathrm{ppm}$ Acetone & $0.4 \%$ & UV & $200 /-s$ & - & {$[90]$} \\
\hline Graphene & $1 \mathrm{ppm} \mathrm{NO} \mathrm{NO}_{2}$ & $20 \%$ & UV & $600 / 900 \mathrm{~s}$ & - & [91] \\
\hline Ti/graphene & $400 \mathrm{ppm} \mathrm{NH}_{3}$ & $17.9 \%$ & Visible & $2.5 / 2.7 \mathrm{~min}$ & - & [92] \\
\hline Graphene/PS & $45 \mathrm{ppb}$ & $2 \%$ & $635 \mathrm{~nm}$ & $1000 /-\mathrm{s}$ & $0.5 \mathrm{ppb}$ & [93] \\
\hline Ag-RGO & $250 \mathrm{ppb} \mathrm{\textrm {NH } _ { 3 }}$ & 5.8 & $400-520 \mathrm{~nm}$ & $76 / 84 \mathrm{~s}$ & $100 \mathrm{ppt}$ & [94] \\
\hline $\mathrm{WO}_{3}$ nanorods/graphene & $1 \mathrm{ppm} \mathrm{NO}$ & 61 & Visible & $-1-$ & - & {$[95]$} \\
\hline Carbon nitride/rGO & $10 \% \mathrm{O}_{2}$ & 32 & UV & $38 / 39 \mathrm{~s}$ & $20 \mathrm{ppm}$ & [96] \\
\hline RGO-CeO ${ }_{2}$ & $10 \mathrm{ppm} \mathrm{NO} 2$ & 4.5 & $365 \mathrm{~nm}$ & $-/ 258 \mathrm{~s}$ & - & [97] \\
\hline $\mathrm{WO}_{3} @ \mathrm{GO}$ & $0.9 \mathrm{ppm} \mathrm{NO} \mathrm{NO}_{2}$ & $63.73 \%$ & $480 \mathrm{~nm}$ & $18.6 / 23.3 \mathrm{~min}$ & - & [98] \\
\hline $\mathrm{MoS}_{2} / \mathrm{rGO}$ & 10 ppm Formaldehyde & $64 \%$ & $>420 \mathrm{~nm}$ & $17 / 98 \mathrm{~s}$ & $20 \mathrm{ppb}$ & [99] \\
\hline $\mathrm{PGO} / \mathrm{InGaN}$ & 100 ppm CO & $32 \%$ & $365 \mathrm{~nm}$ & $70 \mathrm{~s} / 10 \mathrm{~min}$ & - & {$[100]$} \\
\hline $\mathrm{rGO} / \mathrm{ZnO} / \mathrm{Pd}$ & $100 \mathrm{ppm} \mathrm{CH}_{4}$ & $19 \%$ & $470 \mathrm{~nm}$ & $74 / 78 \mathrm{~s}$ & $5 \mathrm{ppm}$ & {$[101]$} \\
\hline $\mathrm{Pd}-\mathrm{WO}_{3} / \mathrm{Gr} / \mathrm{Si}$ & $4 \mathrm{vol} \% \mathrm{H}_{2}$ & $20 \%$ & $980 \mathrm{~nm}$ & $<13 / 43 \mathrm{~s}$ & 0.05 vol $\%$ & [102] \\
\hline $\mathrm{g}-\mathrm{C}_{3} \mathrm{~N}_{4} / \mathrm{rGO}$ & $2 \mathrm{ppm} \mathrm{SO} \mathrm{SO}_{2}$ & $3 \%$ & $365 \mathrm{~nm}$ & $207 / 212 \mathrm{~s}$ & $685 \mathrm{ppb}$ & {$[103]$} \\
\hline $\mathrm{rGO} / \mathrm{SnO}_{2}$ & $5 \mathrm{ppm} \mathrm{SO} \mathrm{SO}_{2}$ & $1.7 \%$ & $365 \mathrm{~nm}$ & $4.3 / 2.5 \mathrm{~min}$ & - & [74] \\
\hline Graphene flexible & $2.5 \mathrm{ppm} \mathrm{NO}$ & $290 \%$ & $254 \mathrm{~nm}$ & $281 / 30 \mathrm{~s}$ & $300 \mathrm{ppt}$ & {$[104]$} \\
\hline $\mathrm{Gr} / \mathrm{bulk} \mathrm{Si/Gr}$ & $50 \mathrm{ppm} \mathrm{H}_{2}$ & $20 \%$ & White & $-1-$ & $1 \mathrm{ppm}$ & {$[105]$} \\
\hline
\end{tabular}

high toxicity of $\mathrm{Pd}$ and $\mathrm{Cd}$. Alternatively, the $\mathrm{Lu}$ group reported the use of $\mathrm{ZnO}$-based composite nanomaterials for photoactivated gas sensors $[58,59$. For example, they proposed the use of graphitic carbon nitride $\left(\mathrm{g}-\mathrm{C}_{3} \mathrm{~N}_{4}\right)$ with a bandgap of $2.7 \mathrm{eV}$ as the photosensitizer to enhance the $\mathrm{ZnO}$ sensors under the illumination of visible lights. As can be seen in Fig. 3c, the $\mathrm{ZnO} / \mathrm{g}-\mathrm{C}_{3} \mathrm{~N}_{4}-10 \mathrm{wt} \%$ shows the best response to $\mathrm{NO}_{2}$ and fast response-recovery characteristics (Fig. 3d) when activated by $460 \mathrm{~nm}$ visible light. It also reveals that the response of all $\mathrm{ZnO} / \mathrm{g}-\mathrm{C}_{3} \mathrm{~N}_{4}$ composites to $\mathrm{NO}_{2}$ generally improves with the increase in wavelength.

Photoactivation of gas sensors enables the detection of gaseous molecules at RT; however, the progress discussed above generally used an external light source like Xe-lamps or LEDs. The power consumption of such devices can be down to sub-milliwatts. To fulfil the future development of the Internet of things (IOTs), miniaturized sensors with an integrated light source with an ultralow-power consumption are highly urgent. Recently, several groups have reported an appealing monolithic integration form of photoactive sensors, in which a micro-LED with a power down to microwatts is mounted with the sensing films. This kind of sensor device has some merits that are not available from the external light-activated sensors such as much lower power, more uniform irradiation of the sensor materials and higher photon energy efficiency.

Figure $4 \mathrm{a}-\mathrm{d}$ exhibits an integrated gas sensor with $\mathrm{ZnO}$ nanoparticle film deposited on a micro-LED with a distance of a few hundred nanometres [60]. The sensor is activated with a visible light (emitting at $455 \mathrm{~nm}$ ) at RT. The sensor shows a response of $20 \%$ to $25 \mathrm{ppb} \mathrm{NO}_{2}$ at an ultralow-power of $30 \mu \mathrm{W}$ and can be improved to $94 \%$ at $200 \mu \mathrm{W}$. A fully recoverable detection of $\mathrm{NO}_{2}$ ranging from $25 \mathrm{ppb}$ to $1 \mathrm{ppm}$ is also shown in Fig. 4f. Park and co-workers recently reported a monolithic photoactivated gas sensor based on $\mathrm{ZnO}$ nanowires grown on a micro-LED, as shown in Fig. 4g, h [61]. Under the activation of UV light of $390 \mathrm{~nm}$, the sensor resistance is observed to increase with the $\mathrm{NO}_{2}$ concentration in the range of $0.25-2 \mathrm{ppm}$ at an operating power of $190 \mu \mathrm{W}$. The calibration of sensor response in Fig. $4 \mathrm{j}$ reveals a LOD of $14.9 \mathrm{ppb}$ to $\mathrm{NO}_{2}$. Although these micro-LED integrated gas sensors have low power consumption, the sensor response dynamics in Fig. 4f, i is very slow and more efforts are need to improve the response speed. 
Table 3 Summary of 2D transition metal dichalcogenides and MXene gas sensors to various gases under photoactivation at room temperature

\begin{tabular}{|c|c|c|c|c|c|c|}
\hline Material & Gas & Sensitivity or response & Light source & $\begin{array}{l}\text { Response/ } \\
\text { RECOVERY } \\
\text { Time }\end{array}$ & Detection limit & References \\
\hline $\mathrm{MoS}_{2}$ & $100 \mathrm{ppm} \mathrm{NO} \mathrm{N}_{2}$ & $160 \%$ & $532 \mathrm{~nm}$ & $-1-$ & - & [112] \\
\hline $\mathrm{MoS}_{2}$ & $100 \mathrm{ppm} \mathrm{NH}_{3}$ & $70 \%$ & $532 \mathrm{~nm}$ & $-1-$ & - & [112] \\
\hline $\mathrm{MoS}_{2}$ & $0.2 \%$ TEA & $5 \%$ & White light & $-1-$ & - & [113] \\
\hline $\mathrm{MoS}_{2}$ & $100 \mathrm{ppm} \mathrm{NO} \mathrm{NO}_{2}$ & $35.16 \%$ & $365 \mathrm{~nm}$ & $29 / 350 \mathrm{~s}$ & - & [114] \\
\hline $\mathrm{MoS}_{2}$ & 100 ppm NO & $70 \%$ & $254 \mathrm{~nm}$ & $250 / 550 \mathrm{~s}$ & - & [117] \\
\hline $\mathrm{MoS}_{2}$ & $5 \mathrm{ppm} \mathrm{NO}$ & $9.2 \%$ & $280 \mathrm{~nm}$ & $-/ 32.9 \mathrm{~s}$ & - & [118] \\
\hline 3D Cone-Shaped $\mathrm{MoS}_{2}$ & 2 ppm NO & $470 \%$ & $365 \mathrm{~nm}$ & $25 \mathrm{~s} /-$ & $0.06 \mathrm{ppm}$ & [119] \\
\hline $\mathrm{MoS}_{2} /$ graphene & $\mathrm{NO}_{2}$ & $3.3 \%$ & $660 \mathrm{~nm}$ & $-1-$ & $0.1 \mathrm{ppb}$ & {$[120]$} \\
\hline $\mathrm{MoS}_{2}-\mathrm{Au}$ & $2.5 \mathrm{ppm} \mathrm{NO}$ & $30 \%$ & $365 \mathrm{~nm}$ & $4 / 14 \min$ & - & [123] \\
\hline $\mathrm{MoS}_{2-}-\mathrm{ZnO}$ & $50 \mathrm{ppb} \mathrm{NO}$ & $20 \%$ & UV & $<1 / 1 \min$ & $50 \mathrm{ppq}$ & {$[124]$} \\
\hline $\mathrm{Sv}-\mathrm{MoS}_{2} / \mathrm{ZnO}$ & $0.2 \mathrm{ppm} \mathrm{NO}$ & $226 \%$ & $780 \mathrm{~nm}$ & $75 / 111 \mathrm{~s}$ & $0.1 \mathrm{ppb}$ & {$[125]$} \\
\hline $\mathrm{MoS}_{2} \mathrm{p}-\mathrm{n}$ junction & 5 ppm $\mathrm{NO}_{2}$ & $8 \%$ & $395 \mathrm{~nm}$ & $150 / 30 \mathrm{~s}$ & $8 \mathrm{ppb}$ & {$[126]$} \\
\hline $\mathrm{n}-\mathrm{MoS}_{2} / \mathrm{p}-\mathrm{GaN}$ & $50 \mathrm{ppm} \mathrm{NO}$ & $64.67 \%$ & $367 \mathrm{~nm}$ & $235 / 800 \mathrm{~s}$ & - & [127] \\
\hline $\mathrm{MoS}_{2}$ flexible & $400 \mathrm{ppb} \mathrm{NO}_{2}$ & $670 \%$ & $625 \mathrm{~nm}$ & $16 / 65 \mathrm{~s}$ & $20 \mathrm{ppb}$ & [129] \\
\hline $\mathrm{MoTe}_{2}$ & $30 \mathrm{ppm} \mathrm{NH}$ & $790 \%$ & $254 \mathrm{~nm}$ & $-1-$ & $3 \mathrm{ppb}$ & [132] \\
\hline $\mathrm{MoTe}_{2}$ & $1 \mathrm{ppm} \mathrm{NO} 2$ & $1300 \%$ & $254 \mathrm{~nm}$ & $5 \mathrm{~min} / 120 \mathrm{~s}$ & $123 \mathrm{ppt}$ & [133] \\
\hline $\mathrm{MoTe}_{2}$ & 100 ppm Acetone & $55 \%$ & $254 \mathrm{~nm}$ & $180 / 180 \mathrm{~s}$ & $200 \mathrm{ppb}$ & [40] \\
\hline $\mathrm{WS}_{2}$ nanoflakes & $\mathrm{NH}_{3}$ & - & $633 \mathrm{~nm}$ & $20 \mathrm{~ms} /-$ & - & {$[135]$} \\
\hline $\mathrm{WS}_{2}$ & $10 \mathrm{ppm} \mathrm{NH}$ & 3.4 & $365 \mathrm{~nm}$ & $252 / 648 \mathrm{~s}$ & - & [136] \\
\hline $\mathrm{Au}-\mathrm{WS}_{2}$ & $250 \mathrm{ppb} \mathrm{NO}_{2}$ & $20 \%$ & $530 \mathrm{~nm}$ & $-1-$ & $250 \mathrm{ppb}$ & [137] \\
\hline $\mathrm{WS}_{2}$-rGO & $1 \mathrm{ppm} \mathrm{NO} \mathrm{N}_{2}$ & 1.27 & $430 \mathrm{~nm}$ & $16 / 18 \mathrm{~min}$ & $400 \mathrm{ppb}$ & [138] \\
\hline $\mathrm{SnS}_{2}$ & $8 \mathrm{ppm} \mathrm{NO} \mathrm{NO}_{2}$ & 10.8 & $520-550 \mathrm{~nm}$ & $164 / 236 \mathrm{~s}$ & $38 \mathrm{ppb}$ & [143] \\
\hline $\mathrm{SnS}_{2}$ suspended & $5 \mathrm{ppm} \mathrm{NH}$ & 0.34 & White & $300 /-\mathrm{s}$ & $20 \mathrm{ppb}$ & [145] \\
\hline $\mathrm{SnS}_{2}$ & $5 \mathrm{ppm} \mathrm{NO}$ & 0.34 & $405 \mathrm{~nm}$ & $300 /-\mathrm{s}$ & $2.5 \mathrm{ppb}$ & [144] \\
\hline $\mathrm{SnS}_{2} / \mathrm{rGO}$ & $10 \mathrm{ppb} \mathrm{\textrm {NO } _ { 2 }}$ & 5.86 & $650 \mathrm{~nm}$ & $1.5 / 0.54 \mathrm{~min}$ & $0.15 \mathrm{ppb}$ & [146] \\
\hline $\operatorname{ReS}_{2}$ & $\mathrm{NH}_{3}$ & $2860 \%$ (EQE) & $633 \mathrm{~nm}$ & $70 / 70 \mathrm{~ms}$ & - & [148] \\
\hline $\mathrm{Ti}_{3} \mathrm{C}_{2} \mathrm{~T}_{\mathrm{x}}$ (MXene) & $\mathrm{O}_{2}$ & - & 200-300 nm & $130 /-\mathrm{s}$ & - & {$[152]$} \\
\hline
\end{tabular}

\section{2 $\mathrm{SnO}_{2}$}

$\mathrm{SnO}_{2}$ is the most widely used materials for MOS gas sensors due to its high sensitivity and good stability ever since its integration into a real sensor device by Taguchi in the $1960 \mathrm{~s}$ [17]. Significant efforts have been explored to lower the high working temperature by fabricating special nanostructures, synthesis of the nanocomposite and surface modification, as well as using photoexcitation instead of thermal heating.

Saura initially studied the gas sensing performance of $\mathrm{SnO}_{2}$ films towards acetone under UV irradiation with varying wavelengths at RT [62]. They stated that the sensor response originated from the photo-dissociation and desorption of the chemisorbed molecules. Later, Comini and co-workers investigated the $\mathrm{NO}_{2}$ sensing performance of
$\mathrm{SnO}_{2}$ films [63]. They showed a stable and sensitive sensor working at RT with UV excitation $(\lambda=365 \mathrm{~nm})$. The UV irradiation enables the fast and full recovery of the sensor by preventing the poisoning of $\mathrm{SnO}_{2}$ surface from strongly adsorbed $\mathrm{NO}_{2}$. The accelerated desorption of $\mathrm{NO}_{2}$ from $\mathrm{SnO}_{2}$ sensors by white light illumination was also observed by Anothainart et al. [64] They showed that the activated desorption was due to the light with a wavelength less than $\lambda=600 \mathrm{~nm}$, and the light intensity also affected the desorption. By measuring the conductance and the work function at both RT and elevated temperature, they deduced the lightactivated desorption was due to the direct photoexcitation of the electrons from $\mathrm{NO}_{2}^{-}$adsorbates into the conduction band of $\mathrm{SnO}_{2}$, rather than the recombination of electron-hole pairs. Recently, Hyodo et al. also reported that UV light 

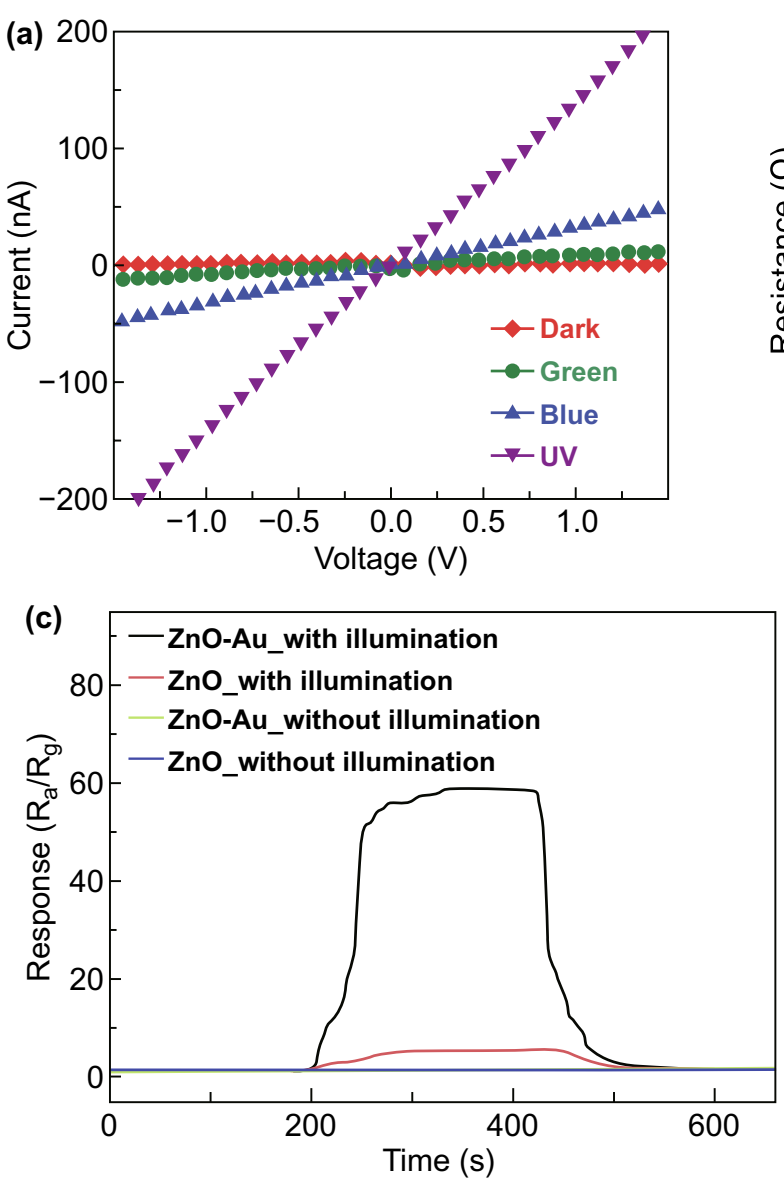
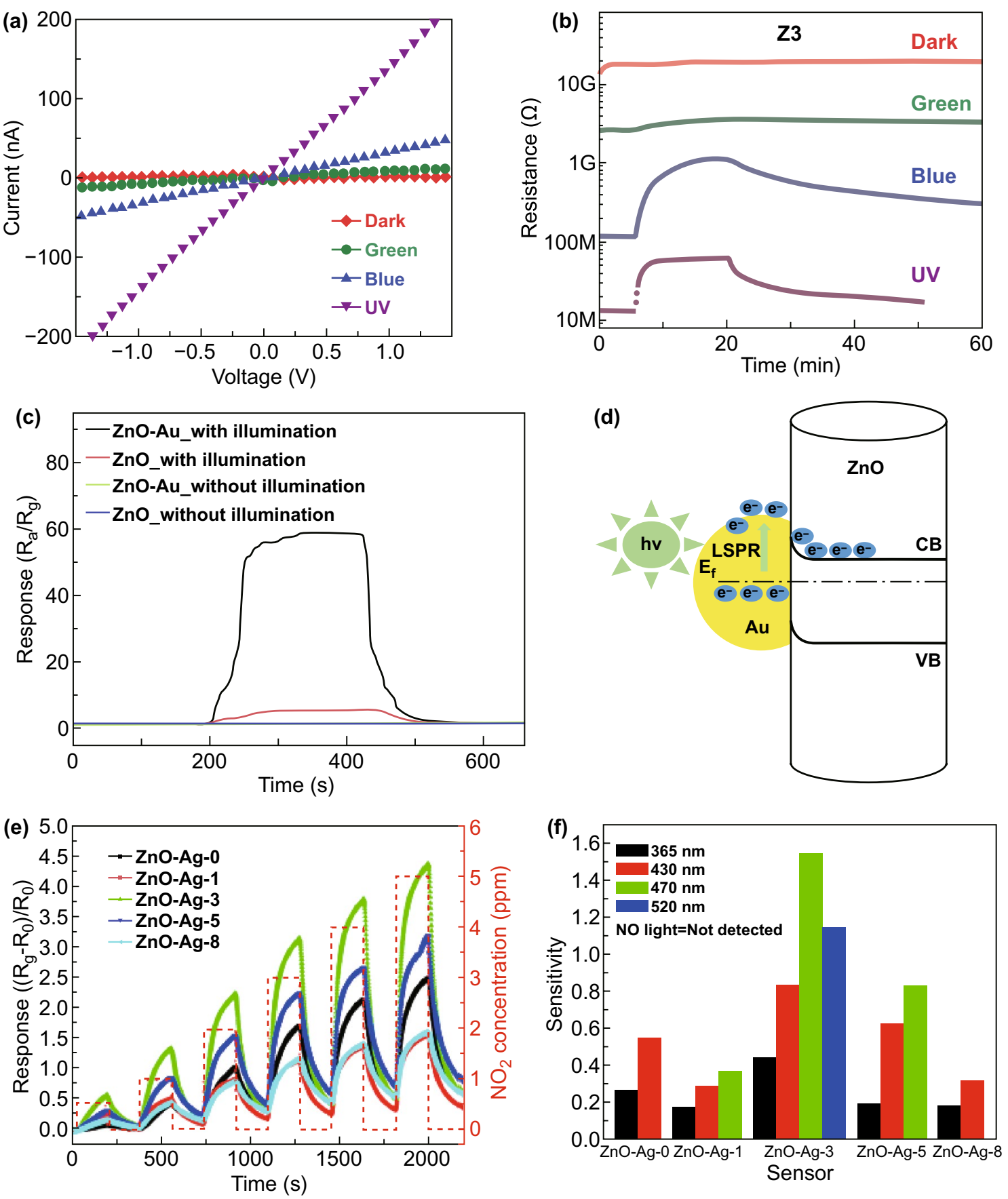

Fig. 2 a Current-voltage $(I-V)$ characteristics of $\mathrm{ZnO}$ film $(8 \mathrm{~nm})$ measured in dark and various wavelength light irradiation. b Resistance change of $\mathrm{ZnO}$ film (37 nm) to $10 \mathrm{ppm} \mathrm{NO}$ under the light of different wavelengths. Reproduced with permission [36]. Copyright 2018, Elsevier. c Real-time sensing response curves to $500 \mathrm{ppm}$ ethanol of sensors made of $\mathrm{ZnO}$ and Au-decorated $\mathrm{ZnO}$ at RT with or without white illumination. d Electron transfers from Au to ZnO due to the LSPR excitations in Au. Reproduced with permission [54]. Copyright 2017, Elsevier. e Dynamic response curves of sensors based on pure $\mathrm{ZnO}$ and $\mathrm{Ag} / \mathrm{ZnO}$ to $0.5-500 \mathrm{ppm} \mathrm{NO}$ under $430 \mathrm{~nm}$ light illumination at RT. f Sensitivities of sensors based on pure $\mathrm{ZnO}$ and $\mathrm{ZnO}-\mathrm{Ag}$ heterostructure nanoparticles to $0.5-500 \mathrm{ppm} \mathrm{NO}_{2}$ illuminated at various light wavelengths at RT. Reproduced with permission [55]. Copyright 2017, Elsevier 

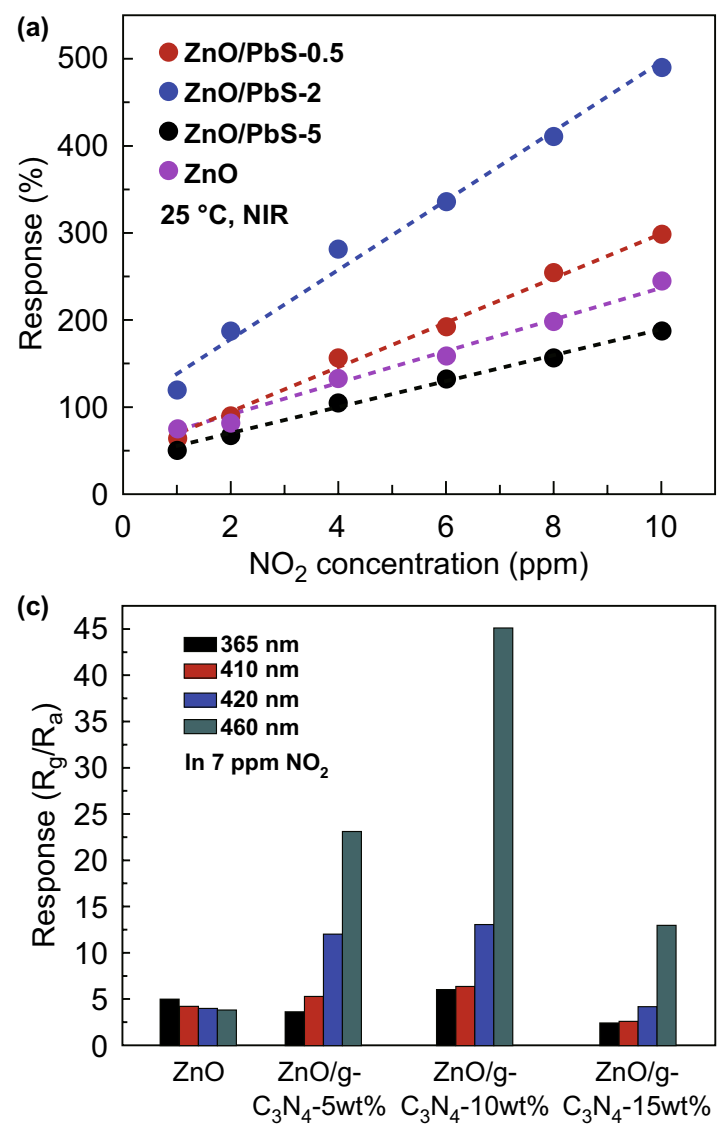
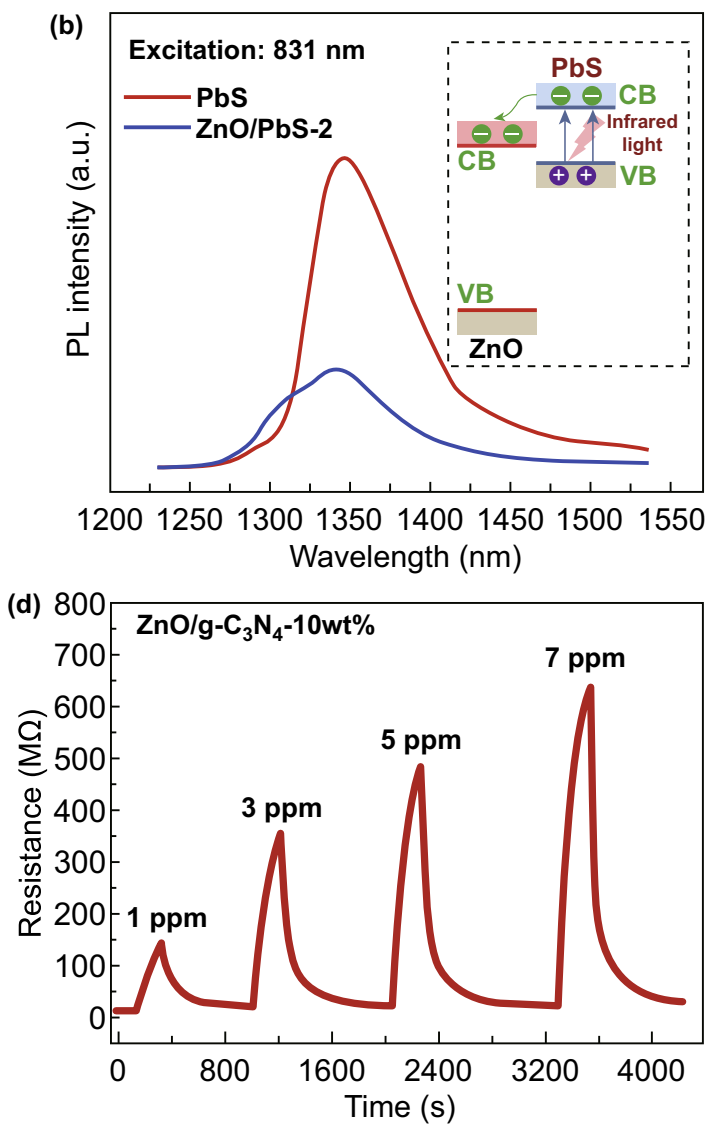

Fig. 3 a Responses of the sensors based on the $\mathrm{ZnO} / \mathrm{PbS}$ nanocomposites with different $\mathrm{PbS}$ loading to $1-10$ ppm of $\mathrm{NO}_{2}$ under $\mathrm{NIR}$ illumination at RT. b Photoluminescence spectra of PbS and $\mathrm{ZnO} / \mathrm{PbS}-2$ under $831 \mathrm{~nm}$ excitation. Reproduced with permission [37]. Copyright 2017, Elsevier. c Responses of $\mathrm{ZnO} / \mathrm{g}-\mathrm{C}_{3} \mathrm{~N}_{4}$ composites with various $\mathrm{g}_{-} \mathrm{C}_{3} \mathrm{~N}_{4}$ content to $7 \mathrm{ppm} \mathrm{NO}$ under different wavelength light illumination. d Dynamic resistance curves of $\mathrm{ZnO} / \mathrm{g}-\mathrm{C}_{3} \mathrm{~N}_{4}-10 \mathrm{wt} \%$ to 1-7 ppm NO $\mathrm{N}_{2}$ under $460 \mathrm{~nm}$ light illumination at RT. Reproduced with permission [64]. Copyright 2019, Elsevier

irradiation ( $365 \mathrm{~nm}$ ) enhanced the $\mathrm{NO}_{2}$ response of the $\mathrm{SnO}_{2}$ sensor at RT [65], and the response can be improved by incorporation of $\mathrm{Pd}$ or $\mathrm{Pt}$ [66].

Liu et al. recently developed an ultrasensitive $\mathrm{NO}_{2}$ gas sensor based on $\mathrm{SnO}_{2}$ monolayer array films under UV illumination [67]. The sensor response is largely affected by light intensity, as shown in Fig. 5a. They also fabricated gas sensors with different array layers of $\mathrm{SnO}_{2}$ nanospheres and found that the sensor with four layers exhibited the highest response (Fig. 5b) with excellent selectivity to $\mathrm{NO}_{2}$ against many other molecules (Fig. 5c). Sensing mechanism follows the photoactivated desorption of pre-adsorbed oxygen and subsequent adsorption of $\mathrm{NO}_{2}$, as depicted in Fig. 5d. On illumination, the built-in electric field in $\mathrm{SnO}_{2}$-induced separation of electron-hole pairs; then, the photogenerated holes react with surface-absorbed oxygen ions to give molecular $\mathrm{O}_{2}$. The depletion layer around the $\mathrm{SnO}_{2}$ spheres is reduced due to the excess of the photogenerated electron, resulting in the decreased sensor resistance. When exposed to $\mathrm{NO}_{2}$, the photoelectrons induced the adsorption of $\mathrm{NO}_{2}$ to give $\mathrm{NO}_{2}{ }^{-}$, resulting in an increase of electron depletion and hence the sensor resistance. Efforts have been explored to fabricate heterojunctions from semiconductors such as $\mathrm{SnO}_{2} / \mathrm{ZnO}$ [68-70]. The formation of heterojunctions has been proposed to suppress the recombination of photoexcited electrons and holes, thus leading to the improved performance of the UV-activated $\mathrm{SnO}_{2}$ gas sensor. 

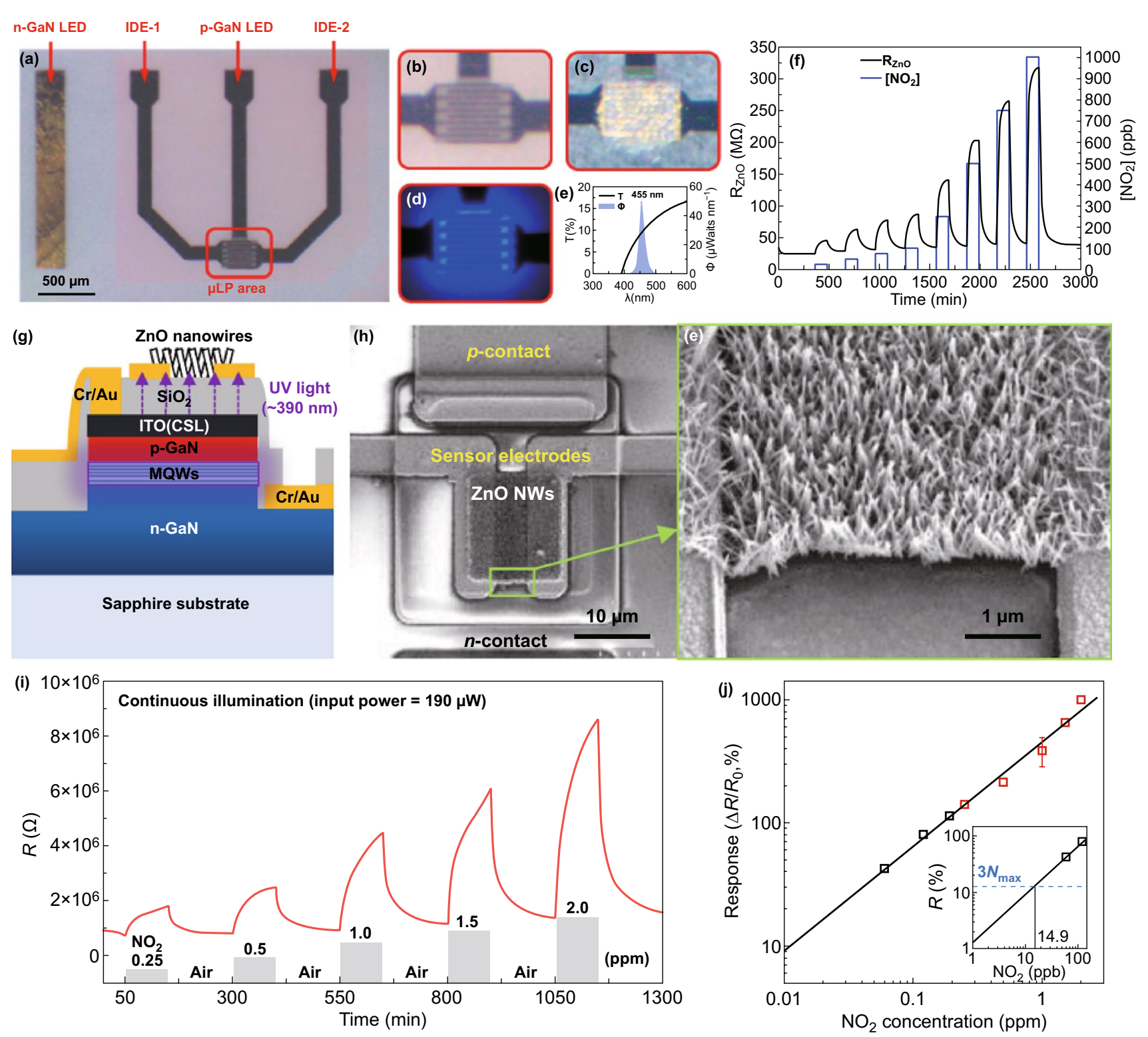

Fig. 4 a Overview of the sensor device with $\mathrm{ZnO}$ nanoparticles on top of the micro-LED. Details of the sensor device $\mathbf{b}$ bare IDE, $\mathbf{c} \mathrm{ZnO}$ material on top of the IDE, and d LED light on. e Light emission spectrum of the micro-LED and light transmission spectrum of the ZnO layer deposited on a sapphire substrate. f Resistance transient of the sensors to increasing $\mathrm{NO}_{2}$ concentrations. Reproduced with permission [60]. Copyright 2019, American Chemical Society. g Schematic cross section illustration of the photoactive sensor with ZnO nanowires grown on a micro-LED. $\mathbf{h}$ SEM images of $\mathrm{ZnO}$ nanowires on the micro-LED. $\mathbf{i ~} \mathrm{NO}_{2}$ sensing performance of the photoactive under operating power of $190 \mu \mathrm{W}$ and $\mathbf{j}$ calibration of normalized sensor response to $\mathrm{NO}_{2}$. Reproduced with permission [61]. Copyright 2020, American Chemical Society

To further improve the photoactivated sensor performance of $\mathrm{SnO}_{2}$ at RT, other materials such as $\mathrm{LaOCl}$ [71], polypyridine $\mathrm{Ru}(\mathrm{II})$ complexes [72], perovskite methylammonium tin iodide (MASnI3) [65], perylene diimide [73] and reduced graphene oxide [74] have been incorporated with $\mathrm{SnO}_{2}$ to serve as a photosensitizer to widen the spectrum into visible range or as a separator to prevent the combination of photoexcited electron-hole pairs. Xue group showed that LaOCl-doped $\mathrm{SnO}_{2}$ hollow spheres exhibited significantly improved selective response to $\mathrm{O}_{2}$ under UV light illumination at RT, due to improved generation of electron-hole pairs and enhanced oxygen adsorption enabled by oxygen vacancy defect due to the presence of $\mathrm{LaOCl}$ dopant. $\mathrm{Xu}$ group reported that under UV illumination $(\lambda=365 \mathrm{~nm})$ the 

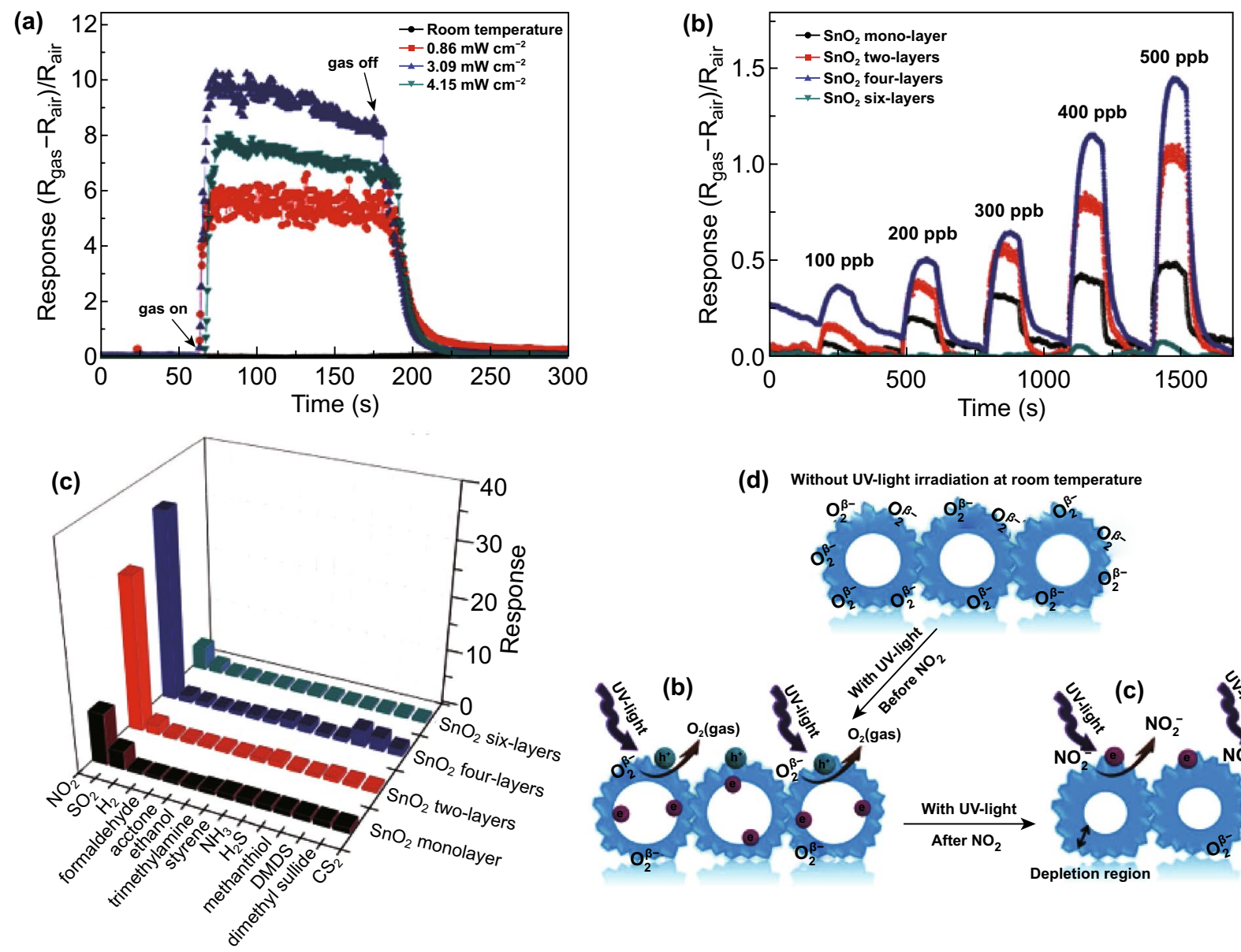

(d) Without UV-light irradiation at room temperature

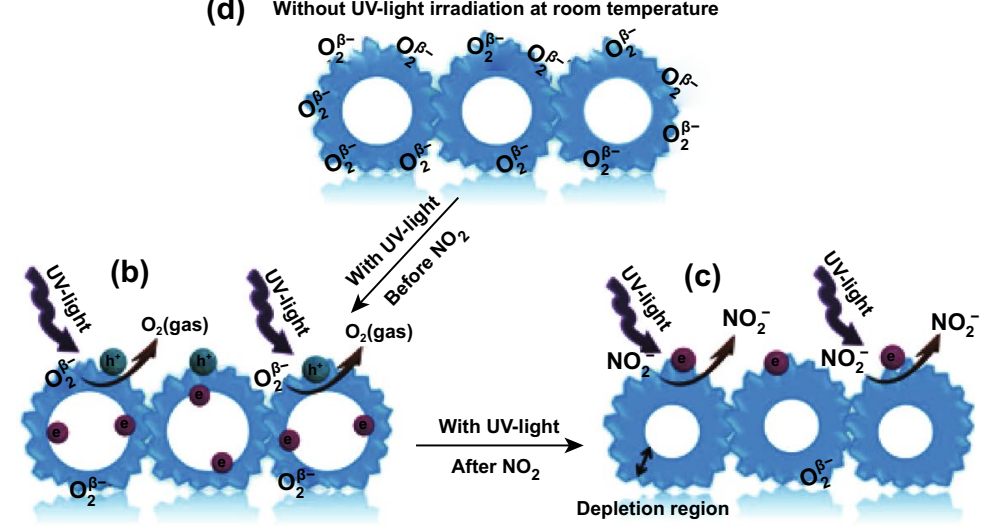

Fig. 5 Response-recovery curves of a $\mathrm{SnO}_{2}$ monolayer array film towards $10 \mathrm{ppm} \mathrm{NO}_{2}$ under different light intensity and $\mathbf{b} \mathrm{SnO} \mathrm{O}_{2}$ film with different thickness towards $100-500 \mathrm{ppb} \mathrm{NO}_{2}$ under the UV light intensity of $3.09 \mathrm{~mW} \mathrm{~cm}^{-2}$, c corresponding sensor responses to $10 \mathrm{ppm} \mathrm{NO}_{2}$. d Sensing mechanism of the $\mathrm{SnO}_{2}$ monolayer sensing film towards $\mathrm{NO}_{2}$ gas under UV light irradiation. Reproduced with permission [67]. Copyright 2019, WILEY-VCH Verlag GmbH \& Co. KGaA, Weinheim

sensor based on $\mathrm{Au} / \mathrm{MASnI}{ }_{3} / \mathrm{SnO}_{2}$ exhibited high response, fast recovery and good selectivity to $\mathrm{NO}_{2}$ compared to sensors based on $\mathrm{SnO}_{2}$ or $\mathrm{Au} / \mathrm{SnO}_{2}$ [65]. They ascribed the enhanced sensing performance to the improved light absorption due to MASnI3, which allowed more photoelectrons transfer from $\mathrm{MASnI}_{3}$ to $\mathrm{SnO}_{2}$, as well as the catalysis of Au nanoparticles. An organic photosensitizer, i.e., heterocyclic $\mathrm{Ru}$ (II) complex, has been proposed by Gaskov group to shift the photosensitivity range of $\mathrm{SnO}_{2}$ towards visible light wavelengths [72]. The Ru(II) complex enables the sensor to have improved response to detecting $\mathrm{NO}_{2}$ under periodic illumination with blue $(\lambda=470 \mathrm{~nm})$, green $(\lambda=535 \mathrm{~nm})$ and red $(\lambda=630 \mathrm{~nm})$ light. The sensing mechanism involves the photoexcitation of electrons from the HOMO to LUMO of $\mathrm{Ru}(\mathrm{II})$ complex and then transfer to the conduction bands of $\mathrm{SnO}_{2}$.

Ren group recently realized the selective detection of $\mathrm{NO}_{2}$ and $\mathrm{SO}_{2}$ on a UV-activated gas sensor based on reduced graphene oxide ( $\mathrm{rGO}) / \mathrm{SnO}_{2}$ nanofiber composites at $\mathrm{RT}$ [74]. The improved selectivity was attributed to the combination of photocatalytic oxidation and photo-chemical desorption arising from the nanocomposite. Their results also showed that the sensor response to $\mathrm{NO}_{2}$ (Fig. 6a) and $\mathrm{SO}_{2}$ (Fig. 6b) was highly relevant to the composition ratio of rGO and $\mathrm{SnO}_{2}$, as well as the light intensity. The enhanced sensor responses were attributed to the synergistic effect of two 
materials, including prominent electron transfer, efficient material structure and p-n heterojunctions. However, this sensor suffers a very sluggish long response and recovery speed (Fig. 6c). Figure 6d shows the sensing mechanism. Under UV illumination, $\mathrm{SnO}_{2}$ acts as a light absorber and electron-hole pairs are generated on light excitation. The photoelectrons move to rGO, which serves as both a photoelectron acceptor and pathway for charge transport. The increased photoelectrons in $\mathrm{rGO}$ promoted the absorption of oxygen species and thus contribute to gas sensing reactions.

\section{3 $\mathrm{TiO}_{2}$}

$\mathrm{TiO}_{2}$ has drawn paramount attention as a photocatalyst, while limited research has been paid to photoactivated gas sensors. $\mathrm{Li}$ et al. showed that mesoporous $\mathrm{TiO}_{2}$ hollow spheres exhibited high sensitivity and selectivity to formaldehyde at RT with UV illumination [75].
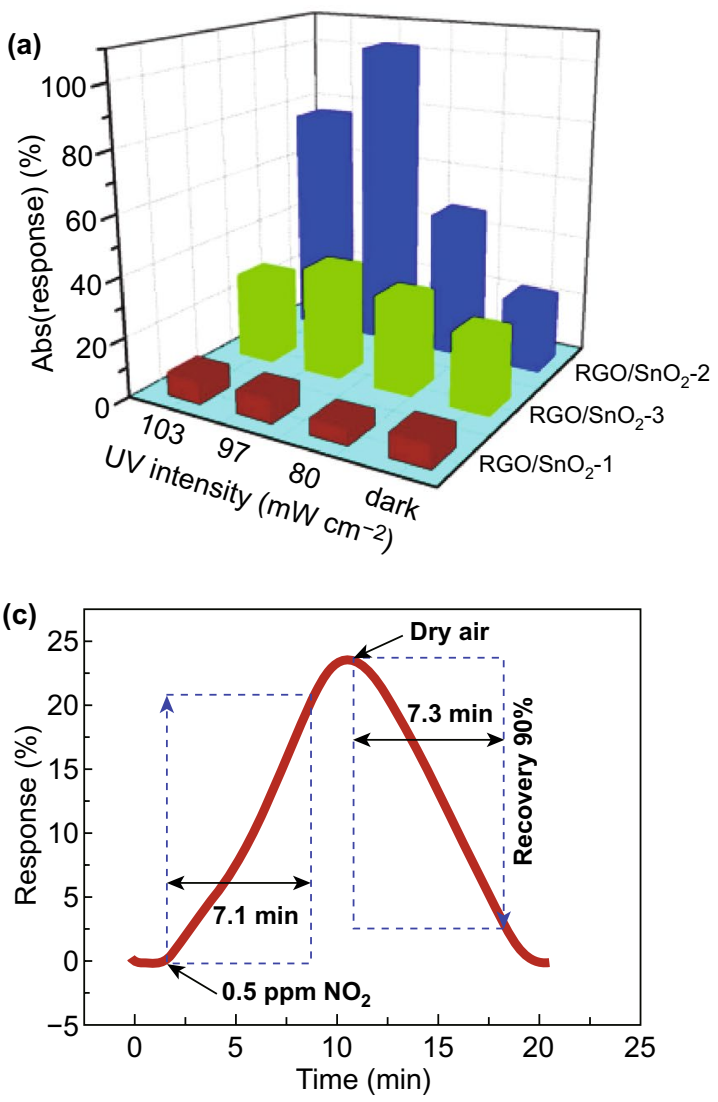

Very recently, Murali and co-workers demonstrated a UV-activated high-performance RT NO gas sensor based on nitrogen-doped graphene quantum dots (NGQDs) decorated $\mathrm{TiO}_{2}$ nanoplates with $\{001\}$ facets exposed [76]. The response of the NGQDs/TiO 2 hybrids without $\mathrm{UV}$ activation was improved from $12.0 \%$ to $100 \mathrm{ppm} \mathrm{NO}$ the decoration of NGQDs on $\mathrm{TiO}_{2}$, which dramatically enhanced the generation of electron-hole pairs due to good light absorption ability of NGQDs. The sensing mechanism is shown in Fig. 7. The bandgap alignment between NGQDs and $\mathrm{TiO}_{2}$ generates $\mathrm{p}-\mathrm{n}$ junctions that can efficiently separate the electron-hole pairs. These p-n junctions promote the hot generated electron transfer from NGQDs to $\mathrm{TiO}_{2}$ and photogenerated holes transfer from $\mathrm{TiO}_{2}$ to NGQDs. In addition, the NGQDs also suggested promoting the formation of oxygen vacancies in the $\mathrm{TiO}_{2}$, which enhances the adsorption of oxygen ions and further facilitates their reaction with pre-adsorbed $\mathrm{NO}^{-}$. All these factors synergistically led to enhance the conversion (b)

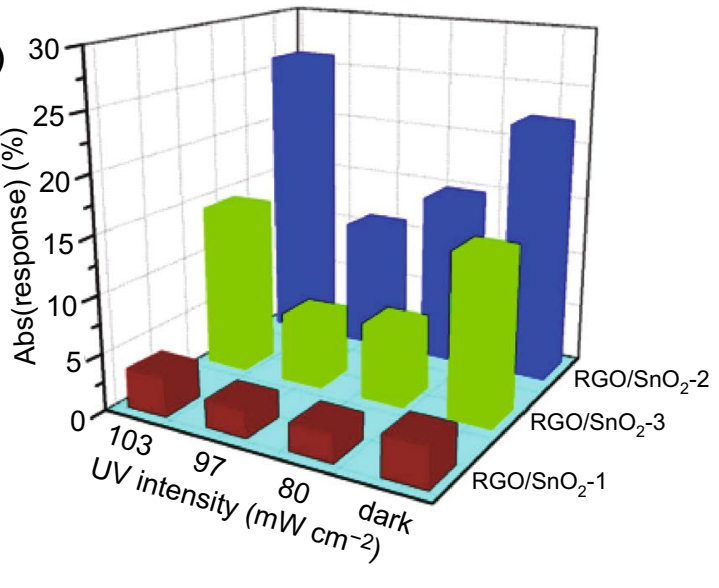

(d)
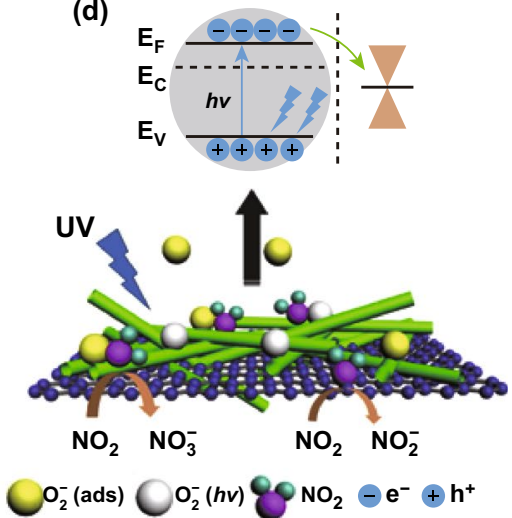

Fig. 6 UV intensity-dependent response absolute value based on $\mathrm{rGO} / \mathrm{SnO}_{2}$ sensors in a 3 ppm $\mathrm{NO}_{2}$ and $\mathbf{b} 30$ ppm $\mathrm{SO}_{2}$. c Enlarged part of response-recovery cureves of $\mathrm{rGO} / \mathrm{SnO}_{2}$ sensor to $0.5 \mathrm{ppm} \mathrm{NO} \mathrm{N}_{2}$. d Sensing mechanism of $\mathrm{rGO} / \mathrm{SnO}_{2}$ to $\mathrm{NO}_{2}$ under UV illumination. Reproduced with permission [74]. Copyright 2019, Elsevier 
efficiency of gas and carriers exchange, and charge separation, and which eventually improved sensing performance.

\section{$3.4 \mathrm{IN}_{2} \mathrm{O}_{3}$}

$\mathrm{In}_{2} \mathrm{O}_{3}$ has been investigated for photoexcited gas sensors. Trocino and co-workers studied the effects of UV illumination on the recovery process of $\mathrm{In}_{2} \mathrm{O}_{3} / \mathrm{PVP}$ fibres after exposure to $\mathrm{NO}_{2}$ at RT [77]. They found that UV illumination could easily desorb the weakly bound adsorbed species, resulting in short recovery time. Nguyen et.al have reported the RT sensor performance of $\mathrm{In}_{2} \mathrm{O}_{3}$ nanostructure for detection of NO under UV illumination [78]. The sensor exhibited a sensitivity of 41.7 to $50 \mathrm{ppm} \mathrm{NO}$ and a response time of only $4 \mathrm{~s}$ because UV illumination promoted the NO (and $\mathrm{O}_{2}$ ) adsorption and desorption. Meanwhile, the response was observed to be affected by UV light intensity. Recently, Shen and co-workers demonstrated that mesoporous $\operatorname{In}_{2} \mathrm{O}_{3}$ nanorod arrays could detect $\mathrm{NO}_{2}$ at a ppb-level concentration at RT without UV illumination, but the sensor showed very poor recovery [79]. They showed that the recovery could be improved to $32 \mathrm{~s}$ by using UV illumination. In another work, Ma et al. achieved RT sensor performance from walnut-like $\mathrm{In}_{2} \mathrm{O}_{3}$ nanostructures to detect $\mathrm{NO}_{2}$ under UV illumination [80]. The sensor exhibits an ultrahigh sensitivity (219) towards 50 ppm $\mathrm{NO}_{2}$ with UV illumination. The studied showed that the high sensitivity of walnut-like $\mathrm{In}_{2} \mathrm{O}_{3}$ was mainly attributed to the effective participation of photogenerated electrons.

\section{$3.5 \mathrm{WO}_{3}$}

In addition to $\mathrm{ZnO}$ and $\mathrm{SnO}_{2}, \mathrm{WO}_{3}$ has been also frequently studied for photoactivated gas sensors. According to Giberti, the increase in the conductivity $\mathrm{WO}_{3}$ gas sensor in the air was attributed to the photodesorption of surface oxygen under UV illumination [81]. RT sensing performance to detect $\mathrm{NO}_{2}$ enabled light illumination was by also reported. For example, Zhang et al. presented an $\mathrm{RT} \mathrm{NO}_{2}$ gas sensor based on $\mathrm{WO}_{3}$ under visible light illumination [52]. It was found that the light wavelength and light intensity had a great influence on

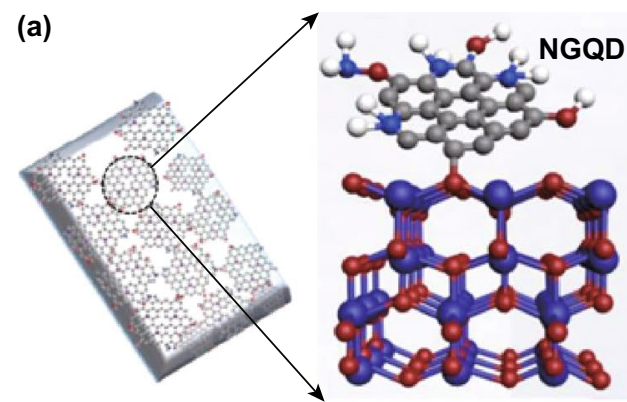

(d) $\mathrm{TiO}_{2}$, NGQD before in contact

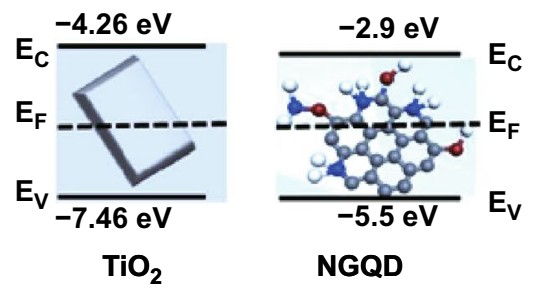

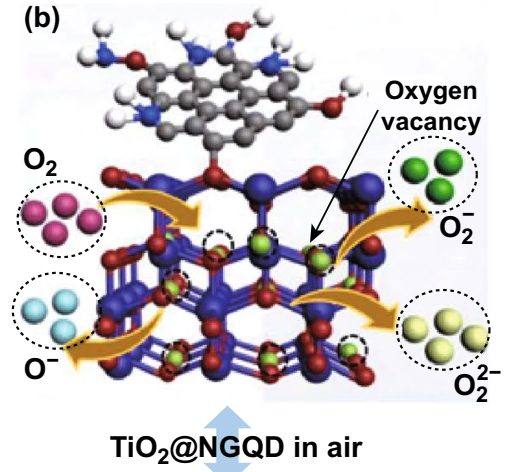

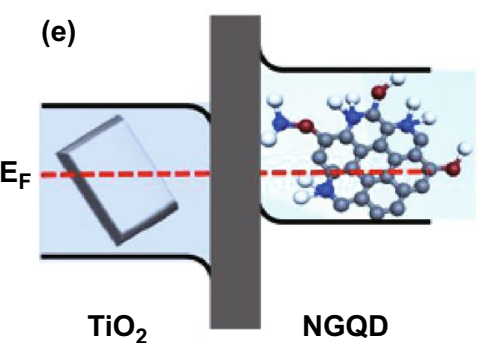

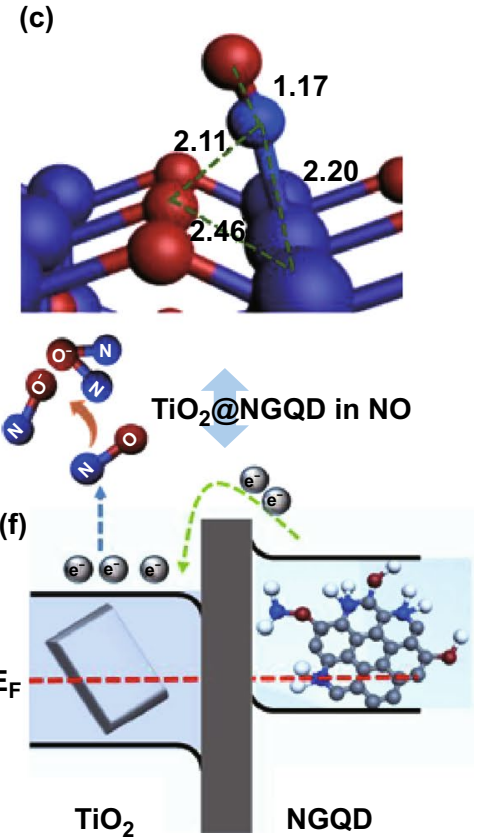

Fig. 7 Schematic sensing mechanism of $\mathbf{a} \mathrm{TiO}_{2} @ \mathrm{NGQDs}$ hybrids, $\mathbf{b} \mathrm{O}_{2}$ adsorption and conversion to oxygen ion species on $\mathrm{TiO} \mathrm{O}_{2}\{001\}$ surface, $\mathbf{c} \mathrm{NO}$ adsorption on to $\mathrm{TiO}_{2}\{001\}$ surface. d Energy band structures of $\mathrm{TiO}_{2} / \mathrm{NGQDs}$ before in contact, and e formation of $\mathrm{p}-\mathrm{n}$ junction after contact, and $\mathbf{f}$ electron transfer in the $\mathrm{TiO}_{2} / \mathrm{NGQDs}$ on exposure to NO. Reproduced with permission [76]. Copyright 2020, American Chemical Society 
sensing characteristics. Under blue light (480 nm) illumination, the sensor exhibited a response of 2.9 to $160 \mathrm{ppb}$ $\mathrm{NO}_{2}$ at RT, but the response/recovery time was long, i.e., 14.9/18.3 $\mathrm{min}$. The improved sensing property was ascribed to the acceleration of the reactions by photoenergy under illumination.

Cantalini and co-workers studied the $\mathrm{NO}_{2}$ sensing performances of $\mathrm{WO}_{3}$ electrospun nanofibers both activated by thermal and light activation including red, green and blue light [82]. They showed that the baseline resistance in dry air was highly dependent on the lights, showing a decrease by switching from dark, red, green and blue light, respectively. Accordingly, the sensor response to $400 \mathrm{ppb} \mathrm{NO}_{2}$ was also improved from $9 \%$ (dark) to $38 \%$ (red), 55\% (green) and 92\% (blue). An interesting finding is that under thermal activation at $75{ }^{\circ} \mathrm{C}$, the sensor response without light illumination is 18.4 , which is higher than that (12.4) under blue light illumination, due to the light-activated desorption of adsorbed oxygen from $\mathrm{WO}_{3}$ surface.

Apart from $\mathrm{NO}_{2}$, the photoactivated $\mathrm{WO}_{3}$ sensors have been used to detect $\mathrm{H}_{2}$. Zhang et al. reported a novel RT $\mathrm{H}_{2}$ sensor based on $\mathrm{PdO}$ loaded $\mathrm{WO}_{3}$ nanohybrids [83]. Their UV-Vis spectra revealed that $\mathrm{PdO}-\mathrm{WO}_{3}$ sensor has a broader visible light absorption range compared with pureWO 3 . This resulted in the good responses to ppm-level $\mathrm{H}_{2}$ gas under visible light illumination (Fig. 8a), and the best performance was achieved with blue light, showing a response of 6.15 to $40 \mathrm{ppm}_{2}$ and the response/recovery time was $3.2 / 7.9 \mathrm{~min}$. This performance is comparable to the result obtained under thermal activation at between 200 and $250{ }^{\circ} \mathrm{C}$ (Fig. 8b). It also has an excellent selectivity, as shown in Fig. 8c. The enhanced properties were attributed to the promotion effect of $\mathrm{PdO}$, the heterojunction between $\mathrm{PdO}$ and $\mathrm{WO}_{3}$, as well as the photoactivation effect, as shown in Fig. 8d.
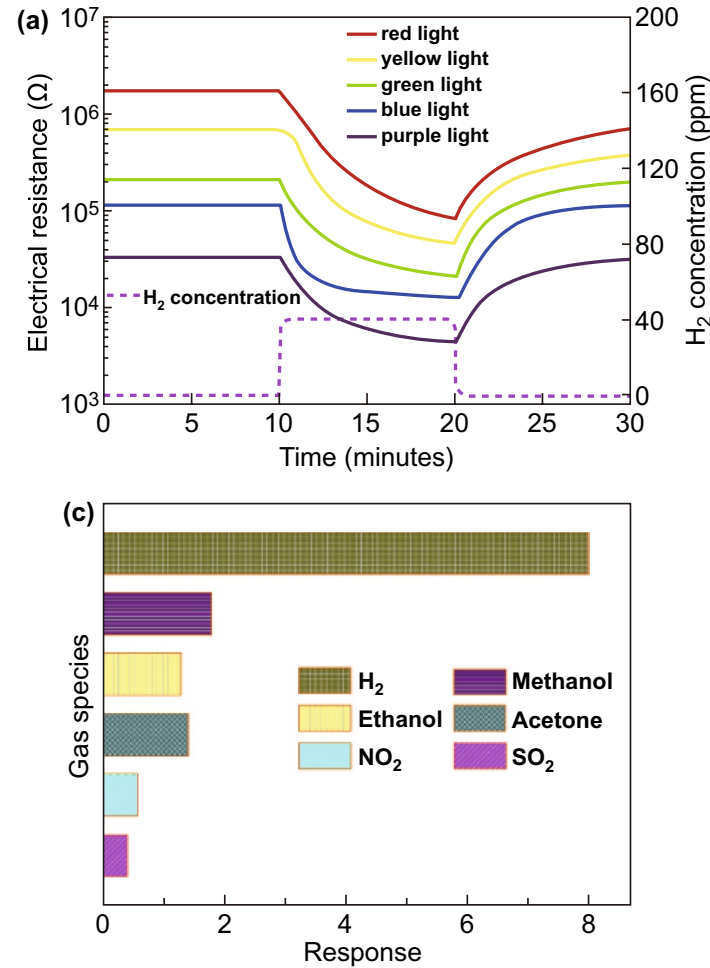
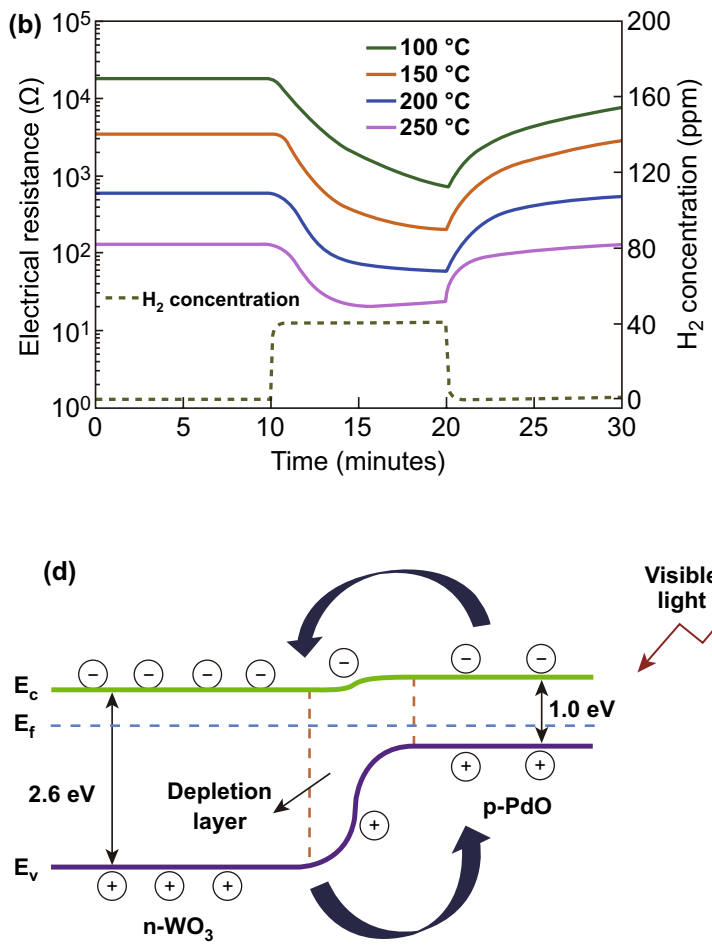

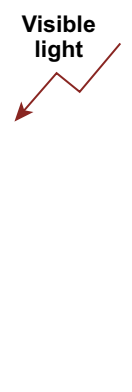

Fig. 8 Resistance variation of the $\mathrm{PdO}-\mathrm{WO}_{3}$ sensor to $40 \mathrm{ppm} \mathrm{H}_{2}$ at $\mathrm{RT}$ under a visible light illumination and $\mathbf{b}$ thermal heating at various temperatures. c Selectivity of the $\mathrm{PdO}-\mathrm{WO}_{3}$ sensor towards $40 \mathrm{ppm} \mathrm{H}_{2}, 300 \mathrm{ppm}$ acetone, $300 \mathrm{ppm}$ ethanol, $300 \mathrm{ppm}$ methanol, 10 ppm $\mathrm{NO}_{2}$ and $100 \mathrm{ppm} \mathrm{SO} \mathrm{S}_{2}$ under blue light illumination at RT. d Schematic carrier excitation in the $\mathrm{PdO}-\mathrm{WO}_{3}$ nanohybrids under visible light illumination. Reproduced with permission [83]. Copyright 2016, Elsevier 


\section{Photoactivated Two-dimensional (2D) Materials}

\subsection{Graphene}

Since the isolation of graphene in 2004 by Novoselov and Geim, graphene has become a promising candidate for advanced electronic device applications owing to its excellent electrical, mechanical and chemical properties [84-86]. The same group fabricated the first graphene gas sensor in 2007 and observed that graphene can detect gases at RT and has the potential to detect even a single gas molecule [28]. Despite the excellent gas adsorption, the fast response and complete desorption of the gas molecules from the surface of graphene at RT are main issues which have been addressed from light illumination or heating the device using micro-heater. Ma and co-workers studied the effects of thermal and optical energy on gas sensing characteristics of graphene via fabricating graphene sensor array (Fig. 9a) [87]. They observed that transferred CVD grown graphenebased gas sensor exhibited deterioration in sensitivity to $\mathrm{NO}_{2}$ gas with increased temperature $\left(25-100{ }^{\circ} \mathrm{C}\right)$. The high temperature increased the desorption rate of $\mathrm{NO}_{2}$ molecules, which results in less adsorption of gas molecules [88]. However, UV light irradiation enhanced the sensitivity of the sensor sevenfold and completed the incomplete recovery with decreased recovery time about fivefold compared to that of in dark condition at RT (Fig. 9b, c). Moreover, the sensor showed reliable selectivity to $\mathrm{NO}_{2}$ gas against many other gases via photoactivation as shown in (Fig. 9d, e). The sensitivity was enhanced due to excess photogenerated electrons and availability of a large number of adsorption sites for more number of $\mathrm{NO}_{2}$ molecules thorough cleaning of graphene surface from pre-adsorbed ambient oxygen ions or water molecules. Moreover, complete recovery at RT was achieved by accelerating desorption rate of $\mathrm{NO}_{2}$ molecules via light energy. Likewise, Harutyunyan et al. enhanced the sensitivity of the graphene gas sensor via in situ cleaning of graphene by UV light [89]. The pristine graphene sensor exhibited unprecedented sensitivity with a detection limit of $158 \mathrm{ppq}, 2.06 \mathrm{ppt}$ and $33.2 \mathrm{ppt}$ to $\mathrm{NO}, \mathrm{NO}_{2}$ and $\mathrm{NH}_{3}$ gases at RT. This ultra-sensitivity at RT was attributed to the cleaning of graphene via continuous in situ UV light illumination under inert atmosphere (under $\mathrm{N}_{2}$ gas ambient).
Further, Lai et al. enhanced acetone sensing properties of graphene sensor via UV light irradiation with optimized spacing between electrodes of resistive sensor device [90]. In this work, they fabricated different resistive gas sensor devices having electrodes spacing of 50,100, 200, and $400 \mu \mathrm{m}$ by using transferring CVD grown graphene on a glass substrate. The sensor with $400 \mu \mathrm{m}$ electrodes spacing exhibited two times higher sensitivity to acetone in a range of 100 to $1000 \mathrm{ppb}$ than that of the $50 \mu \mathrm{m}$ spacing electrodes sensor device. This improved sensitivity by large electrodes spacing was attributed to a combination effect of tensile strain on graphene, doping effect of glass and increased surface area with many defects at grain boundaries. Moreover, the sensitivity was enhanced to acetone by seven times under UV illumination at RT with response/recovery time of $300 \mathrm{~s}$ through desorption of natural atmospheric oxygen and water molecules from the surface of the graphene. The same group also improved the response/ recovery kinetics of the graphene sensor to $\mathrm{NO}_{2}$ gas at RT by using rapid thermal annealing (RTA) and UV light irradiation [91]. The as-fabricated sensor device using transferred CVD grown graphene was treated via RTA at $300{ }^{\circ} \mathrm{C}$ in $\mathrm{N}_{2}$ environment for providing more adsorption surface area through removing the polymer residue of transfer process. This sensor exhibited four times more sensitivity to $\mathrm{NO}_{2}$ than that of pristine graphene sensor without RTA treated. However, the sensor's incomplete recovery at RT was improved to complete by UV illumination during recovery time.

To further improve the gas sensing performance of the photoactivated graphene sensors, graphene sensing layer was decorated with noble metals, metal oxide and polymer nanoparticles. Chu et al. fabricated a photoactivated $\mathrm{NH}_{3}$ RT gas sensor by depositing different thickness of Ti on the graphene surface [92]. The optimized $5 \mathrm{~nm}$ thickness of Ti on the graphene surface was oxidized in terms of titanium oxide with different $\mathrm{Ti}$ valances and lower valances helped to reduce optical bandgap. Visible light was sufficient to create electron-hole pairs and these photoexcited electron-hole pairs as well as synergistic catalysis effects of TiOx/graphene assisted to improve the sensitivity of the sensor to $\mathrm{NH}_{3}$ gas with complete recovery (2.5 min) at RT under visible light irradiation. Further, Wu et al. enhanced the sensitivity of graphene sensor to $\mathrm{NO}_{2}$ gas at RT under visible light irradiation via decorating polymer (polystyrene (PS)) beads on graphene surface [93]. 

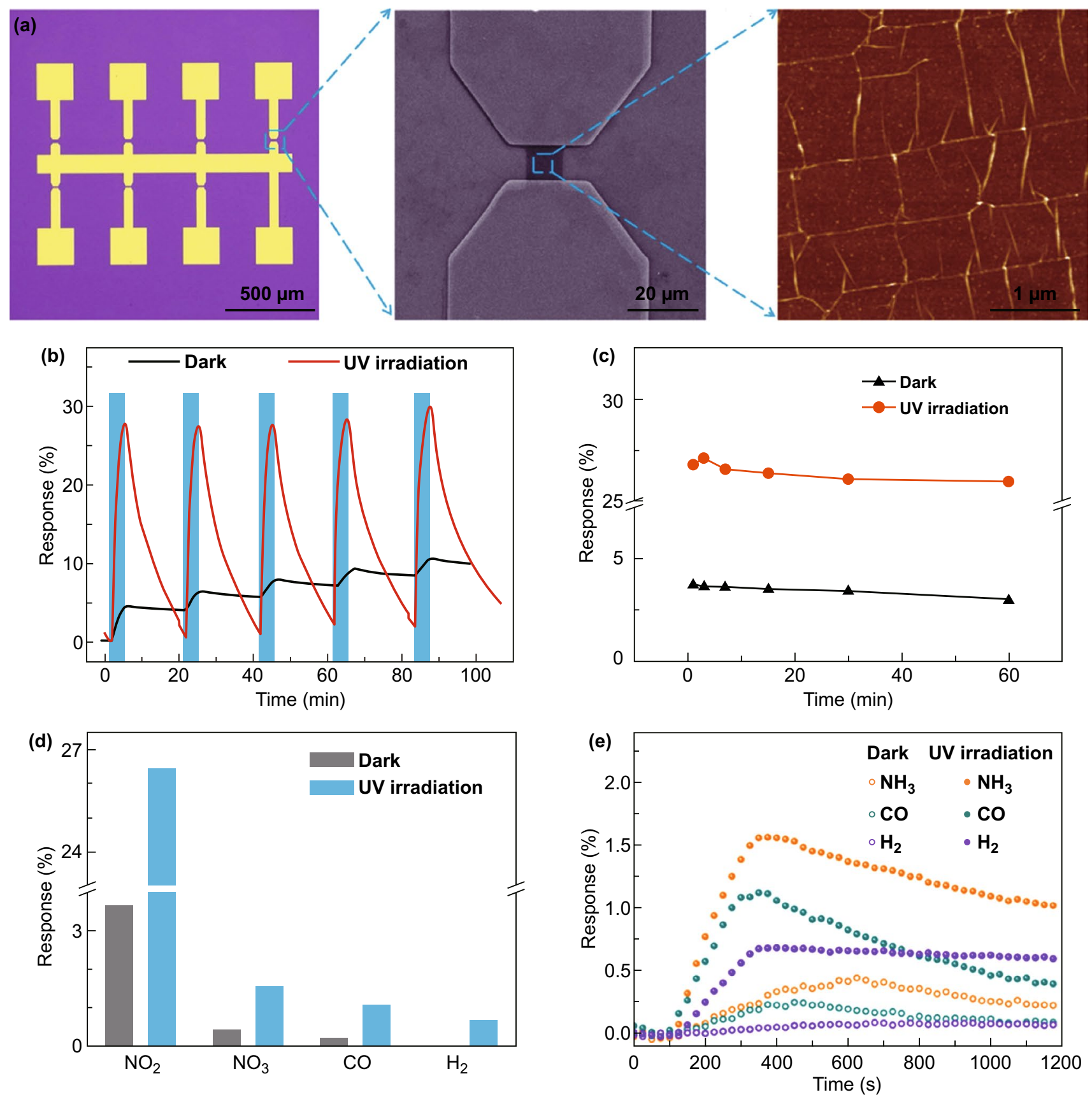

Fig. 9 a Optical image of graphene sensors array, SEM image of graphene device, and AFM image of graphene. b Response and $\mathbf{c}$ stability test of graphene sensor to $100 \mathrm{ppm} \mathrm{NO}$ in dark and UV illumination. $\mathbf{d}$ Selectivity bar diagram, and e transient response of graphene sensor to $\mathrm{NH}_{3}$, $\mathrm{CO}$ and $\mathrm{H}_{2}$ at room temperature in dark and UV illumination. Reproduced with permission [87]. Copyright 2019, American Chemical Society

There was electron transfer from graphene to PS beads at the graphene/PS interface and some exciting surface plasmon polaritons are also present in graphene through diffraction of light on microbeads (Fig. 10a), which helped to enhance the sensitivity of graphene sensor with a detection limit of $0.5 \mathrm{ppb} \mathrm{NO}_{2}$ at $\mathrm{RT}$ under laser illumination. Figure 10b, c clearly illustrates the concave region at PS bead/ graphene interface and upon $\mathrm{NO}_{2}$ exposure, two static forces, one from the bead and another from graphene drag more number of gas molecules which results in enhanced gas 
response in PS decorated graphene than that of the pristine graphene sensor. Moreover, under light illumination, photoexcited electrons transferred from graphene to PS bead and thereby, a dipole layer was formed at PS/graphene interface. As a result, dipolar interaction was occurred in between the dipole layer and polar $\mathrm{NO}_{2}$ molecules. This dipolar interaction under light illumination was stronger from static interaction in dark condition and which was helpful to enhance sensitivity and fast adsorption to $\mathrm{NO}_{2}$ gas at RT. Likewise, Banihashemian et al. reported enhanced ammonia detection by using Ag particles decorated graphene sensor at RT under blue LED (10 $\left.\mathrm{mW} \mathrm{cm}^{-2}\right)$ exposure [94]. The enhancement in sensitivity was attributed to surface plasmon resonance and spillover effects. Besides the decoration of graphene surface via nanoparticles, different nanocomposites and hybrids of graphene such as $\mathrm{WO}_{3}$ nanorodes/Graphene [95], carbon nitride/rGO [96], RGO-CeO 2 [97], $\mathrm{WO}_{3} / \mathrm{rGO}$ [98], $\mathrm{MoS}_{2} /$
rGO [99], p-phenylenediamine-graphene oxide (PGO)/ InGaN [100], Pd-decorated $\mathrm{ZnO} / \mathrm{rGO}$ [101] and $\mathrm{Pd}-\mathrm{WO}_{3} /$ graphene/Si [102] were utilized for improving the gas sensing performance of graphene sensor at RT under light irradiation. Zhang et al. designed a gasochromic-Pd- $\mathrm{WO}_{3} /$ graphene/Si tandem structure (Fig. 10d) for hydrogen sensing at RT under light irradiation [102]. In this structure, $\mathrm{Pd}-\mathrm{WO}_{3}$ and graphene/Si worked as sensing and photodetector layer through utilizing their gasochromic and photovoltaic properties, respectively. Upon hydrogen exposure, $\mathrm{Pd}$ dissociated the $\mathrm{H}_{2}$ into $\mathrm{H}$ atoms and $\mathrm{WO}_{3}$ converted to $\mathrm{H}_{\mathrm{x}} \mathrm{WO}_{3}$ which decreased the transmittance and was synchronously sensed by graphene/Si photodetector and that changed its photocurrent corresponding to $\mathrm{H}_{2}$ concentration. Thus, the sensor detected even low concentration of $0.05 \mathrm{vol} \% \mathrm{H}_{2}$ with fast response time (13 s) and recovery time (43 s) at RT under laser $(980 \mathrm{~nm})$ illumination as shown in Fig. 10e.
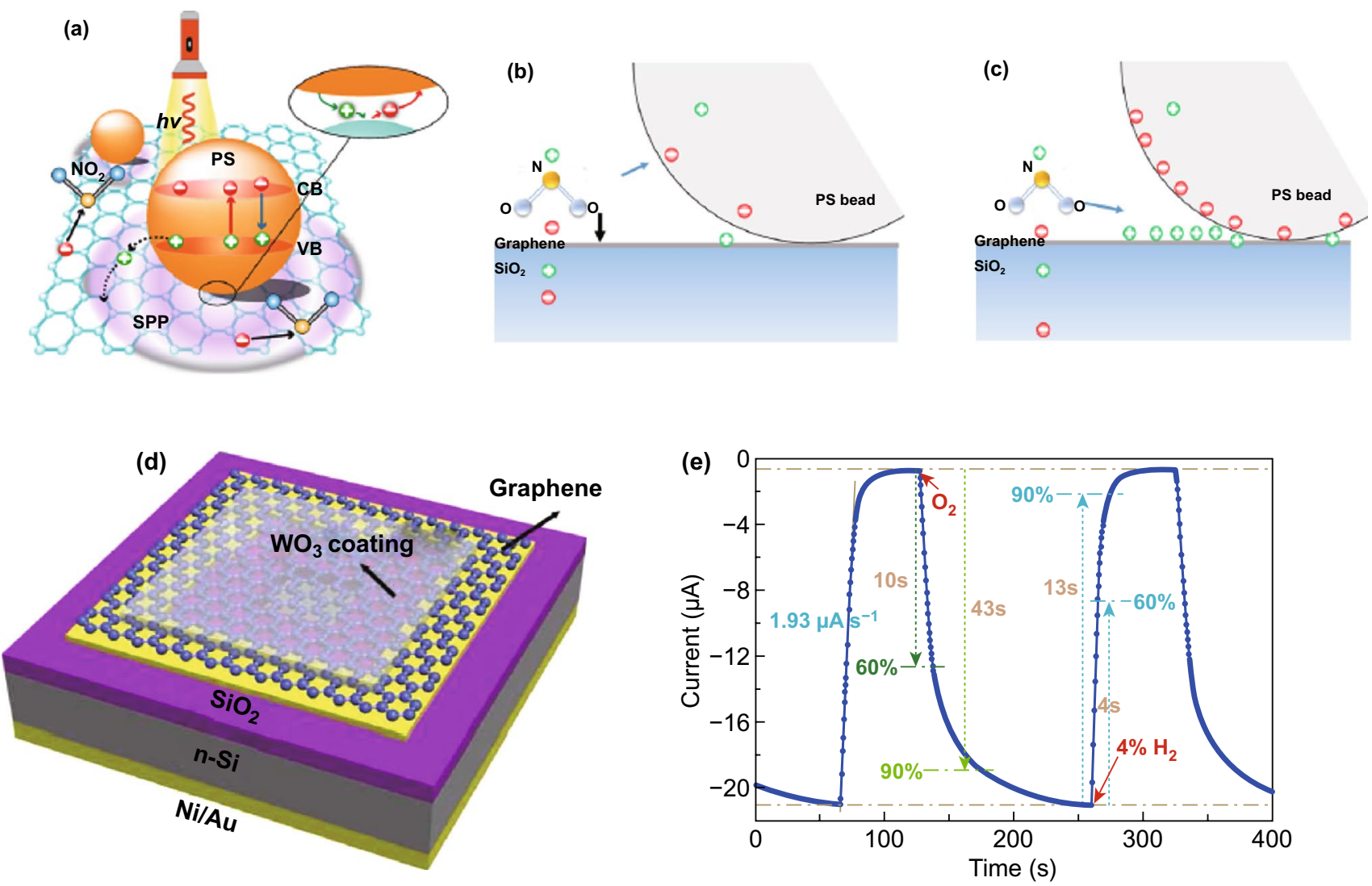

Fig. 10 a Schematic representation of charge transfer in between graphene and PS bead under light illumination. The electric potential and static forces on adsorbed $\mathrm{NO}_{2}$ molecules on graphene/PS hybrid under $\mathbf{b}$ dark condition and $\mathbf{c}$ light illumination. Reproduced with permission [93]. Copyright 2019, American Chemical Society. d Schematic illustration of gasochromic-Pd- $\mathrm{WO}_{3} /$ graphene/Si tandem structure of hydrogen sensor. e The transient gas response of the sensor to $\mathrm{H}_{2}$ gas under light illumination. Reproduced with permission [102]. Copyright 2018, Elsevier 
Besides the high sensitivity and fast response/recovery kinetics, selectivity of the sensor is also one of the most important aspects for the usage of the sensor on the commercial sensing platform. In this context, Wu et al. reported a 'light on and off' strategy for selective detection of $\mathrm{NO}_{2}$ and $\mathrm{SO}_{2}$ gas by using the $2 \mathrm{D} \mathrm{g-C} \mathrm{C}_{3} \mathrm{~N}_{4} / \mathrm{rGO}$ van der Waals heterostructure [103]. In this work, a layer-by-layer self-assembly approach was used for fabricating $\mathrm{g}-\mathrm{C}_{3} \mathrm{~N}_{4} / \mathrm{rGO}$ stacking hybrid on a paper substrate (Fig. 11a, b, d, e). The p-type semiconducting g- $\mathrm{C}_{3} \mathrm{~N}_{4} / \mathrm{rGO}$ sensor under light off condition exhibited no response to $\mathrm{SO}_{2}$ and high sensitivity to $\mathrm{NO}_{2}$ gas with detection as low as $100 \mathrm{ppb}$ at RT (Fig. 11c). In contrast, under UV light irradiation, the sensor with changed n-type semiconducting behaviour showed sensitivity to $\mathrm{SO}_{2}$
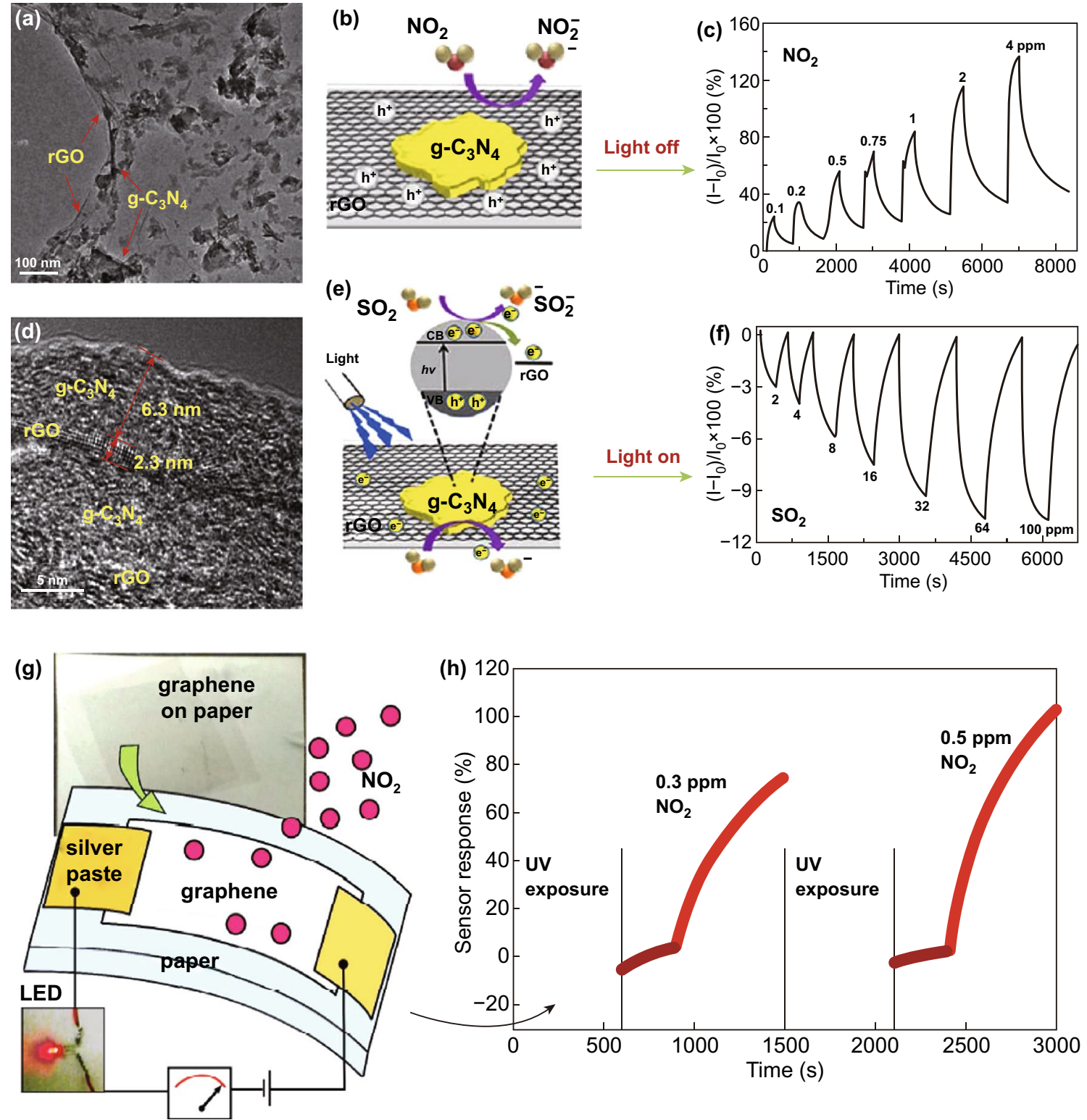

Fig. 11 SEM image of g- $\mathrm{C}_{3} \mathrm{~N}_{4} / \mathrm{rGO}$ hybrid $\mathbf{a}$ in low, and $\mathbf{d}$ high magnification. $\mathbf{b}$ Schematic representation of charge transfer between g- $\mathrm{C}_{3} \mathrm{~N}_{4} /$ rGO hybrid and $\mathrm{NO}_{2}$ under dark condition. $\mathbf{c}$ Transient gas response of the hybrid sensor to $\mathrm{NO}_{2}$ gas under dark condition. e Schematic representation of charge transfer between $\mathrm{g}_{-} \mathrm{C}_{3} \mathrm{~N}_{4} / \mathrm{rGO}$ hybrid and $\mathrm{SO}_{2}$ under $\mathrm{UV}$ light illumination. $\mathbf{f}$ Transient gas response of the hybrid sensor to $\mathrm{SO}_{2}$ gas under UV light illumination. Reproduced with permission [103]. Copyright 2017, American Chemical Society. g Schematic illustration of a graphene sensor on paper substrate. $\mathbf{h}$ Gas response of the flexible graphene sensor. Reproduced with permission [104]. Copyright 2015, American Chemical Society 
with detection as low as $2 \mathrm{ppm}$, as shown in Fig. 11f. Under UV irradiation, photon energy excited the electrons in valance band of $\mathrm{g}-\mathrm{C}_{3} \mathrm{~N}_{4}$, and then, these photoexcited electrons transferred into $\mathrm{rGO}$ and a negative charge layer formed on the surface. Thereby, $\mathrm{SO}_{2}$ gas molecules extracted electrons which results in negative response through decreasing electrons concentration in the $\mathrm{g}-\mathrm{C}_{3} \mathrm{~N}_{4} / \mathrm{rGO}$. This approach to distinguish the $\mathrm{NO}_{2}$ and $\mathrm{SO}_{2}$ gas via light source was attributed to effective charge transfer between g- $_{3} \mathrm{~N}_{4}$ and $\mathrm{rGO}$. Likewise, Ren et al. also reported UV light-activated gas sensor for selective detection of $\mathrm{NO}_{2}$ and $\mathrm{SO}_{2}$ gas by using a nanocomposite of $\mathrm{SnO}_{2}$ nanofibers and $\mathrm{rGO}$ [74]. On the other hand, high flexibility and transparency aspects of graphene make it a leading candidate for emerging flexible and wearable gas sensing technology.

In this regard, Raghavan et al. [104] demonstrated deep UV light-activated flexible graphene sensor for $\mathrm{NO}_{2}$ detection at RT. They directly transferred the CVD grown graphene on paper without any intermediate layers and called it G-paper (Fig. 11g) which showed a detection limit of 300 ppt to $\mathrm{NO}_{2}$ at RT. Under deep UV light irradiation, fast response and recovery time were achieved at RT due to cleaning of graphene through desorption of atmospheric adsorbents (Fig. 11h) and this also was confirmed by Raman spectroscopy with indicating reduction of p-type doping in G-paper. Besides the high gas sensing performance of the sensor, this method is very useful for biodegradable and wearable sensor applications due to simplicity, low cost and high productivity.

It is noted from all above results that photoactivation removes the heating element from the graphene sensors to achieve fast response and complete recovery at RT and it also improves the sensitivity and selectivity of the graphene sensors. However, chemiresistive sensor required external supply voltage or current to electrical readout and so, it consumed electrical power for its operation. Nowadays, chemical sensors consuming ultralow-power are needed for its usage in the Internet of things applications. Lee et al. reported a self-powered chemical sensor fabricated by a graphene-based heterojunction device [105]. In this work, photovoltaic heterojunctions were fabricated via contact of top graphene layer with photoactive materials silicon $(\mathrm{Si})$ or tungsten disulphide $\left(\mathrm{WS}_{2}\right)$ as shown in Fig. 12a. Upon gas exposure, the electrochemical potential of graphene was changed owing to the one-atom-thick layer, which results in modulation of built-in potential at the interface of graphene and $\mathrm{Si}$ or $\mathrm{WS}_{2}$. Thereby, change in photocurrent or photovoltage of the device was measured at RT without applying external bias. As a result, the sensor showed good response to $\mathrm{NO}_{2}, \mathrm{NH}_{3}$ and $\mathrm{H}_{2}$ gases with detection as low as 1 ppm $\mathrm{H}_{2}$ at RT (Fig. 12b-f).

\section{2 $\mathrm{MoS}_{2}$}

$\mathrm{MoS}_{2}$ is one of the most famous members of layered transitional metal dichalcogenides (TMDCs) family for electronics device applications [106-108] and particularly, gas sensor devices owing to its unique electrical and physical properties [24, 34, 109-111]. $\mathrm{MoS}_{2}$ sensor has attracted immense attention in gas sensing field under light illumination due to its excellent optoelectronics aspects. Late et al. performed a gas sensing experiment on mechanically exfoliated five layers $\mathrm{MoS}_{2}$ based gas sensor under the green light illumination (532 nm) [112]. The SEM image of the $\mathrm{MoS}_{2}$ device and mounted device on a chip are shown in Fig. 13a, b. They measured the sensitivity to each $100 \mathrm{ppm} \mathrm{NO}$ and $\mathrm{NH}_{3}$ upon exposure to green light with different optical powers. The sensitivity of the sensor was enhanced up to optimal irradiation power and suddenly decreased for high irradiation power, as shown in Fig. 13c. This behaviour was similar to photoactivated metal oxide-based gas sensor. Likewise, Friedman et al. also measured the sensitivity of mechanically exfoliated $\mathrm{MoS}_{2}$ sensor under the illumination of white light at RT [113]. They observed that the sensor exhibited about 10 times higher sensitivity to trimethylamine upon exposure to light than that of switched off light condition. However, gas sensing mechanism of enhancing the sensitivity of the $\mathrm{MoS}_{2}$ gas sensor under the illumination of the light source was not clear. Therefore, many research efforts have been attempted to elucidate the improvement in gas sensing characteristics of photoactivated $\mathrm{MoS}_{2}$. Kumar et al. demonstrated gas sensing performance of CVD grown multilayer $\mathrm{MoS}_{2}$ at RT under UV illumination [114]. The sensor showed high selectivity towards $\mathrm{NO}_{2}$ against many other gases $\left(\mathrm{CO}_{2}, \mathrm{NH}_{3}, \mathrm{CH}_{4}, \mathrm{H}_{2}\right.$ and $\left.\mathrm{H}_{2} \mathrm{~S}\right)$ under UV illumination. Optical energy assisted to provide more numbers of adsorption active sites on the surface of $\mathrm{MoS}_{2}$ through desorption of ambient oxygen and contamination because photogenerated holes reacted with pre-adsorbed oxygen ions and formed $\mathrm{O}_{2}$ gas as shown in Fig. 13f. On 


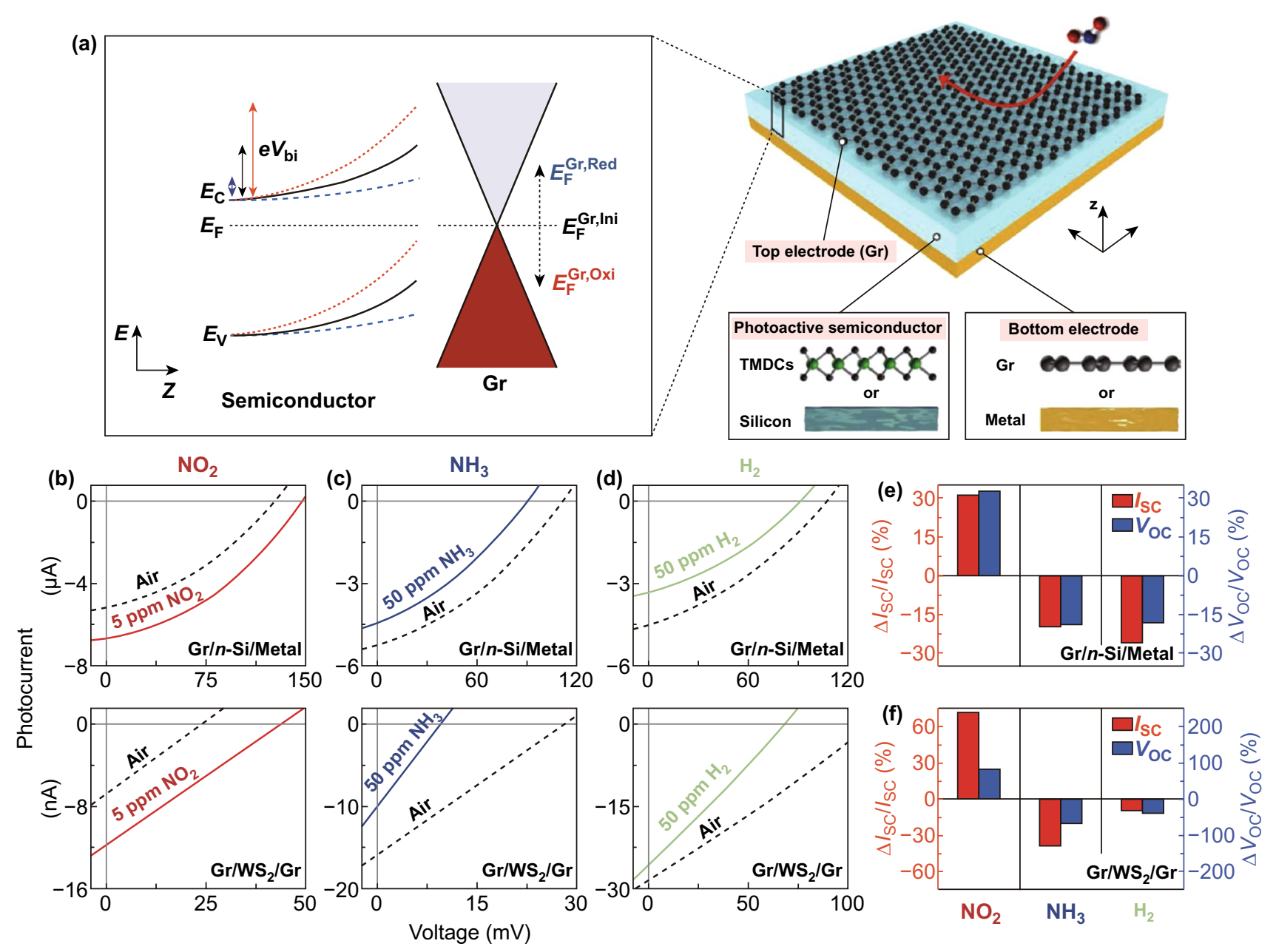

Fig. 12 a Schematic representation of a self-powered chemical sensor fabricated by graphene-based photovoltaic heterojunction device (right) and energy band diagram of the device (left). Change in photocurrent of graphene/Si/metal and graphene/WS $/ \mathrm{graphene}_{2}$ device under $\mathbf{b} \mathrm{NO}_{2}, \mathbf{c}$ $\mathrm{NH}_{3}$ and $\mathbf{d ~ H} \mathrm{H}_{2}$ ambient. Histograms of the relative percentage change in photocurrent (red) and photovoltage (blue) to $\mathrm{NO}_{2}, \mathrm{NH}_{3}$ and $\mathrm{H}_{2}$ gases of e graphene/Si/metal and $\mathbf{f}$ graphene/ $\mathrm{WS}_{2} /$ graphene device under white light illumination. Reproduced with permission [105]. Copyright 2018, WILEY-VCH Verlag GmbH \& Co. KGaA, Weinheim

the other hands, thermal energy decreased the sensitivity of the sensor to $\mathrm{NO}_{2}$ gas because thermoactivation accelerated the desorption rate than adsorption rate (Fig. 13e) $[115,116]$. In addition, CVD grown monolayer $\mathrm{MoS}_{2}$ also showed enhanced sensitivity to NO gas at RT under UV light (254 nm) [117].

From the above all reports, it is clear that light source was switched on during throughout gas sensing experiment and this optical energy enhanced the sensitivity of the $\mathrm{MoS}_{2}$ gas sensor to different gases and gas sensing mechanism under the light illumination also was proposed. However, complete recovery at RT under light illumination was still vague. In this context, Kim et al. proposed a complete recovery mechanism for $\mathrm{MoS}_{2}$ gas sensor via illumination of light during recovery process [118]. Under UV illumination, photogenerated hole reacted with adsorbed $\mathrm{NO}^{-}$, which results in $\mathrm{NO}_{2}$ desorption through changing its chemical state. Simultaneously, photogenerated electrons decrease the resistance value of the $\mathrm{MoS}_{2}$ sensor, and thereby, the sensor achieved its initial baseline resistance value. Thus, photogenerated electron-hole pairs helped to obtain complete recovery at RT without raising the temperature of the $\mathrm{MoS}_{2}$ sensor. Moreover, this proposed mechanism also verified by Raman and PL experiments.

However, gas sensing mechanism of $\mathrm{MoS}_{2}$ gas sensor under light illumination is needed to further explain 

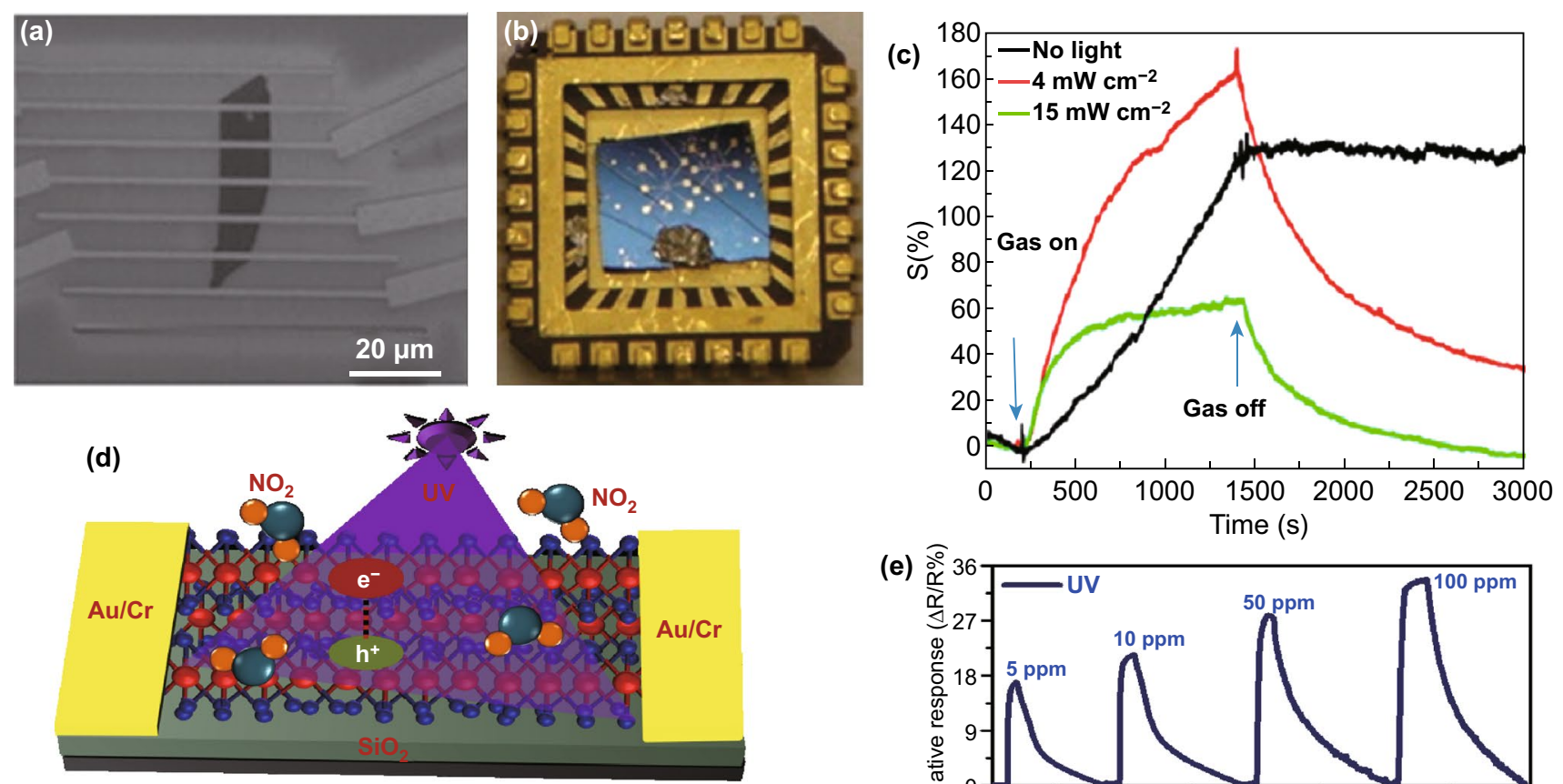

(e)
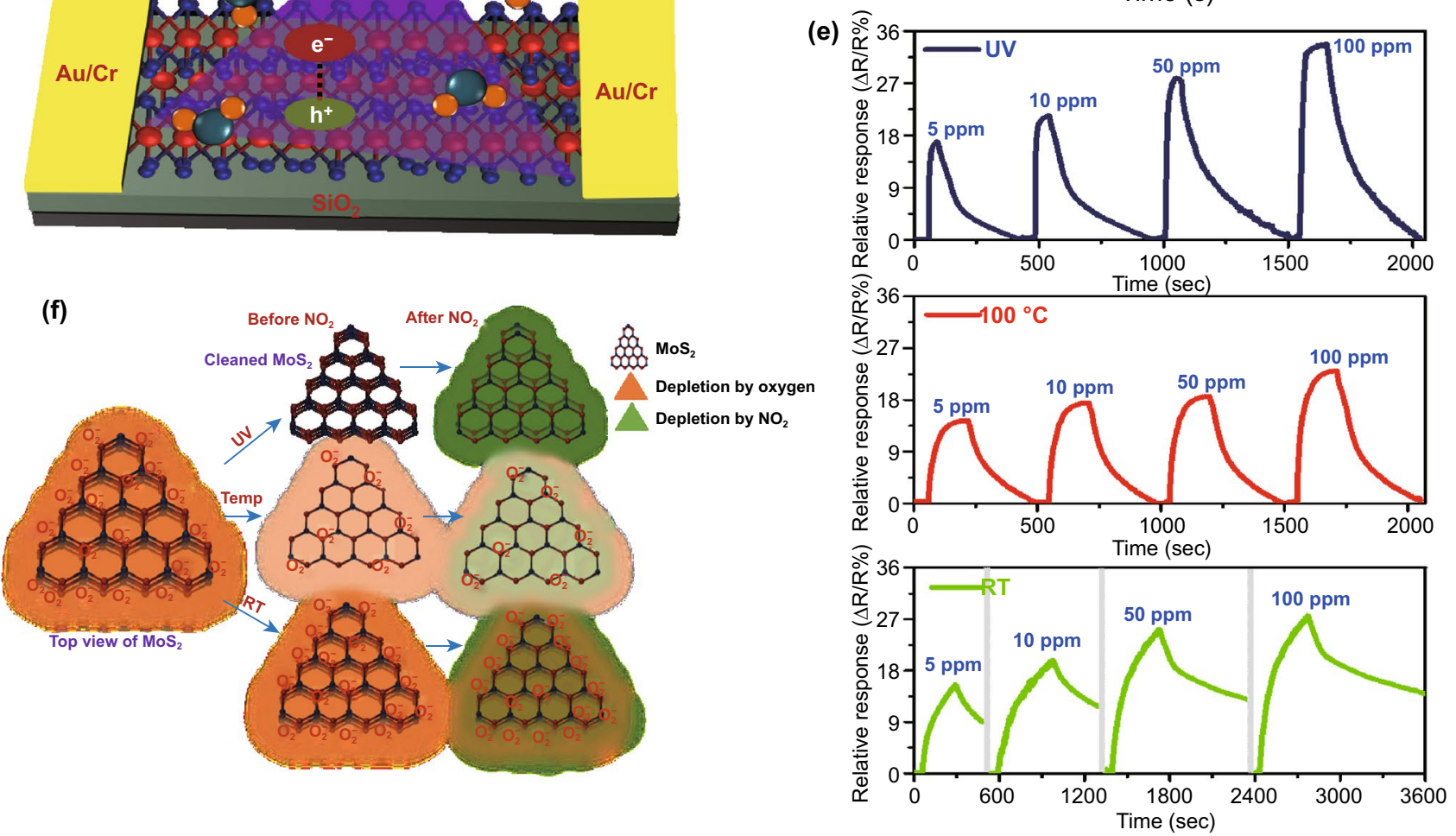

Fig. 13 a SEM image of mechanically exfoliated $\mathrm{MoS}_{2}$-based device. b $\mathrm{MoS}_{2}$ device mounted on the chip. $\mathbf{c}$ Sensitivity to $\mathrm{NO}_{2}$ gas of the $\mathrm{MoS}_{2}$ sensor under different intensities of the green light source. Reproduced with permission [112]. Copyright 2013, American Chemical Society. d Schematic representation of a CVD grown $\mathrm{MoS}_{2}$ sensor under UV light illumination. e Transient gas response to different concentrations of $\mathrm{NO}_{2}$, and $\mathbf{f}$ gas sensing mechanism, of the CVD grown $\mathrm{MoS}_{2}$ sensor at room temperature, $100{ }^{\circ} \mathrm{C}$ and under UV illumination. Reproduced with permission [114]. Copyright 2017, American Chemical Society

quantitatively in the context of a number of adsorption sites and adsorption energy values.

In order to improve gas sensing performance of $\mathrm{MoS}_{2}$ sensor under light illumination, some suitable approaches and strategies were adopted by exploiting structure and interface engineering. Chueh et al. reported the detection of $\mathrm{NO}$ gas at ppb level using 3D cone-shaped $\mathrm{MoS}_{2}$ bilayers under indoor light illumination [119]. In this work, 3D cone-shaped $\mathrm{MoS}_{2}$ bilayers were fabricated by sulphurizing 2-nm-thick $\mathrm{MoO}_{3}$ film on pre-patterned 2" cone patterned sapphire substrate. The sensor exhibited sensitivity of $\sim 189.2 \% / \mathrm{ppm}$ with detection as low as $\sim 0.06 \mathrm{ppm}$ NO at RT under UV light illumination. Moreover, this 3D structure of $\mathrm{MoS}_{2}$ showed about twofold higher sensitivity than that of flat $\mathrm{MoS}_{2}$ sensor. The 
enhancement in sensitivity of 3D architecture of $\mathrm{MoS}_{2}$ under light source was attributed to $30 \%$ increased surface area as well as enhanced light absorption through light scattering effects. In addition, electrode's materials also play a crucial role in tuning the sensing performance of chemiresistive/ FET- type gas sensor. From this view, Mulchandani et al. reported ultrasensitive optoelectronic $\mathrm{NO}_{2}$ gas sensor using special arrangements in the electrode's materials of FETtype $\mathrm{MoS}_{2}$ sensor (Fig. 14a-c) [120]. The Au electrodesbased $\mathrm{Au} / \mathrm{MoS}_{2} / \mathrm{Au}$ sensor exhibited excellent sensitivity $4.9 \% / \mathrm{ppb}(4900 \% / \mathrm{ppm})$ at RT under red light illumination. In contrast to $\mathrm{Au} / \mathrm{MoS}_{2} / \mathrm{Au}$ sensor, Au coated graphene $(\mathrm{Gr})$ electrode-based Au/Gr-MoS ${ }_{2}-\mathrm{Gr} / \mathrm{Au}$ sensor showed ultrasensitivity to $\mathrm{NO}_{2}$ with detection as low as $0.1 \mathrm{ppb}$ concentration at RT.

Incorporation of another material into $\mathrm{MoS}_{2}$ in terms of nanocomposite or hybrid as a new sensing material also used for enhancing the gas sensing performance through chemical and electronic sensitization effects $[14,121]$. Controlled
Au nanoparticles functionalization changed carrier concentration of $\mathrm{MoS}_{2}$ through electrons transferring from $\mathrm{Au}$ to $\mathrm{MoS}_{2}$ [109]. This controlled n-type doping effect helped to discriminate hydrocarbon- and oxygen-functional group based VOCs by showing different sensing behaviour. Pristine $\mathrm{MoS}_{2}$ exhibited increase resistance value upon exposure to all VOCs, but Au: $\mathrm{MoS}_{2}$ showed decrease resistance value to oxygen-functionalized compounds and the same increase resistance value behaviour to hydrocarbon-based VOCs. Likewise, Jung et al. demonstrated different sensing behaviour to oxygen-functionalized VOCs via functionalization of the $\mathrm{MoS}_{2}$ by a thiolated ligand (mercaptoundecanoic acid (MUA)) [122]. The MUA-conjugated $\mathrm{MoS}_{2}$ showed a negative response to oxygen-functionalized VOCs but, pristine $\mathrm{MoS}_{2}$ exhibited a positive response to the same VOCs at RT. Further, Guo et al. improved the gas sensing characteristics of decorating Au nanoparticles on the surface of $\mathrm{MoS}_{2}$ under UV light illumination [123]. The Au-MoS 2 gas sensor exhibited about three times higher response to $\mathrm{NO}_{2}$
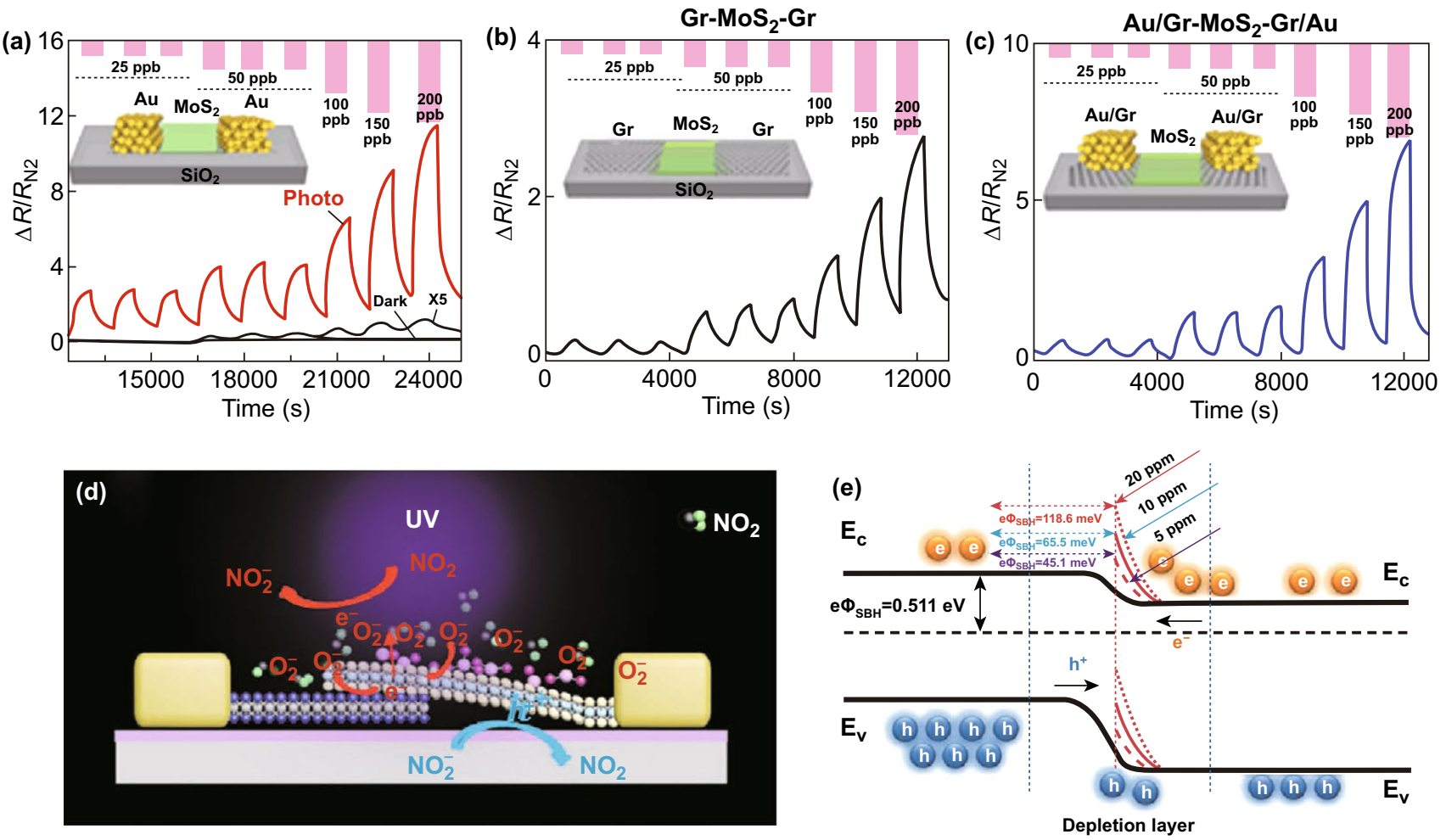

Fig. 14 Gas response to different concentrations of $\mathrm{NO}_{2}$ gas at room temperature under red light illumination of a $\mathrm{Au} / \mathrm{MoS} 2 / \mathrm{Au}, \mathbf{b} \mathrm{Gr} / \mathrm{MoS} 2 / \mathrm{Gr}$, and $\mathbf{c} \mathrm{Au} / \mathrm{Gr}-\mathrm{MoS}_{2}-\mathrm{Gr} / \mathrm{Au}$ device. Reproduced with permission [120]. Copyright 2019, American Chemical Society. d Schematic representation of an n-p-type van der Waals homojunction of $\mathrm{MoS}_{2}$ under UV illumination. e Gas sensing mechanism of the n-p-type van der Waals homojunction of $\mathrm{MoS}_{2}$ via energy band diagram. Reproduced with permission [126]. Copyright 2020, WILEY-VCH Verlag GmbH \& Co. KGaA, Weinheim 
with complete recovery at RT under UV illumination than that of in the dark condition. The enhancement in sensitivity was attributed to an increased number of active adsorption sites as well as introducing active catalysts via Au nanoparticles. Moreover, Au nanoparticles accelerated trapping of more numbers of photons which generated additional photoexcited charge carriers for more gas-solid interaction. Under UV illumination, effective separation of photoexcited charge carriers at $\mathrm{MoS}_{2} / \mathrm{Au}$ interface due to different work function of $\mathrm{MoS}_{2}$ and Au was also helpful to contribute for obtaining fast full recovery at RT. Guo et al. reported an ultrasensitive UV-assisted $\mathrm{NO}_{2}$ gas sensor based on a nanocomposite sensing layer of $\mathrm{MoS}_{2}$ and $\mathrm{ZnO}$ nanowires [124]. The $\mathrm{MoS}_{2} / \mathrm{ZnO}$ sensor showed excellent sensitivity of $0.93 /$ ppb with a detection limit of $50 \mathrm{ppq}$ and complete recovery at RT under UV illumination. This improved performance of the sensor under optical energy was the results of two reasons. On the one hand, under UV illumination, additional photogenerated charge carriers react with more number of $\mathrm{NO}_{2}$ molecules. On the other hand, a large number of $\mathrm{MoS}_{2} /$ $\mathrm{ZnO}$ nanoheterojunctions helped for extension of depletion region and photoexcited electrons moved into $\mathrm{ZnO}$ from the conduction band of $\mathrm{MoS}_{2}$, while excited hole transferred into $\mathrm{MoS}_{2}$ from valance band of $\mathrm{ZnO}$. This effective separation of charge carriers improved the sensing characteristics by avoiding charge recombination at the interface. To further enhance the sensing characteristics, Wang et al. fabricated a near-infrared (NIR) optoelectronic $\mathrm{NO}_{2}$ gas sensor using a nanocomposite of $\mathrm{ZnO}$ quantum dots decorated sulphur vacancy-enrich $\mathrm{MoS}_{2}\left(\mathrm{~Sv}-\mathrm{MoS}_{2}\right)$ [125]. Sulphur vacancy introduced new energy levels between conduction and valance band of $\mathrm{MoS}_{2}$. These localized levels helped to increase photoexcited charge carriers and charge transfer by absorbing more light photons under NIR illumination. As a result, the $\mathrm{Sv}-\mathrm{MoS}_{2} / \mathrm{ZnO}$ sensor exhibited high sensitivity of $226 \%$ to $200 \mathrm{ppb} \mathrm{NO}_{2}$ at RT under NIR illumination. Moreover, the sensor also showed fast response and recovery time (75 and $111 \mathrm{~s}$ ) at RT.

The optoelectronic gas sensors based on van der Waals heterostructures are recently attracting enormous attention for developing high-performance gas sensor. Van der Waals heterostructures owing to its strong light matter interaction and tuning of carrier concentration or energy band diagram by electrical, magnetic and optical energy render them a promising candidate for optoelectronic gas sensors. Despite the huge potential of heterostructures of $\mathrm{MoS}_{2}$ in gas sensing field, there are still few reports of $\mathrm{MoS}_{2}$ heterostructuresbased optoelectronics gas sensors and it is in the nascent stage. Recently, Zhang and co-worker reported a highly selective $\mathrm{NO}_{2}$ gas sensor using $2 \mathrm{D}$ planar van der Waals p-n homojunction of $\mathrm{MoS}_{2}$ under UV illumination [126]. In this work, n-type and p-type $\mathrm{MoS}_{2}$ were fabricated by CVD and sol-gel process, respectively (Fig. 14d). The p-n van der Waals homojunction of $\mathrm{MoS}_{2}$ exhibited about 60 times higher sensitivity to $20 \mathrm{ppm} \mathrm{NO}$ than that of the individual p-type $\mathrm{MoS}_{2}$. Moreover, the sensor showed a low detection limit of $8 \mathrm{ppb}$ with very fast complete recovery $(<30 \mathrm{~s})$ at RT under the UV illumination. This excellent sensing performance of van der Waals-based sensor was attributed to modulation of barrier height at the p-n junctions of $\mathrm{MoS}_{2}$ upon exposure to $\mathrm{NO}_{2}$ gas (Fig. 14d, e). Further, Kim et al. demonstrated $\mathrm{NO}_{2}$ gas sensor under UV light illumination using 2D/3D heterostructure of $n-\mathrm{MoS}_{2} / \mathrm{p}-\mathrm{GaN}$ [127]. The sensor showed high sensitivity of $98.42 \%$ to 50 ppm $\mathrm{NO}_{2}$ with complete recovery at RT under UV illumination with applied reverse bias. Besides the well-known mechanism of heterostructures as modulation of barrier height at heterojunctions upon exposure to gas molecules, reverse bias strategy also utilized here to enhance the sensing performance of heterostructure sensor through improving the photoextraction from the p-n junction [128].

All the above reports are limited to optoelectronic $\mathrm{MoS}_{2}$ gas sensors on rigid substrates; nonetheless, excellent flexibility and mechanical properties of the $\mathrm{MoS}_{2}$ render it a promising candidate for flexible and wearable sensors applications. Wang et al. reported a high-performance flexible $\mathrm{MoS}_{2}$ gas sensor at RT by exploiting photogating and piezo-phototronic effects [129]. Figure 15a, b illustrates the schematic of the flexible device and 3D representation of the current response of the sensor to $\mathrm{NO}_{2}$ gas under different optical powers and tensile strain. The sensor exhibited excellent sensitivity of $671 \%$ to $400 \mathrm{ppb} \mathrm{NO}_{2}$ at RT under red light $(625 \mathrm{~nm})$ illumination with $0.67 \%$ tensile strain (Fig. 15d). Moreover, the sensor showed dramatically improved response time of $16 \mathrm{~s}$ and complete recovery time of $65 \mathrm{~s}$ at RT. The excellent sensing performance of the sensor was attributed to tuning the Schottky barrier height at two back-to-back $\mathrm{Pd}-\mathrm{MoS}_{2}$ junctions upon exposure to gas molecules via a combination of photo-gating and piezophototronic effects (Fig. 15e). 


\section{3 $\mathrm{MOTe}_{2}$}

Molybdenum ditelluride $\left(\mathrm{MoTe}_{2}\right)$ is an emerging material in TMDCs family and has a lower energy bandgap of $\sim 1.0 \mathrm{eV}$ than other semiconducting TMDCs materials. Due to a smaller bandgap, $\mathrm{MoTe}_{2}$ showed photodetection in a wider range from visible to near-infrared wavelengths [130, 131]. Besides the excellent optoelectrical properties, larger bond length and lower binding energy of $\mathrm{MoTe}_{2}$ are important aspects for utilizing it in the optoelectronic gas sensing field. Zhang et al. reported enhancement in sensitivity of $\mathrm{MoTe}_{2}$ gas sensor via continuous illumination of light throughout the gas sensing experiment [132].
In this work, the $\mathrm{MoTe}_{2}$ sensor was fabricated by mechanical exfoliation, and interestingly, $\mathrm{MoTe}_{2}$ device converted its p-type semiconducting behaviour into n-type after continuous illumination of UV light for $2 \mathrm{~h}$ in an $\mathrm{N}_{2}$ environment. This changed behaviour under UV illumination was attributed to the removal of contamination of impurity molecules $\left(\mathrm{O}_{2}\right.$ and $\left.\mathrm{H}_{2} \mathrm{O}\right)$. The n-type $\mathrm{MoTe}_{2}$ sensor showed increase sensitivity to $\mathrm{NH}_{3}$ gas under illumination with reducing wavelength sources (near-infrared-red-to-UV region). Further, the sensor showed a rapid increase in sensitivity to $\mathrm{NH}_{3}$ gas with increased intensity from 0.25 to 1 $\mathrm{mW} / \mathrm{cm}^{2}$ of UV light source $(254 \mathrm{~nm})$ and saturation trend in sensitivity for increased intensity up to $2.5 \mathrm{~mW} \mathrm{~cm}^{-2}$.
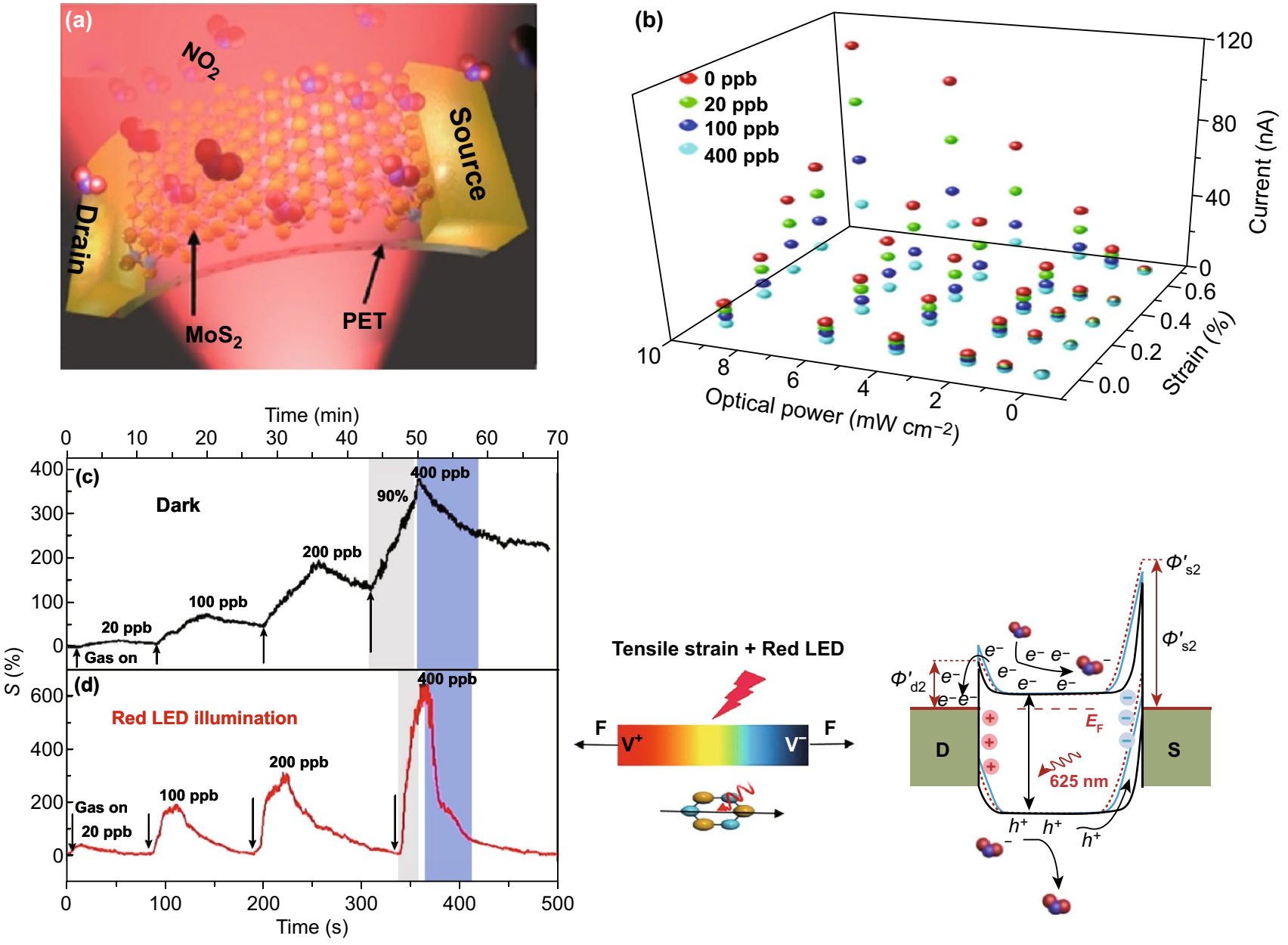

Fig. 15 a Schematic representation of a flexible $\mathrm{MoS}_{2}$ sensor under red light illumination. b Device current in different concentrations of $\mathrm{NO}_{2}$ gas ambient under different optical power of red light illumination with an applied different strain. Gas response to different concentrations of $\mathrm{NO}_{2}$ gas of the flexible sensor under $\mathbf{c}$ dark and $\mathbf{d}$ red illumination. e Gas sensing mechanism of the flexible $\mathrm{MoS}_{2}$ sensor via energy band diagram under tensile strain and red illumination. Reproduced with permission [129]. Copyright 2018, Science China Press. Published by Elsevier B.V. and Science China Press 
As a result, the sensor exhibited excellent sensitivity about 25 times more with a low detection limit of $3 \mathrm{ppb} \mathrm{NH}_{3}$ gas under UV illumination with an intensity of $2.5 \mathrm{~mW} \mathrm{~cm}^{-2}$. Also, the same group used the as-fabricated p-type $\mathrm{MoTe}_{2}$ gas sensor for $\mathrm{NO}_{2}$ detection under UV light illumination [133]. The sensor dramatically exhibited enhanced sensitivity of $58-1744 \%$ to $20-300$ ppb $\mathrm{NO}_{2}$ with an extraordinary low detection limit of $123 \mathrm{ppt}$ under UV illumination (254 nm). Moreover, the sensor showed complete recovery within $5 \mathrm{~min}$ at RT through accelerating desorption rate of $\mathrm{NO}_{2}$ via photoactivation of $\mathrm{MoTe}_{2}$. They suggested three reasons for enhancing the sensitivity of the sensor. First, p-type behaviour of $\mathrm{MoTe}_{2}$ is more sensitive to oxidizing gas $\left(\mathrm{NO}_{2}\right)$ which extracts a large number of electrons from $\mathrm{MoTe}_{2}$ and which results in shifting of Fermi level towards valence band. Thereby, holes easily tunnel from decreased Schottky barrier. Second, photon energy desorbed preadsorbed ambient oxygen ions from the surface of $\mathrm{MoTe}_{2}$, and therefore, a large number of availability of adsorption sites enhanced the adsorption of more number of $\mathrm{NO}_{2}$ molecules. Third, photoexcited plasmons promote molecular desorption because UV light wavelength of $254 \mathrm{~nm}$ lies in strong optical absorption window of $\mathrm{MoTe}_{2}$ owing to $\pi$-electrons plasmon excitation. Moreover, photogenerated holes react with adsorbed $\mathrm{NO}_{2}^{-}$and formed $\mathrm{NO}_{2}$ gas during recovery process. Further, the same group also used p-type $\mathrm{MoTe}_{2}$ FET-type gas sensor for discriminating ketone compounds with high sensitivity from other volatile organic compounds (VOCs) by the influence of UV light (Fig. 16a) [40]. The sensor exhibited excellent sensitivity to acetone with a low detection limit of $0.2 \mathrm{ppm}$ at RT under UV illumination. The sensor showed a negative response to all VOCs in dark condition because electrons donor behaviour of VOCs decreased hole carriers concentration in p-type $\mathrm{MoTe}_{2}$. Surprisingly, under UV illumination, the sensor showed positive response to acetone and same negative response to all other VOCs (Fig. 16b). This type of opposite response to acetone was also observed in $\mathrm{MoS}_{2}$ and $\mathrm{ReS}_{2}$ sensors with the influence of UV light. An acetyl group in ketone compound enhanced UV absorption of $254 \mathrm{~nm}$ wavelength which stimulated strong photon-electron interaction within molecules, resulting in change behaviour of acetone from reducing to oxidizing. That change was responsible to show positive response to acetone under UV illumination, while the sensor exhibited negative response in dark condition.

\section{4 $\mathrm{WS}_{2}$}

Excellent photoelectrical properties of tungsten disulphide $\left(\mathrm{WS}_{2}\right)$ [134], a member of TMDCs family, make it a promising candidate for optoelectronic gas sensor. Li et al. fabricated a field-effect transistor using mechanically exfoliated multilayer $\mathrm{WS}_{2}$ (Fig. 16c) and measured the photoelectrical properties under the influence of different gases molecules [135]. Under the illumination of red light (633 nm) approximate to $\mathrm{WS}_{2}$ bandgap, the device showed a change in its responsivity $\left(R_{\lambda}\right)$ and external quantum efficiency (EQE) for both oxidizing and reducing gases at RT. This change was attributed to perturbation in charge carrier density in $\mathrm{WS}_{2}$ by charge transfer between $\mathrm{WS}_{2}$ and physical-adsorbed gas molecules. The oxidizing gas $\left(\mathrm{O}_{2}\right)$ as 'p-dopants' extracted photogenerated electrons from $\mathrm{WS}_{2}$ and reduced the $\left(R_{\lambda}\right)$ and EQE of the device. In contrast, reducing gas (ethanol, $\mathrm{NH}_{3}$ ) as 'n-dopants' contributed electrons into photoactivated $\mathrm{WS}_{2}$ and enhanced the $\left(R_{\lambda}\right)$ and EQE value as shown in Fig. 16d. As a result, the device exhibited maximum $\left(R_{\lambda}\right)$ and EQE value of $884 \mathrm{~A} \mathrm{~W}^{-1}$ and $1.7 \times 10^{5} \%$, respectively, under $\mathrm{NH}_{3}$ ambient due to strong electronic interaction between $\mathrm{NH}_{3}$ and $\mathrm{WS}_{2}$. Further, Gaskov et al. demonstrated sensing performance of $\mathrm{WS}_{2}$ gas sensor under a wide wavelength range from UV to near-infrared light (Fig. 16e) [136]. Among these light sources, the sensor exhibited the highest response of 3.4 to $10 \mathrm{ppm} \mathrm{NH}_{3}$ with fast response and recovery time at RT under UV light illumination $(365 \mathrm{~nm})$. The enhancement in the response under UV light was attributed to the orbital mixing theory. Due to optical energy, electrons in the highest occupied molecular orbital (HOMO) of $\mathrm{NH}_{3}$ on the $\mathrm{N}$ atom were excited and transferred to $\mathrm{WS}_{2}$ (Fig. 16f). Thereby, the response was increased under UV illumination compared to that of dark condition.

In addition to enhancing the sensitivity of $\mathrm{WS}_{2}$ under light illumination, some research efforts such as noble metal decoration and incorporation of another material into $\mathrm{WS}_{2}$ in terms of nanocomposites or hybrid are also used. Goodilin et al. decorated plasmonic Au nanoparticles on $\mathrm{WS}_{2}$ nanotubes $\left(\mathrm{NT}-\mathrm{WS}_{2}\right.$ ) and examined the sensing behaviour under the illumination of $530 \mathrm{~nm}$ LED source [137]. The Au-NT-WS ${ }_{2}$ sensor exhibited higher sensitivity in a range of 0.25-2.0 ppm $\mathrm{NO}_{2}$ at RT than that of pristine NT-WS . Gas sensing mechanism was attributed to physisorptioncharge transfer between $\mathrm{NO}_{2}$ and NT-WS${ }_{2}$. Further, Cantalini et al. reported a high-performance $\mathrm{NO}_{2}$ gas sensor using 

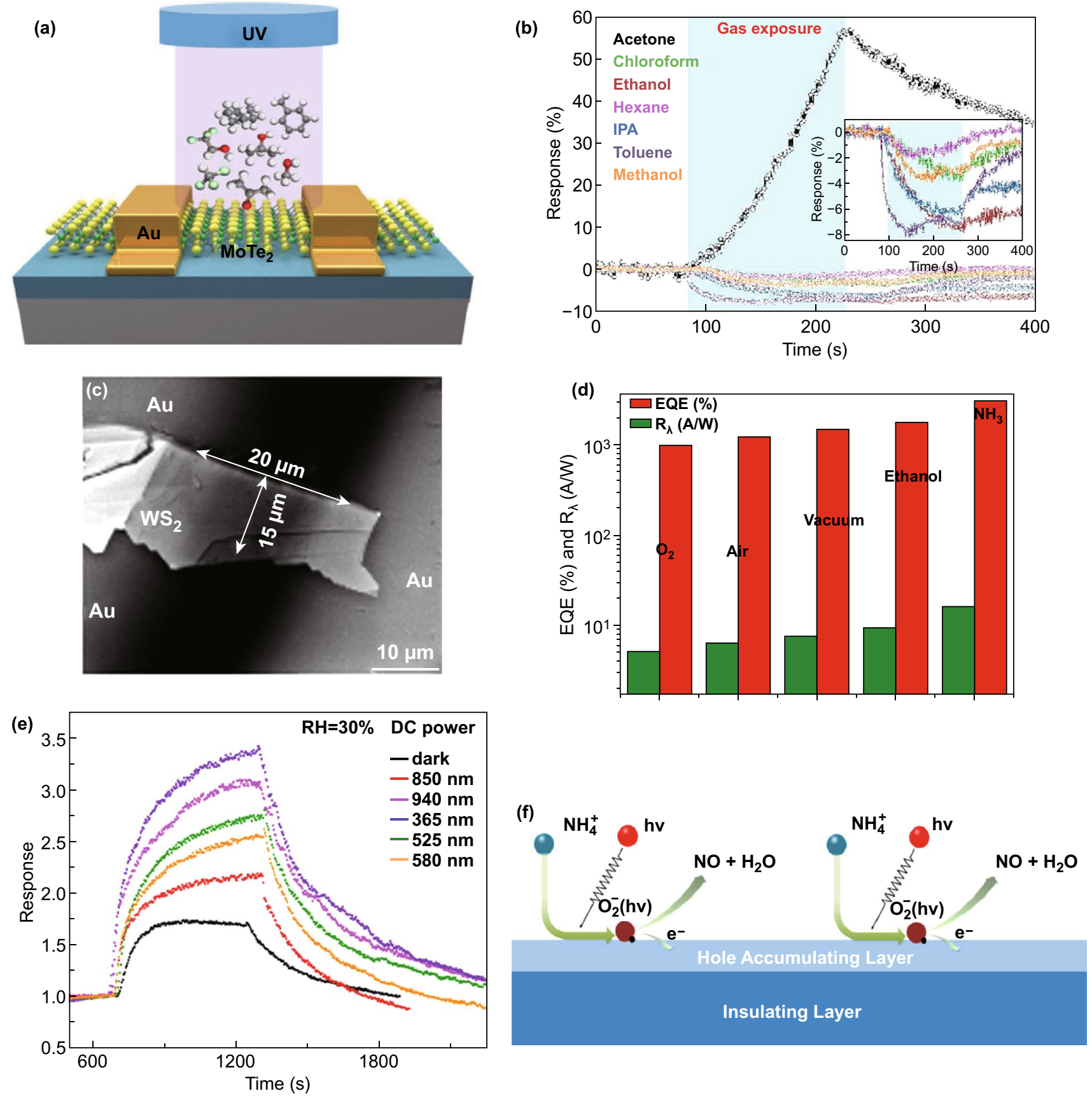

Fig. 16 a Schematic representation of a MoTe ${ }_{2}$ sensor under UV light illumination. b Gas response to different VOCs under UV illumination. Reproduced with permission [40]. Copyright 2018, American Chemical Society. c SEM image of mechanically exfoliated WS ${ }_{2}$ flake. d Photoresponsivity and external quantum efficiency of the $\mathrm{WS}_{2}$ sensor under light illumination in different gas ambient. Reproduced with permission [135]. Published by Nature Publishing Group. e Gas response of the sensor to $\mathrm{NO}_{2}$ gas under different wavelengths of light sources. f Gas sensing mechanism of the sensor under light illumination. Reproduced with permission [136]. Copyright 2017, Elsevier

$\mathrm{WS}_{2}$-rGO hybrids under purple-blue light (430 nm) illumination [138]. The sensor showed excellent sensitivity to $\mathrm{NO}_{2}$ with a low detection limit of $400 \mathrm{ppb}$ and fast response and recovery kinetics.

\section{$4.5 \mathrm{SnS}_{2}$}

Tin disulphide $\left(\mathrm{SnS}_{2}\right)$ is an n-type semiconducting layered material, and its structure is similar to members of TMDCs 
family [139-142]. Naturally abundant, higher electronegativity than TMDCs materials and wider direct bandgap $(2.1 \mathrm{eV})$ have been attracted attention for the usage of $\mathrm{SnS}_{2}$ in optoelectronic gas sensing applications. Gu et al. reported a $\mathrm{RT} \mathrm{NO}_{2}$ gas sensor of $\mathrm{SnS}_{2}$ under green light illumination [143]. A chemiresistive sensor was fabricated using $\mathrm{SnS}_{2}$ nanosheets which were synthesized via a simple one-step hydrothermal method. Under green light, the sensor exhibited reliable selectivity towards $\mathrm{NO}_{2}$ with detection as low as $38 \mathrm{ppb}$ concentration and also showed a fast response and complete recovery at RT. Improvement in the sensing performance of the sensor was ascribed to increased carriers concentration in $\mathrm{SnS}_{2}$ via photon energy. Number of electrons increased in conduction band of $\mathrm{SnS}_{2}$ via direct photogenerated electrons as well as releasing electrons by adsorbed oxygen ions after reacting with photoexcited holes (Fig. 17a). As a result, increased electrons in the conduction band of $\mathrm{SnS}_{2}$ attracted more number of $\mathrm{NO}_{2}$ molecules, and thereby, sensitivity was enhanced through charge transfer. On the other hand, thermal activation first enhances the sensitivity of the sensor with increase temperature from 100 to $110{ }^{\circ} \mathrm{C}$ (Fig. 17b) and later sensitivity was severely decreased above $110^{\circ} \mathrm{C}$ temperature due to higher desorption rate than adsorption rate. Further, Wu et al. enhanced the gas response of $\mathrm{SnS}_{2}$ sensor under light source via deliberately generated nanoscale defects as sulphur vacancy [144]. Sulphur vacancy containing $\mathrm{SnS}_{2}$ showed excellent gas response with detection as low as $2.5 \mathrm{ppb}$ at RT under UV illumination. Besides the photoexcited electron-hole pairs, sulphur vacancy acted as additional adsorption sites with high adsorption energy for $\mathrm{NO}_{2}$ which was also verified via density functional theory calculations.

To further enhance the sensitivity of the $\mathrm{SnS}_{2}$ gas sensor, increased adsorption sites on sensing materials play a crucial role. In this view, Huang et al. demonstrated a RT ultrasensitive ammonia detection under white light irradiation using suspended $\mathrm{SnS}_{2}$ layers which are shown in Fig. 17c [145]. The suspended structure increased sensing surface area for more number of $\mathrm{NH}_{3}$ molecules interaction and also eliminated charge trap states at $\mathrm{SnS}_{2} /$ $\mathrm{SiO}_{2}$ interface due to existence of air between $\mathrm{SnS}_{2}$ and $\mathrm{SiO}_{2}$ (substrate). As a result, the suspended $\mathrm{SnS}_{2}$ sensor exhibited about three times higher sensitivity to $\mathrm{NH}_{3}$ with faster response-recovery rate than that of the traditional $\mathrm{SnS}_{2}$ sensor. Moreover, the sensor showed high selectivity towards $\mathrm{NH}_{3}$ with detection as low as $20 \mathrm{ppb}$ at RT under white light illumination. The enhancement in sensitivity was attributed to direct charge transfer as well as modulation of Schottky barrier upon exposure to $\mathrm{NH}_{3}$, as illustrated in Fig. 17d. In addition, Wang et al. further enhanced the sensitivity of $\mathrm{SnS}_{2}$ sensor at RT by synthesizing $\mathrm{SnS}_{2} / \mathrm{rGO}$ nanohybrids [146]. The n-type $\mathrm{SnS}_{2} / \mathrm{rGO}$ nanohybrids exhibited about five times higher sensitivity to $10 \mathrm{ppb} \mathrm{NO}_{2}$ with detection as low as $0.15 \mathrm{ppb}$ and also showed a fast response and complete recovery at RT under red light $(650 \mathrm{~nm})$ illumination. The enhanced sensitivity was attributed to additional photoexcited electron-hole pairs and modulation of the potential barrier at $\mathrm{SnS}_{2} / \mathrm{rGO}$ interface upon exposure to $\mathrm{NO}_{2}$ gas.

\subsection{Other Materials}

$\operatorname{ReS}_{2}$ is a member of VII-group layered TMDCs family with distorted triclinic $\mathrm{CdCl}_{2}$-type layer structure contrary to the hexagonal structure of VI-group TMDCs materials [147]. In contrast to VI-group TMDCs materials, VII-group TMDC $\mathrm{ReS}_{2}$ possesses an extra d-orbital electron which introduces different and unique properties into $\operatorname{ReS}_{2}$. The $\operatorname{ReS}_{2}$ has shown great interest in advance electronic devices owing to in-plane anisotropy, interlayer coupling and hard to energy bandgap conversion from indirect to direct. Inspiring from all these significant properties, Jiang et al. investigated the photoelectrical properties of $\mathrm{ReS}_{2}$ in the different gas environment under red light $(633 \mathrm{~nm})$ source [148]. In this work, they fabricated a sensor from mechanically exfoliated $\mathrm{ReS}_{2}$ nanosheet and the sensor exhibited different changes in photocurrent values corresponding to various environments such as $\mathrm{O}_{2}$, air, and $\mathrm{NH}_{3}$, as shown in Fig. 17f. Two important calculated parameters responsivity $\left(R_{\lambda}\right)$ and external quantum efficiency (EQE) have higher values in $\mathrm{NH}_{3}$ ambient than that of in air or $\mathrm{O}_{2}$ ambient. This improvement was due to strong electronic interaction or higher charge transfer between $\mathrm{NH}_{3}$ and $\mathrm{ReS}_{2}$ which was also verified by firstprinciples calculations. Adsorbed $\mathrm{NH}_{3}$ molecules have better adsorption energy of $-205 \mathrm{meV}$ compared to $-130 \mathrm{meV}$ of $\mathrm{O}_{2}$ on $\mathrm{ReS}_{2}$ surface. Physisorption of molecules substantially changed the carrier density of the $\mathrm{ReS}_{2}$ through charge transfer (Fig. 17g), and hence, the device showed good response to different gases through changing its current value under red light illumination. 

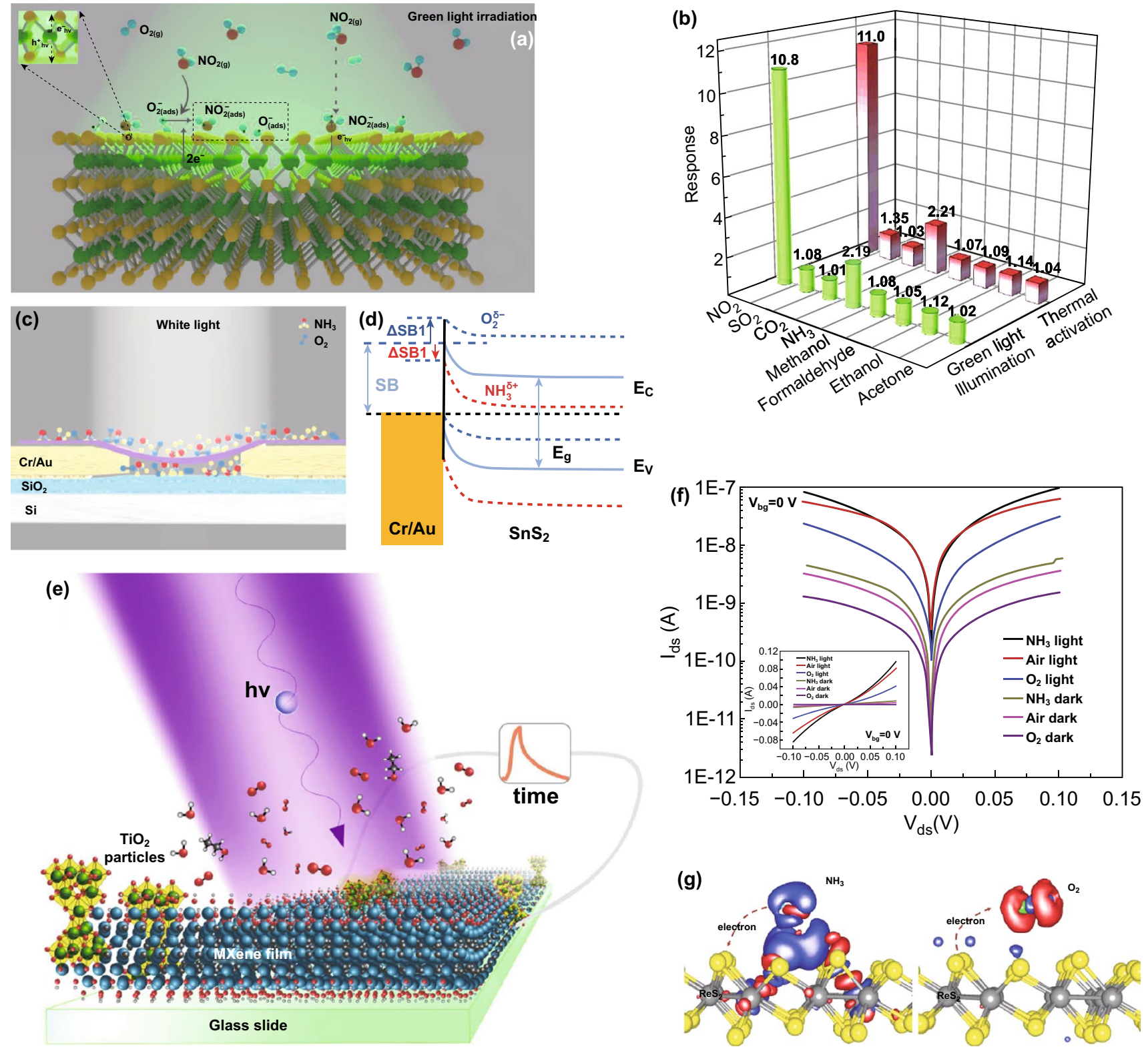

Fig. 17 a Schematic representation of gas sensing mechanism of $\mathrm{SnS}_{2}$ sensor under green light illumination. b Gas response to different gases of the sensor under green light illumination and thermal activation. Reproduced with permission [143]. Copyright 2019, Elsevier. c Schematic illustration of the suspended $\mathrm{SnS}_{2}$-based device under white light illumination. d Gas sensing mechanism of the SnS 2 sensor based on modulation of Schottky barrier upon exposure to $\mathrm{NH}_{3}$. Reproduced with permission [145]. Copyright 2018, WILEY-VCH Verlag GmbH \& Co. KGaA, Weinheim. e Schematic of MXene gas sensor under UV light illumination. Reproduced with permission [152]. Copyright 2018, American Chemical Society. f Current versus voltage of the suspended $\mathrm{ReS}_{2}$ sensor in different gas ambient. $\mathbf{g}$ Charge transfer between $\mathrm{ReS}_{2}$ and $\mathrm{NH}_{3}$ or $\mathrm{O}_{2}$. Reproduced with permission [148]. Copyright 2016, WILEY-VCH Verlag GmbH \& Co. KGaA, Weinheim

Among the discovery of new 2D materials, MXenes as a new family of 2D materials were first discovered in 2011. MXenes have shown their potential in different applications, including water purification, optoelectronics, energy storage, gas sensing, etc. [149-151]. Mochalin et al. examined the effect of $\mathrm{H}_{2}$, air, $\mathrm{O}_{2}$ and $\mathrm{H}_{2} \mathrm{O}$ vapour on MXene at RT under a light source illumination [152]. Therefore, visible light energy was not sufficient to produce a considerable change in photocurrent. However, under UV illumination, the MXene exhibited significant photoresponse owing to 
containing in situ formed phase of $\mathrm{TiO}_{2}$ (Fig. 17e). The photoinduced current decay was observed very long time $(\sim 24 \mathrm{~h})$ in inert ambient due to long relaxation process. Oxygen-containing species such as $\mathrm{O}_{2}$ and $\mathrm{H}_{2} \mathrm{O}$ vapour accelerated the relaxation process and achieved fast decay of photoinduced current. This reversible process was obtained due to electron trapping by electronegative atoms as well as intercalation and swelling of MXene which reduced the electrical connection of MXene flakes. Thus, these results lead the utilization of MXene in optoelectronic gas sensor on a commercial platform.

\section{Conclusion and Outlook}

In this comprehensive review, gas sensing characteristics of different materials including metal oxide semiconductors (MOS), and emerging 2D materials, under the light illumination are presented. In the context of MOS materials, photoactivation has been proved to be a promising technique to enhance the gas sensing performances at RT. As discussed, in most cases, photoactivation can be an effective method to replace thermal heating activation to achieve detection of gases at RT. Removing the microheater from MOS sensors decreases power consumption and reduces number of fabrication steps and which results in portable and miniaturized gas sensors for emerging IOT applications. Light illumination on MOS improves the generation of photoelectrons and modulates the carrier density in MOS, thus influence on the sensing properties can be expected. Improved sensing response, response-recovery speed and selectivity have been obtained using MOS such as $\mathrm{SnO}_{2}, \mathrm{ZnO}$ and $\mathrm{WO}_{3}$ to detect $\mathrm{NO}_{2}, \mathrm{O}_{3}$ and $\mathrm{O}_{2}$. Mostly, individual metal oxide sensors exhibit gas sensing at RT in only UV wavelength region due to their higher energy bandgap and exploitation of UV light source over the long time is harmful for human beings. In this regard to further improve the photoactivation, various photosensitizers have been applied to MOS to expand the light absorption spectrum. It is important to note that the LSPR adsorption of noble metals can extend the light absorption spectrum into the visible range. This has driven the research in photoactivated gas sensors from UV to visible lights such as blue, green, and red, as well as the mixed monochromatic, i.e., the white light. Heterojunctions of MOS can improve the separation of photoexcited electron-holes. When designing photoactivated sensors, factors affecting the sensing characteristics to be considered include light intensity, wavelength, size of nanoparticles and film thickness. It also shows that most photoactivated sensors are more sensitive to oxidizing molecules such as $\mathrm{NO}_{2}$ and $\mathrm{O}_{2}$, although some works reported photo-enhanced sensitivity to $\mathrm{H}_{2}$. In the future, more efforts should be explored to develop highperformance detection of organic compounds.

Emerging 2D materials including graphene, TMDCs and MXenes show huge potential in gas sensing at RT under the light sources. Photoactivation enhanced the gas response of 2D materials-based sensors by increasing carrier density through photogenerated electron-hole pairs and also increasing adsorption sites on the surface of 2D materials through desorption of pre-adsorbed atmosphere oxygen ions after reacting with photoexcited holes. Especially, one of the most important problems slow response and recovery kinetics of 2D materials was rectified via photoactivation through improving response time and complete recovery at RT. On the other hand, thermoactivation improves response/ recovery kinetics of 2D material sensor; however, it deteriorates sensitivity of the sensor by increasing desorption rate than adsorption rate. Integration of $2 \mathrm{D}$ material with other materials improved the sensitivity by including their individual merits and modulation of the potential barrier at the interface upon exposure to gas. Besides the enhanced sensitivity with fast response/recovery kinetics of the sensor, photoactivation improved the reliable selectivity through detection a particular gas by changing the semiconducting behaviour of material from $n$ - to p-type or vice versa and helping to easy movement of carriers at the interface for in a particular direction. For example, $2 \mathrm{D} \mathrm{g}-\mathrm{C}_{3} \mathrm{~N}_{4} / \mathrm{rGO}$ hybrid showed a response to $\mathrm{NO}_{2}$ with its p-type semiconducting behaviour under the dark condition, and in contrast, the hybrid exhibited a response to $\mathrm{SO}_{2}$ with its changed n-type behaviour under UV illumination. Despite the high sensing performance of 2D materials heterostructures-based gas sensors, synthesis of large scale and high quality of heterostructures of 2D materials is limited and not yet reached on commercial platforms.

The detection of gases at elevated temperature is one of the major drawbacks of MOS sensors which has been addressed via photoactivation through generating active adsorbed oxygen ions on MOS surface for performing redox reaction with target analytes. On the other hand, emerging 2D materials-based gas sensors show detection of gases at RT through charge transfer mechanism without using any 
extra stimuli thermal or optical energy sources. However, slow response and incomplete recovery at RT problems of these sensors have been rectified under photoactivation. Besides the UV light, white light is also sufficient for reducing the desorption barrier to ease desorption of gases from sensing 2D materials surface due to the smaller bandgap of $2 \mathrm{D}$ materials in the visible range. The sensing results such as sensor response and response/recovery dynamics are not always enhanced. Light activation can sometimes lead to a compromise between the sensitivity and recovery performance of the gas sensor. As a result, selection of light source with proper wavelength and power intensity should be in priority for designing an optoelectronic gas sensor. Besides the perfect selection of appropriate light sources, choosing an individual material or a combination of materials (in the form of nanocomposites and heterostructures) and engineering in sensing material structure would assist to further enhance sensitivity and selectivity of the optoelectronic sensors. The exploitation of van der Waals heterostructures of $2 \mathrm{D}$ materials in gas sensing would be a new exciting area in optoelectronic sensor field for multifunctional sensing applications because they have already shown great potential in optoelectronic field owing its remarkable and extraordinary optical properties. The proper selection of 2D materials in van der Waals heterostructure would make selective and highly sensitive sensing platform through significant change in band alignment and carriers transport by the contribution of each and every constituents materials. In addition, 2D materials would also be good candidates for developing optoelectronic gas sensors on flexible and wearable sensing platform for a particular sensing application due to their excellent flexibility and stretchability properties.

Photoactivation has improved gas response with fast response/recovery kinetics at RT, but there is limited research for improving selectivity and stability of the sensor. Moreover, a general consent on the correlations between the light activation, sensor structure and materials selection is still missing. So, optimization of the sensor structure, lighting conditions and initialization of sensor state would be helpful to obtain the best performance. Beyond the laboratory gas sensing results under photoactivation, testing and analysing of the sensor for detecting gas in presence of interfering gases in the environment are challenging task. Generally, an external light source like Xe-lamps or LEDs is used for photoactivation; however, advent of the Internet of things (IOTs), miniaturized sensors with an integrated light source as an appealing monolithic integration of sensing materials on a micro-LED is highly urgent. So, advanced micro-fabrication techniques for implementing innovative sensor designs for lower power consumption, more uniform irradiation of the sensor materials and higher photon energy efficiency should be further studied. Many researches in these contexts are still in progress, and we can expect that photoactivation would be a perfect tool for developing a gas sensor for practical applications.

Acknowledgements The authors acknowledge the financial support of the Department of Science and Engineering Research Board (SERB) (Sanction Order No. CRG/2019/000112).

Open Access This article is licensed under a Creative Commons Attribution 4.0 International License, which permits use, sharing, adaptation, distribution and reproduction in any medium or format, as long as you give appropriate credit to the original author(s) and the source, provide a link to the Creative Commons licence, and indicate if changes were made. The images or other third party material in this article are included in the article's Creative Commons licence, unless indicated otherwise in a credit line to the material. If material is not included in the article's Creative Commons licence and your intended use is not permitted by statutory regulation or exceeds the permitted use, you will need to obtain permission directly from the copyright holder. To view a copy of this licence, visit http://creativecommons.org/licenses/by/4.0/.

\section{References}

1. Z. Yunusa, M.N. Hamidon, A. Kaiser, Z. Awang, Gas sensors: a review. Sens. Transducers 4, 61-75 (2014)

2. K. Arshak, E. Moore, G.M. Lyons, J. Harris, S. Clifford, A review of gas sensors employed in electronic nose applications. Sens. Rev. 24(2), 181-198 (2004). https://doi. org/10.1108/02602280410525977

3. N. Yamazoe, Toward innovations of gas sensor technology. Sens. Actuat. B Chem. 108(1-2), 2-14 (2005). https://doi. org/10.1016/j.snb.2004.12.075

4. J. Hodgkinson, R.P. Tatam, Optical gas sensing: a review. Meas. Sci. Technol. 24, 012004 (2013). https://doi. org/10.1088/0957-0233/24/1/012004

5. J.R. Stetter, J. Li, Amperometric gas sensors-a review. Chem. Rev. 108(2), 352-366 (2008). https://doi.org/10.1021/cr068 1039

6. S. Lakkis, R. Younes, Y. Alayli, M. Sawan, Review of recent trends in gas sensing technologies and their miniaturization potential. Sens. Rev. 34(1), 24-35 (2014). https://doi. org/10.1108/SR-11-2012-724

7. Z. Meng, R.M. Stolz, L. Mendecki, K.A. Mirica, Electricallytransduced chemical sensors based on two-dimensional nanomaterials. Chem. Rev. 119(1), 478-598 (2019). https://doi. org/10.1021/acs.chemrev.8b00311 
8. J. Zhang, X. Liu, G. Neri, N. Pinna, Nanostructured materials for room-temperature gas sensors. Adv. Mater. 28, 795-831 (2016). https://doi.org/10.1002/adma.201503825

9. S.W. Chiu, K.T. Tang, Towards a chemiresistive sensorintegrated electronic nose: a review. Sensors 13(10), 14214 14247 (2013). https://doi.org/10.3390/s131014214

10. Y. Jiang, N. Tang, C. Zhou, Z. Han, H. Qu, X. Duan, A chemiresistive sensor array from conductive polymer nanowires fabricated by nanoscale soft lithography. Nanoscale 10(44), 20578-20586 (2018). https://doi.org/10.1039/c8nr0 $4198 \mathrm{a}$

11. J. Shin, Y. Hong, M. Wu, Y. Jang, J.S. Kim et al., Highly improved response and recovery characteristics of Si FETtype gas sensor using pre-bias. IEEE Int. Electron Devices Meet. IEDM, San Francisco, CA, USA. (2016). https://doi. org/10.1109/IEDM.2016.7838443

12. S.J. Choi, I.D. Kim, Recent developments in 2D nanomaterials for chemiresistive-type gas sensors. Electron. Mater. Lett. 14, 221-260 (2018). https://doi.org/10.1007/s1339 $1-018-0044-\mathrm{Z}$

13. X. Liu, T. Ma, N. Pinna, J. Zhang, Two-dimensional nanostructured materials for gas sensing. Adv. Funct. Mater. 27, 1-30 (2017). https://doi.org/10.1002/adfm.201702168

14. R. Kumar, N. Goel, A.V. Agrawal, R. Raliya, S. Rajamani et al., Boosting sensing performance of vacancy-containing vertically aligned $\mathrm{MoS}_{2}$ using rGO particles. IEEE Sens. J. 19(22), 10214-10220 (2019). https://doi.org/10.1109/ jsen.2019.2932106

15. N. Barsan, D. Koziej, U. Weimar, Metal oxide-based gas sensor research: how to? Sens. Actuat. B Chem. 121(1), 18-35 (2007). https://doi.org/10.1016/j.snb.2006.09.047

16. N. Joshi, T. Hayasaka, Y. Liu, H. Liu, O.N. Oliveira, L. Lin, A review on chemiresistive room temperature gas sensors based on metal oxide nanostructures, graphene and 2D transition metal dichalcogenides. Microchim. Acta 185, 213 (2018). https://doi.org/10.1007/s00604-018-2750-5

17. N. Taguchi, Gas detecting device, US Patent (1971)

18. N. Barsan, U. Weimar, Conduction model of metal oxide gas sensors. J. Electroceramics 7, 143-167 (2001). https:// doi.org/10.1023/A:1014405811371

19. Y.F. Sun, S.B. Liu, F.L. Meng, J.Y. Liu, Z. Jin, L.T. Kong, J.H. Liu, Metal oxide nanostructures and their gas sensing properties: a review. Sensors 12(3), 2610-2631 (2012). https://doi.org/10.3390/s120302610

20. C. Wang, L. Yin, L. Zhang, D. Xiang, R. Gao, Metal oxide gas sensors: sensitivity and influencing factors. Sensors 10(3), 2088-2106 (2010). https://doi.org/10.3390/s100302088

21. E. Espid, F. Taghipour, UV-LED photo-activated chemical gas sensors: a review. Crit. Rev. Solid State Mater. Sci. 42(5), 416-432 (2017). https://doi.org/10.1080/10408 436.2016.1226161

22. F. Xu, H.P. Ho, Light-activated metal oxide gas sensors: a review. Micromachines 8(11), 333 (2017). https://doi. org/10.3390/mi8110333
23. K. Aguir, S. Bernardini, B. Lawson, T. Fiorido, 8 - Trends in Metal Oxide Thin Films: Synthesis and Applications of Tin Oxide. M.O. Orlandi (Ed.), Tin Oxide Mater., (Elsevier, 2020) pp. 219-246. https://doi.org/10.1016/B978-012-815924-8.00008-6

24. R. Kumar, W. Zheng, X. Liu, J. Zhang, M. Kumar, $\mathrm{MoS}_{2}$-based nanomaterials for room-temperature gas sensors. Adv. Mater. Technol. 5(5), 1901062 (2020). https:// doi.org/10.1002/admt.201901062

25. S. Yang, C. Jiang, S. Huai Wei, Gas sensing in 2D materials. Appl. Phys. Rev. (2017). https://doi.org/10.1063/1.4983310

26. C. Anichini, W. Czepa, D. Pakulski, A. Aliprandi, A. Ciesielski, P. Samorì, Chemical sensing with 2D materials. Chem. Soc. Rev. 47(13), 4860-4908 (2018). https:// doi.org/10.1039/c8cs00417j

27. E. Lee, Y.S. Yoon, D.J. Kim, Two-dimensional transition metal dichalcogenides and metal oxide hybrids for gas sensing. ACS Sens. 3(10), 2045-2060 (2018). https://doi. org/10.1021/acssensors.8b01077

28. F. Schedin, A.K. Geim, S.V. Morozov, E.W. Hill, P. Blake, M.I. Katsnelson, K.S. Novoselov, Detection of individual gas molecules adsorbed on graphene. Nat. Mater. 6, 652 (2007). https://doi.org/10.1038/nmat1967

29. R. Kumar, N. Goel, M. Hojamberdiev, M. Kumar, Transition metal dichalcogenides-based flexible gas sensors. Sens. Actuat. A Phys. 303, 111875 (2020). https://doi. org/10.1016/j.sna.2020.111875

30. S. Cui, H. Pu, S.A. Wells, Z. Wen, S. Mao et al., Ultrahigh sensitivity and layer-dependent sensing performance of phosphorene-based gas sensors. Nat. Commun. 6, 8632 (2015). https://doi.org/10.1038/ncomms9632

31. G. Oxide, M. Donarelli, 2D materials for gas sensing applications: a review. Sensors 18, 3638 (2018). https://doi. org/10.3390/s18113638

32. R. Kumar, P.K. Kulriya, M. Mishra, F. Singh, G. Gupta, M. Kumar, Highly selective and reversible $\mathrm{NO}_{2}$ gas sensor using vertically aligned $\mathrm{MoS}_{2}$ flake networks. Nanotechnology 29, 46 (2018). https://doi.org/10.1088/1361-6528/aade20

33. H. Long, A. Harley-Trochimczyk, T. Pham, Z. Tang, T. Shi et al., High surface area $\mathrm{MoS}_{2}$ /graphene hybrid aerogel for ultrasensitive $\mathrm{NO}_{2}$ detection. Adv. Funct. Mater. 26, 51585165 (2016). https://doi.org/10.1002/adfm.201601562

34. R. Kumar, N. Goel, M. Kumar, High performance $\mathrm{NO}_{2}$ sensor using $\mathrm{MoS}_{2}$ nanowires network. Appl. Phys. Lett. 112, 053502 (2018). https://doi.org/10.1063/1.5019296

35. J.D. Fowler, M.J. Allen, V.C. Tung, Y. Yang, R.B. Kaner, B.H. Weiller, Practical chemical sensors from chemically derived graphene. ACS Nano 3, 301-306 (2009). https://doi. org/10.1021/nn800593m

36. N.D. Chinh, T.T. Hien, L. Van Do, N.M. Hieu, N.D. Quang, S.M. Lee, C. Kim, D. Kim, Adsorption/desorption kinetics of nitric oxide on zinc oxide nano film sensor enhanced by light irradiation and gold-nanoparticles decoration. Sens. Actuat. B Chem. 281, 262-272 (2019). https://doi.org/10.1016/j. snb.2018.10.113 
37. R. Chen, J. Wang, Y. Xia, L. Xiang, Near infrared light enhanced room-temperature $\mathrm{NO}_{2}$ gas sensing by hierarchical $\mathrm{ZnO}$ nanorods functionalized with $\mathrm{PbS}$ quantum dots. Sens. Actuat. B Chem. 255, 2538-2545 (2018). https://doi. org/10.1016/j.snb.2017.09.059

38. J. Gong, Y. Li, X. Chai, Z. Hu, Y. Deng, UV-light-activated $\mathrm{ZnO}$ fibers for organic gas sensing at room temperature. J. Phys. Chem. C 114(2), 1293-1298 (2010). https://doi. org/10.1021/jp906043k

39. J. Li, D. Gu, Y. Yang, H. Du, X. Li, UV light activated $\mathrm{SnO}_{2} / \mathrm{ZnO}$ nanofibers for gas sensing at room temperature. Front. Mater. 6, 158 (2019). https://doi.org/10.3389/fmats .2019 .00158

40. E. Wu, Y. Xie, B. Yuan, D. Hao, C. An et al., Specific and highly sensitive detection of ketone compounds based on p-type $\mathrm{MoTe}_{2}$ under ultraviolet illumination. ACS Appl. Mater. Interfaces. 10(41), 35664-35669 (2018). https://doi. org/10.1021/acsami.8b14142

41. Q.H. Li, Q. Wan, Y.X. Liang, T.H. Wang, Electronic transport through individual $\mathrm{ZnO}$ nanowires. Appl. Phys. Lett. 84, 4556 (2004). https://doi.org/10.1063/1.1759071

42. B.P.J. De Lacy Costello, R.J. Ewen, N.M. Ratcliffe, M. Richards, Highly sensitive room temperature sensors based on the UV-LED activation of zinc oxide nanoparticles. Sens. Actuat. B Chem. 134(2), 945-952 (2008). https://doi.org/10.1016/j. snb.2008.06.055

43. S.W. Fan, A.K. Srivastava, V.P. Dravid, UV-activated room-temperature gas sensing mechanism of polycrystalline ZnO. Appl. Phys. Lett. 95, 142106 (2009). https://doi. org/10.1063/1.3243458

44. X. Su, G. Duan, Z. Xu, F. Zhou, W. Cai, Structure and thickness-dependent gas sensing responses to $\mathrm{NO}_{2}$ under UV irradiation for the multilayered $\mathrm{ZnO}$ micro/nanostructured porous thin films. J. Colloid Interface Sci. 503, 150-158 (2017). https://doi.org/10.1016/j.jcis.2017.04.055

45. J. Cui, L. Shi, T. Xie, D. Wang, Y. Lin, UV-light illumination room temperature $\mathrm{HCHO}$ gas-sensing mechanism of $\mathrm{ZnO}$ with different nanostructures. Sens. Actuat. B Chem. 227, 220-226 (2016). https://doi.org/10.1016/j.snb.2015.12.010

46. L. Peng, Q. Zhao, D. Wang, J. Zhai, P. Wang, S. Pang, T. Xie, Ultraviolet-assisted gas sensing: a potential formaldehyde detection approach at room temperature based on zinc oxide nanorods. Sens. Actuat. B Chem. 136(1), 80-85 (2009). https://doi.org/10.1016/j.snb.2008.10.057

47. L. Peng, J. Zhai, D. Wang, Y. Zhang, P. Wang, Q. Zhao, T. Xie, Size- and photoelectric characteristics-dependent formaldehyde sensitivity of $\mathrm{ZnO}$ irradiated with UV light. Sens. Actuat. B Chem. 148(1), 66-73 (2010). https://doi. org/10.1016/j.snb.2010.04.045

48. M. Kumar, R. Kumar, S. Rajamani, S. Ranwa, M. Fanetti, M. Valant, M. Kumar, Efficient room temperature hydrogen sensor based on UV-activated $\mathrm{ZnO}$ nano-network. Nanotechnology 28, 36 (2017). https://doi.org/10.1088/1361-6528/aa7cad

49. C.B. Jacobs, A.B. Maksov, E.S. Muckley, L. Collins, M. Mahjouri-Samani et al., UV-activated $\mathrm{ZnO}$ films on a flexible substrate for room temperature $\mathrm{O}_{2}$ and $\mathrm{H}_{2} \mathrm{O}$ sensing. Sci. Rep. 7, 6053 (2017). https://doi.org/10.1038/s41598-017-05265-5

50. N. Joshi, L.F. da Silva, F.M. Shimizu, V.R. Mastelaro, J.C. M'Peko, L. Lin, O.N. Oliveira, UV-assisted chemiresistors made with gold-modified $\mathrm{ZnO}$ nanorods to detect ozone gas at room temperature. Microchim. Acta 186, 418 (2019). https ://doi.org/10.1007/s00604-019-3532-4

51. L. Han, D. Wang, J. Cui, L. Chen, T. Jiang, Y. Lin, Study on formaldehyde gas-sensing of $\mathrm{In}_{2} \mathrm{O}_{3}$-sensitized $\mathrm{ZnO}$ nanoflowers under visible light irradiation at room temperature. J. Mater. Chem. 22(25), 12915-12920 (2012). https://doi. org/10.1039/c2jm16105b

52. C. Zhang, A. Boudiba, P. De Marco, R. Snyders, M.G. Olivier, M. Debliquy, Room temperature responses of visible-light illuminated $\mathrm{WO}_{3}$ sensors to $\mathrm{NO}_{2}$ in sub-ppm range. Sens. Actuat. B Chem. 181, 395-401 (2013). https://doi. org/10.1016/j.snb.2013.01.082

53. P. Chakrabarty, M. Banik, N. Gogurla, S. Santra, S.K. Ray, R. Mukherjee, Light trapping-mediated room-temperature gas sensing by ordered $\mathrm{ZnO}$ nano structures decorated with plasmonic Au nanoparticles. ACS Omega 4(7), 12071-12080 (2019). https://doi.org/10.1021/acsomega.9b01116

54. F. Xu, H.F. Lv, S.Y. Wu, H.P. HO, Light-activated gas sensing activity of $\mathrm{ZnO}$ nanotetrapods enhanced by plasmonic resonant energy from Au nanoparticles. Sens. Actuat. B Chem. 259, 709-716 (2018). https://doi.org/10.1016/j. snb.2017.12.128

55. Q. Zhang, G. Xie, M. Xu, Y. Su, H. Tai, H. Du, Y. Jiang, Visible light-assisted room temperature gas sensing with $\mathrm{ZnO}$ Ag heterostructure nanoparticles. Sens. Actuat. B Chem. 259, 269-281 (2018). https://doi.org/10.1016/j.snb.2017.12.052

56. A.S. Chizhov, M.N. Rumyantseva, R.B. Vasiliev, D.G. Filatova, K.A. Drozdov et al., Visible light activated room temperature gas sensors based on nanocrystalline $\mathrm{ZnO}$ sensitized with $\mathrm{CdSe}$ quantum dots. Sens. Actuat. B Chem. 205, 305-312 (2014). https://doi.org/10.1016/j. snb.2014.08.091

57. A.S. Chizhov, M.N. Rumyantseva, R.B. Vasiliev, D.G. Filatova, K.A. Drozdov et al., Visible light activation of room temperature $\mathrm{NO}_{2}$ gas sensors based on $\mathrm{ZnO}, \mathrm{SnO}_{2}$ and $\mathrm{In}_{2} \mathrm{O}_{3}$ sensitized with CdSe quantum dots. Thin Solid Films 618, 253-262 (2016). https://doi.org/10.1016/j.tsf.2016.09.029

58. H. Wang, L. Zhou, Y. Liu, F. Liu, X. Liang et al., UV-activated ultrasensitive and fast reversible $\mathrm{ppb} \mathrm{NO}_{2}$ sensing based on $\mathrm{ZnO}$ nanorod modified by constructing interfacial electric field with $\mathrm{In}_{2} \mathrm{O}_{3}$ nanoparticles. Sens. Actuat. B Chem. 305, 127498 (2020). https://doi.org/10.1016/j.snb.2019.127498

59. H. Wang, J. Bai, M. Dai, K. Liu, Y. Liu et al., Visible light activated excellent $\mathrm{NO}_{2}$ sensing based on 2D/2D ZnO/g$\mathrm{C}_{3} \mathrm{~N}_{4}$ heterojunction composites. Sens. Actuat. B Chem. 304, 127287 (2020). https://doi.org/10.1016/j.snb.2019.127287

60. O. Casals, N. Markiewicz, C. Fabrega, I. Gràcia, C. Cane et al., A parts per billion (ppb) sensor for $\mathrm{NO}_{2}$ with microwatt $(\mu \mathrm{W})$ power requirements based on micro light plates. ACS Sens. 4(4), 822-826 (2019). https://doi.org/10.1021/acsse nsors. $9 \mathrm{~b} 00150$ 
61. I. Cho, Y.C. Sim, M. Cho, Y.H. Cho, I. Park, Monolithic micro light-emitting diode/metal oxide nanowire gas sensor with microwatt-level power consumption. ACS Sens. 5(2), 563-570 (2020). https://doi.org/10.1021/acssensors.9b02487

62. J. Saura, Gas-sensing properties of $\mathrm{SnO}_{2}$ pyrolytic films subjected to ultraviolet radiation. Sens. Actuat. B Chem. 17(3), 211-214 (1994). https://doi.org/10.1016/09254005(93)00874-X

63. E. Comini, G. Faglia, G. Sberveglieri, UV light activation of tin oxide thin films for $\mathrm{NO}_{2}$ sensing at low temperatures. Sens. Actuat. B Chem. 78, 73-77 (2001). https://doi. org/10.1016/S0925-4005(01)00796-1

64. K. Anothainart, Light enhanced $\mathrm{NO}_{2}$ gas sensing with tin oxide at room temperature: conductance and work function measurements. Sens. Actuat. B Chem. 93, 580-584 (2003). https://doi.org/10.1016/S0925-4005(03)00220-X

65. T. Hyodo, K. Urata, K. Kamada, T. Ueda, Y. Shimizu, Semiconductor-type $\mathrm{SnO}_{2}$-based $\mathrm{NO}_{2}$ sensors operated at room temperature under UV-light irradiation. Sens. Actuat. B Chem. 253, 630-640 (2017). https://doi.org/10.1016/j. snb.2017.06.155

66. F.H. Saboor, T. Ueda, K. Kamada, T. Hyodo, Y. Mortazavi, A.A. Khodadadi, Y. Shimizu, Enhanced $\mathrm{NO}_{2}$ gas sensing performance of bare and Pd-loaded $\mathrm{SnO}_{2}$ thick film sensors under UV-light irradiation at room temperature. Sens. Actuat. B Chem. 223, 429-439 (2016). https://doi.org/10.1016/j. snb.2015.09.075

67. B. Liu, Y. Luo, K. Li, H. Wang, L. Gao, G. Duan, Roomtemperature $\mathrm{NO}_{2}$ Gas sensing with ultra-sensitivity activated by ultraviolet light based on $\mathrm{SnO}_{2}$ monolayer array film. Adv. Mater. Interfaces 6(12), 1900376 (2019). https://doi. org/10.1002/admi.201900376

68. L.F. da Silva, J.C. M'Peko, A.C. Catto, S. Bernardini, V.R. Mastelaro, K. Aguir, C. Ribeiro, E. Longo, UV-enhanced ozone gas sensing response of $\mathrm{ZnO}-\mathrm{SnO}_{2}$ heterojunctions at room temperature. Sens. Actuat. B Chem. 240, 573-579 (2017). https://doi.org/10.1016/j.snb.2016.08.158

69. S. Park, S. An, Y. Mun, C. Lee, UV-enhanced $\mathrm{NO}_{2}$ gas sensing properties of $\mathrm{SnO}_{2}$-Core/ $\mathrm{ZnO}$-shell nanowires at room temperature. ACS Appl. Mater. Interfaces. 5(10), 4285-4292 (2013). https://doi.org/10.1021/am400500a

70. L. Zhao, Y. Chen, X. Li, X. Li, S. Lin, T. Li, M.N. Rumyantseva, A.M. Gaskov, Room temperature formaldehyde sensing of hollow $\mathrm{SnO}_{2} / \mathrm{ZnO}$ heterojunctions under uv-led activation. IEEE Sens. J. 19(17), 7207-7214 (2019). https:// doi.org/10.1109/JSEN.2019.2916879

71. Y. Xiong, W. Lu, D. Ding, L. Zhu, X. Li, C. Ling, Q. Xue, Enhanced room temperature oxygen sensing properties of LaOCl-SnO ${ }_{2}$ hollow spheres by UV light illumination. ACS Sens. 2(5), 679-686 (2017). https://doi.org/10.1021/acsse nsors. 7b00129

72. A. Nasriddinov, M. Rumyantseva, T. Shatalova, S. Tokarev, P. Yaltseva et al., Organic-inorganic hybrid materials for room temperature light-activated sub-ppm no detection.
Nanomaterials 10(1), 70 (2020). https://doi.org/10.3390/ nano10010070

73. X. Tian, X. Yang, F. Yang, T. Qi, A visible-light activated gas sensor based on perylenediimide-sensitized $\mathrm{SnO}_{2}$ for $\mathrm{NO}_{2}$ detection at room temperature. Colloids Surfaces A Physicochem. Eng. Asp. 578, 123621 (2019). https://doi. org/10.1016/j.colsurfa.2019.123621

74. W. Li, J. Guo, L. Cai, W. Qi, Y. Sun et al., UV light irradiation enhanced gas sensor selectivity of $\mathrm{NO}_{2}$ and $\mathrm{SO}_{2}$ using $\mathrm{rGO}$ functionalized with hollow $\mathrm{SnO}_{2}$ nanofibers. Sens. Actuat. B Chem. 290, 443-452 (2019). https://doi.org/10.1016/j. snb.2019.03.133

75. X. Li, X. Li, J. Wang, S. Lin, Highly sensitive and selective room-temperature formaldehyde sensors using hollow $\mathrm{TiO}_{2}$ microspheres. Sens. Actuat. B Chem. 219, 158-163 (2015). https://doi.org/10.1016/j.snb.2015.05.031

76. G. Murali, M. Reddeppa, C. Seshendra Reddy, S. Park, T. Chandrakalavathi, M.D. Kim, I. In, Enhancing the charge carrier separation and transport via nitrogen-doped graphene quantum dot- $\mathrm{TiO}_{2}$ nanoplate hybrid structure for an efficient NO gas sensor. ACS Appl. Mater. Interfaces 12(11), 1342813436 (2020). https://doi.org/10.1021/acsami.9b19896

77. S. Trocino, P. Frontera, A. Donato, C. Busacca, L.A. Scarpino, P. Antonucci, G. Neri, Gas sensing properties under UV radiation of $\mathrm{In}_{2} \mathrm{O}_{3}$ nanostructures processed by electrospinning. Mater. Chem. Phys. 147(1-2), 35-41 (2014). https:// doi.org/10.1016/j.matchemphys.2014.03.057

78. N.D. Chinh, N.D. Quang, H. Lee, T.T. Hien, N.M. Hieu et al., NO gas sensing kinetics at room temperature under UV light irradiation of $\operatorname{In}_{2} \mathrm{O}_{3}$ nanostructures. Sci. Rep. 6, 35066 (2016). https://doi.org/10.1038/srep35066

79. Y. Shen, X. Zhong, J. Zhang, T. Li, S. Zhao et al., In-situ growth of mesoporous $\mathrm{In}_{2} \mathrm{O}_{3}$ nanorod arrays on a porous ceramic substrate for ppb-level $\mathrm{NO}_{2}$ detection at room temperature. Appl. Surf. Sci. 498, 143873 (2019). https://doi. org/10.1016/j.apsusc.2019.143873

80. H. Ma, L. Yu, X. Yuan, Y. Li, C. Li, M. Yin, X. Fan, Room temperature photoelectric $\mathrm{NO}_{2}$ gas sensor based on direct growth of walnut-like $\mathrm{In}_{2} \mathrm{O}_{3}$ nanostructures. J. Alloys Compd. 782, 1121-1126 (2019). https://doi.org/10.1016/j.jallc om.2018.12.180

81. A. Giberti, C. Malag, V. Guidi, $\mathrm{WO}_{3}$ sensing properties enhanced by UV illumination: an evidence of surface effect. Sens. Actuat. B Chem. 165(1), 59-61 (2012). https://doi. org/10.1016/j.snb.2012.02.012

82. L. Giancaterini, S.M. Emamjomeh, A. De Marcellis, E. Palange, C. Cantalini, $\mathrm{NO}_{2}$ gas response of $\mathrm{WO}_{3}$ nanofibers by light and thermal activation. Procedia Eng. 120, 791-794 (2015). https://doi.org/10.1016/j.proeng.2015.08.824

83. X. Geng, Y. Luo, B. Zheng, C. Zhang, Photon assisted roomtemperature hydrogen sensors using $\mathrm{PdO}$ loaded $\mathrm{WO}_{3}$ nanohybrids. Int. J. Hydrogen Energy 42(9), 6425-6434 (2017). https://doi.org/10.1016/j.ijhydene.2016.12.117

84. A.K. Geim, Graphene: status and prospects. Science 324, 1530-1534 (2009). https://doi.org/10.1126/science.1158877 
85. K.S. Novoselov, V.I. Fal'Ko, L. Colombo, P.R. Gellert, M.G. Schwab, K. Kim, A roadmap for graphene. Nature 490, 192 200 (2012). https://doi.org/10.1038/nature11458

86. A.K. Geim, K.S. Novoselov, The rise of graphene. Nat. Mater. 6, 182 (2007). https://doi.org/10.1038/nmat1849

87. X. Yan, Y. Wu, R. Li, C. Shi, R. Moro, Y. Ma, L. Ma, Highperformance UV-assisted $\mathrm{NO}_{2}$ sensor based on chemical vapor deposition graphene at room temperature. ACS Omega. 4(10), 14179-14187 (2019). https://doi.org/10.1021/acsom ega.9b00935

88. M.G. Chung, D.H. Kim, H.M. Lee, T. Kim, J.H. Choi et al., Highly sensitive $\mathrm{NO}_{2}$ gas sensor based on ozone treated graphene. Sens. Actuat. B Chem. 166-167, 172-176 (2012). https://doi.org/10.1016/j.snb.2012.02.036

89. G. Chen, T.M. Paronyan, A.R. Harutyunyan, Sub-ppt gas detection with pristine graphene. Appl. Phys. Lett. 101, 053119 (2012). https://doi.org/10.1063/1.4742327

90. C.M. Yang, T.C. Chen, Y.C. Yang, M. Meyyappan, C.S. Lai, Enhanced acetone sensing properties of monolayer graphene at room temperature by electrode spacing effect and UV illumination. Sens. Actuat. B Chem. 253, 77-84 (2017). https:// doi.org/10.1016/j.snb.2017.06.116

91. C.M. Yang, T.C. Chen, Y.C. Yang, M. Meyyappan, Annealing effect on UV-illuminated recovery in gas response of graphene-based $\mathrm{NO}_{2}$ sensors. RSC Adv. 9(40), 23343-23351 (2019). https://doi.org/10.1039/c9ra01295h

92. M. Zhao, L. Yan, X. Zhang, L. Xu, Z. Song et al., Room temperature $\mathrm{NH}_{3}$ detection of Ti/graphene devices promoted by visible light illumination. J. Mater. Chem. C 5, 1113-1120 (2017). https://doi.org/10.1039/c6tc04416f

93. H. Fei, G. Wu, W.Y. Cheng, W. Yan, H. Xu et al., Enhanced $\mathrm{NO}_{2}$ sensing at room temperature with graphene via monodisperse polystyrene bead decoration. ACS Omega 4(2), 38123819 (2019). https://doi.org/10.1021/acsomega.8b03540

94. J. Azizi Jarmoshti, A. Nikfarjam, H. Hajghassem, S.M. Banihashemian, Visible light enhancement of ammonia detection using silver nanoparticles decorated on reduced graphene oxide. Mater. Res. Express 6, 066306 (2019). https://doi. org/10.1088/2053-1591/ab0bbf

95. X. An, J.C. Yu, Y. Wang, Y. Hu, X. Yu, G. Zhang, $\mathrm{WO}_{3}$ nanorods/graphene nanocomposites for high-efficiency visible-light-driven photocatalysis and $\mathrm{NO}_{2}$ gas sensing. J. Mater. Chem. 22(17), 8525-8531 (2012). https://doi.org/10.1039/ c2jm16709c

96. J.E. Ellis, D.C. Sorescu, S.C. Burkert, D.L. White, A. Star, Uncondensed graphitic carbon nitride on reduced graphene oxide for oxygen sensing via a photoredox mechanism. ACS Appl. Mater. Interfaces. 9(32), 27142-27151 (2017). https:// doi.org/10.1021/acsami.7b06017

97. J. Hu, C. Zou, Y. Su, M. Li, X. Ye et al., Light-assisted recovery for a highly-sensitive $\mathrm{NO}_{2}$ sensor based on RGO-CeO hybrids. Sens. Actuat. B Chem. 270, 119-129 (2018). https ://doi.org/10.1016/j.snb.2018.05.027

98. X. Geng, J. You, J. Wang, C. Zhang, Visible light assisted nitrogen dioxide sensing using tungsten oxide-Graphene oxide nanocomposite sensors. Mater. Chem. Phys. 191,
114-120 (2017). https://doi.org/10.1016/j.matchemphy s.2017.01.046

99. J. Wang, H. Deng, X. Li, C. Yang, Y. Xia, Visible-light photocatalysis enhanced room-temperature formaldehyde gas sensing by $\mathrm{MoS}_{2} / \mathrm{rGO}$ hybrids. Sens. Actuat. B Chem. 304, 127317 (2020). https://doi.org/10.1016/j.snb.2019.127317

100. M. Reddeppa, T. Chandrakalavathi, B.G. Park, G. Murali, R. Siranjeevi et al., UV-light enhanced CO gas sensors based on InGaN nanorods decorated with p-Phenylenediamine-graphene oxide composite. Sens. Actuat. B Chem. 307, 127649 (2020). https://doi.org/10.1016/j.snb.2019.127649

101. Y. Xia, J. Wang, L. Xu, X. Li, S. Huang, A room-temperature methane sensor based on Pd-decorated $\mathrm{ZnO} / \mathrm{rGO}$ hybrids enhanced by visible light photocatalysis. Sens. Actuat. B Chem. 304, 127334 (2020). https://doi.org/10.1016/j. snb.2019.127334

102. M. Chen, L. Zou, Z. Zhang, J. Shen, D. Li et al., Tandem gasochromic-Pd- $\mathrm{WO}_{3}$ /graphene/Si device for room-temperature high-performance optoelectronic hydrogen sensors. Carbon 130, 281-287 (2018). https://doi.org/10.1016/j.carbo n.2018.01.013

103. A. Chen, R. Liu, X. Peng, Q. Chen, J. Wu, 2D Hybrid Nanomaterials for Selective Detection of $\mathrm{NO}_{2}$ and $\mathrm{SO}_{2}$ Using "light on and Off" Strategy. ACS Appl. Mater. Interfaces. 9(42), 37191-37200 (2017). https://doi.org/10.1021/acsam i.7b11244

104. S. Kumar, S. Kaushik, R. Pratap, S. Raghavan, Graphene on paper: a simple, low-cost chemical sensing platform. ACS Appl. Mater. Interfaces. 7, 2189-2194 (2015). https://doi. org/10.1021/am5084122

105. D. Lee, H. Park, S.D. Han, S.H. Kim, W. Huh et al., Self-powered chemical sensing driven by graphene-based photovoltaic heterojunctions with chemically tunable built-in potentials. Small 15(2), 1804303 (2019). https://doi.org/10.1002/ smll.201804303

106. R. Ganatra, Q. Zhang, Few-layer $\mathrm{MoS}_{2}$ : a promising layered semiconductor. ACS Nano 8(5), 4074-4099 (2014). https:// doi.org/10.1021/nn405938z

107. B. Radisavljevic, A. Radenovic, J. Brivio, V. Giacometti, A. Kis, Single-layer $\mathrm{MoS}_{2}$ transistors. Nat. Nanotechnol. 6, 147 (2011). https://doi.org/10.1038/nnano.2010.279

108. T. Mueller, E. Malic, Exciton physics and device application of two-dimensional transition metal dichalcogenide semiconductors. Npj 2D Mater. Appl. 2 (2018). https://doi. org/10.1038/s41699-018-0074-2

109. S.Y. Cho, H.J. Koh, H.W. Yoo, J.S. Kim, H.T. Jung, Tunable volatile-organic-compound sensor by using Au nanoparticle incorporation on $\mathrm{MoS}_{2}$. ACS Sens. 2, 183-189 (2017). https ://doi.org/10.1021/acssensors.6b00801

110. M. Donarelli, L. Ottaviano, $2 \mathrm{~d}$ materials for gas sensing applications: a review on graphene oxide, $\mathrm{MoS}_{2}, \mathrm{WS}_{2}$ and phosphorene. Sensors 18(11), 3638 (2018). https://doi. org/10.3390/s18113638

111. F.K. Perkins, A.L. Friedman, E. Cobas, P.M. Campbell, G.G. Jernigan, B.T. Jonker, Chemical vapor sensing with 
monolayer $\mathrm{MoS}_{2}$. Nano Lett. 13, 668-673 (2013). https:// doi.org/10.1021/n13043079

112. D.J. Late, Y.K. Huang, B. Liu, J. Acharya, S.N. Shirodkar et al., Sensing behavior of atomically thin-layered $\mathrm{MoS}_{2}$ transistors. ACS Nano 7, 4879-4891 (2013). https://doi. org/10.1021/nn400026u

113. A.L. Friedman, F. Keith Perkins, E. Cobas, G.G. Jernigan, P.M. Campbell, A.T. Hanbicki, B.T. Jonker, Chemical vapor sensing of two-dimensional $\mathrm{MoS}_{2}$ field effect transistor devices. Solid State. Electron. 101, 2-7 (2014). https://doi. org/10.1016/j.sse.2014.06.013

114. R. Kumar, N. Goel, M. Kumar, UV-activated $\mathrm{MoS}_{2}$ based fast and reversible $\mathrm{NO}_{2}$ sensor at room temperature. ACS Sensors 2, 1744-1752 (2017). https://doi.org/10.1021/acsse nsors.7b00731

115. R. Kumar, P.K. Kulriya, M. Mishra, F. Singh, G. Gupta, M. Kumar, Highly selective and reversible $\mathrm{NO}_{2}$ gas sensor using vertically aligned $\mathrm{MoS}_{2}$ flake networks. Nanotechnology 29(46), 464001 (2018). https://doi.org/10.1088/1361-6528/ aade 20

116. B. Cho, M.G. Hahm, M. Choi, J. Yoon, A.R. Kim et al., Charge-transfer-based gas sensing using atomic-layer $\mathrm{MoS}_{2}$. Sci. Rep. 5, 80525 (2015). https://doi.org/10.1038/ srep08052

117. S. Ramu, T. Chandrakalavathi, G. Murali, K.S. Kumar, A. Sudharani et al., UV enhanced NO gas sensing properties of the $\mathrm{MoS}_{2}$ monolayer gas sensor. Mater. Res. Express. 6, 85075 (2019). https://doi.org/10.1088/2053-1591/ab20b7

118. Y. Kang, S. Pyo, E. Jo, J. Kim, Light-assisted recovery of reacted $\mathrm{MoS}_{2}$ for reversible $\mathrm{NO}_{2}$ sensing at room temperature. Nanotechnology 30, 355504 (2019). https://doi. org/10.1088/1361-6528/ab2277

119. Y.Z. Chen, S.W. Wang, C.C. Yang, C.H. Chung, Y.C. Wang et al., An indoor light-activated 3D cone-shaped $\mathrm{MoS}_{2}$ bilayer-based NO gas sensor with PPb-level detection at room-temperature. Nanoscale 11(21), 10410-10419 (2019). https://doi.org/10.1039/c8nr10157d

120. T. Pham, G. Li, E. Bekyarova, M.E. Itkis, A. Mulchandani, $\mathrm{MoS}_{2}$-based optoelectronic gas sensor with sub-parts-perbillion limit of $\mathrm{NO}_{2}$ gas detection. ACS Nano 13(3), 31963205 (2019). https://doi.org/10.1021/acsnano.8b08778

121. R. Kumar, N. Goel, M. Mishra, G. Gupta, M. Fanetti, M. Valant, M. Kumar, Growth of $\mathrm{MoS}_{2}-\mathrm{MoO}_{3}$ hybrid microflowers via controlled vapor transport process for efficient gas sensing at room temperature. Adv. Mater. Interfaces 5(10), 1800071 (2018). https://doi.org/10.1002/admi.201800071

122. J.-S. Kim, H.-W. Yoo, H.O. Choi, H.-T. Jung, Tunable volatile organic compounds sensor by using thiolated ligand conjugation on $\mathrm{MoS}_{2}$. Nano Lett. 14, 5941-5947 (2014). https://doi. org/10.1021/nl502906a

123. Y. Zhou, C. Zou, X. Lin, Y. Guo, UV light activated $\mathrm{NO}_{2}$ gas sensing based on Au nanoparticles decorated few-layer $\mathrm{MoS}_{2}$ thin film at room temperature. Appl. Phys. Lett. 113, 1-7 (2018). https://doi.org/10.1063/1.5042061
124. Y. Zhou, C. Gao, Y. Guo, UV assisted ultrasensitive trace $\mathrm{NO}_{2}$ gas sensing based on few-layer $\mathrm{MoS}_{2}$ nanosheet-ZnO nanowire heterojunctions at room temperature. J. Mater. Chem. A 6, 10286-10296 (2018). https://doi.org/10.1039/ c8ta02679c

125. Y. Xia, C. Hu, S. Guo, L. Zhang, M. Wang et al., Sulfurvacancy-enriched $\mathrm{MoS}_{2}$ nanosheets based heterostructures for near-infrared optoelectronic $\mathrm{NO}_{2}$ sensing. ACS Appl. Nano Mater. 3(1), 665-673 (2020). https://doi.org/10.1021/acsan m.9b02180

126. W. Zheng, Y. Xu, L. Zheng, C. Yang, N. Pinna, X. Liu, J. Zhang, $\mathrm{MoS}_{2}$ van der waals $\mathrm{p}-\mathrm{n}$ junctions enabling highly selective room-temperature $\mathrm{NO}_{2}$ sensor. Adv. Funct. Mater. 30(19), 2000435 (2020). https://doi.org/10.1002/adfm.20200 0435

127. M. Reddeppa, B.G. Park, G. Murali, S.H. Choi, N.D. Chinh et al., NOx gas sensors based on layer-transferred n- $\mathrm{MoS}_{2} / \mathrm{p}$ $\mathrm{GaN}$ heterojunction at room temperature: study of UV light illuminations and humidity. Sens. Actuat. B Chem. 308, 127700 (2020). https://doi.org/10.1016/j.snb.2020.127700

128. N. Goel, R. Kumar, S.K. Jain, S. Rajamani, B. Roul et al., A high-performance hydrogen sensor based on a reverse-biased $\mathrm{MoS}_{2} / \mathrm{GaN}$ heterojunction. Nanotechnology 30, 314001 (2019). https://doi.org/10.1088/1361-6528/ab1102

129. J. Guo, R. Wen, J. Zhai, Z.L. Wang, Enhanced $\mathrm{NO}_{2}$ gas sensing of a single-layer $\mathrm{MoS}_{2}$ by photogating and piezo-phototronic effects. Sci. Bull. 64, 128-135 (2019). https://doi. org/10.1016/j.scib.2018.12.009

130. L. Zhou, K. Xu, A. Zubair, A.D. Liao, W. Fang et al., Largearea synthesis of high-quality uniform few-layer $\mathrm{MoTe}_{2}$. J. Am. Chem. Soc. 137(37), 11892-11895 (2015). https://doi. org/10.1021/jacs.5b07452

131. T.J. Octon, V.K. Nagareddy, S. Russo, M.F. Craciun, C.D. Wright, Fast high-responsivity few-layer $\mathrm{MoTe}_{2}$ photodetectors. Adv. Opt. Mater. 4(11), 1750-1754 (2016). https://doi. org/10.1002/adom.201600290

132. Z. Feng, Y. Xie, E. Wu, Y. Yu, S. Zheng et al., Enhanced sensitivity of $\mathrm{MoTe}_{2}$ chemical sensor through light illumination. Micromachines 8(5), 155 (2017). https://doi.org/10.3390/ mi8050155

133. E. Wu, Y. Xie, B. Yuan, H. Zhang, X. Hu, J. Liu, D. Zhang, Ultrasensitive and fully reversible $\mathrm{NO}_{2}$ gas sensing based on p-type $\mathrm{MoTe}_{2}$ under ultraviolet illumination. ACS Sens. 3(9), 1719-1726 (2018). https://doi.org/10.1021/acssensors.8b004 61

134. H.S. Kim, M. Patel, J. Kim, M.S. Jeong, Growth of waferscale standing layers of $\mathrm{WS}_{2}$ for self-biased high-speed UVvisible-NIR optoelectronic devices. ACS Appl. Mater. Interfaces. 10, 3964-3974 (2018). https://doi.org/10.1021/acsam i. 7 b 16397

135. N. Huo, S. Yang, Z. Wei, S.S. Li, J.B. Xia, J. Li, Photoresponsive and gas sensing field-effect transistors based on multilayer $\mathrm{WS}_{2}$ nanoflakes. Sci. Rep. 4, 5209 (2014). https://doi. org/10.1038/srep05209

136. D. Gu, X. Li, H. Wang, M. Li, Y. Xi et al., Light enhanced VOCs sensing of $\mathrm{WS}_{2}$ microflakes based chemiresistive 
sensors powered by triboelectronic nangenerators. Sens. Actuat. B Chem. 256, 992-1000 (2018). https://doi. org/10.1016/j.snb.2017.10.045

137. A.Y. Polyakov, D.A. Kozlov, V.A. Lebedev, R.G. Chumakov, A.S. Frolov et al., Gold decoration and photoresistive response to nitrogen dioxide of $\mathrm{WS}_{2}$ nanotubes. Chem. A Eur. J. 24(71), 18952-18962 (2018). https://doi.org/10.1002/ chem.201803502

138. V. Paolucci, S.M. Emamjomeh, L. Ottaviano, C. Cantalini, Near room temperature light-activated $\mathrm{WS}_{2}$-decorated $\mathrm{rGO}$ as $\mathrm{NO}_{2}$ gas sensor. Sensors 19(11), 2617 (2019). https://doi. org/10.3390/s19112617

139. L.A. Burton, D. Colombara, R.D. Abellon, F.C. Grozema, L.M. Peter et al., Synthesis, characterization, and electronic structure of single-crystal $\mathrm{SnS}, \mathrm{Sn}_{2} \mathrm{~S}_{3}$, and $\mathrm{SnS}_{2}$. Chem. Mater. 25(24), 4908-4916 (2013). https://doi.org/10.1021/ $\mathrm{cm} 403046 \mathrm{~m}$

140. Y. Huang, E. Sutter, J.T. Sadowski, M. Cotlet, O.L.A. Monti et al., Tin disulfide-an emerging layered metal dichalcogenide semiconductor: materials properties and device characteristics. ACS Nano 8(10), 10743-10755 (2014). https://doi. org/10.1021/nn504481r

141. G. Su, V.G. Hadjiev, P.E. Loya, J. Zhang, S. Lei et al., Chemical vapor deposition of thin crystals of layered semiconductor $\mathrm{SnS}_{2}$ for fast photodetection application. Nano Lett. 15, 506-513 (2015). https://doi.org/10.1021/nl503857r

142. T.J. Whittles, L.A. Burton, J.M. Skelton, A. Walsh, T.D. Veal, V.R. Dhanak, Band alignments, valence bands, and core levels in the tin sulfides $\mathrm{SnS}, \mathrm{SnS}_{2}$, and $\mathrm{Sn}_{2} \mathrm{~S}_{3}$ : experiment and theory. Chem. Mater. 28(11), 3718-3726 (2016). https://doi. org/10.1021/acs.chemmater.6b00397

143. D. Gu, X. Wang, W. Liu, X. Li, S. Lin et al., Visible-light activated room temperature $\mathrm{NO}_{2}$ sensing of $\mathrm{SnS}_{2}$ nanosheets based chemiresistive sensors. Sens. Actuat. B Chem. 305, 127455 (2020). https://doi.org/10.1016/j.snb.2019.127455

144. W.J. Yan, D.Y. Chen, H.R. Fuh, Y.L. Li, D. Zhang et al., Photo-enhanced gas sensing of $\mathrm{SnS}_{2}$ with nanoscale defects.
RSC Adv. 9(2), 626-635 (2019). https://doi.org/10.1039/ c8ra08857h

145. H. Chen, Y. Chen, H. Zhang, D.W. Zhang, P. Zhou, J. Huang, Suspended $\mathrm{SnS}_{2}$ layers by light assistance for ultrasensitive ammonia detection at room temperature. Adv. Funct. Mater. 28(20), 1801035 (2018). https://doi.org/10.1002/adfm.20180 1035

146. Y. Huang, W. Jiao, Z. Chu, G. Ding, M. Yan, X. Zhong, R. Wang, Ultrasensitive room temperature ppb-level $\mathrm{NO}_{2}$ gas sensors based on $\mathrm{SnS}_{2} / \mathrm{rGO}$ nanohybrids with $\mathrm{P}-\mathrm{N}$ transition and optoelectronic visible light enhancement performance. J. Mater. Chem. C 7(28), 8616-8625 (2019). https://doi. org/10.1039/c9tc02436k

147. S. Tongay, H. Sahin, C. Ko, A. Luce, W. Fan et al., Monolayer behaviour in bulk $\mathrm{ReS}_{2}$ due to electronic and vibrational decoupling. Nat. Commun. 5, 3252 (2014). https://doi. org/10.1038/ncomms4252

148. S. Yang, J. Kang, Q. Yue, J.M.D. Coey, C. Jiang, Defect-modulated transistors and gas-enhanced photodetectors on $\mathrm{ReS}_{2}$ nanosheets. Adv. Mater. Interfaces 3(6), 1500707 (2016). https://doi.org/10.1002/admi.201500707

149. B. Anasori, M.R. Lukatskaya, Y. Gogotsi, 2D metal carbides and nitrides (MXenes) for energy storage. Nat. Rev. Mater. 2, 16098 (2017). https://doi.org/10.1038/natrevmats.2016.98

150. J. Pang, R.G. Mendes, A. Bachmatiuk, L. Zhao, H.Q. Ta, T. Gemming, H. Liu, Z. Liu, M.H. Rummeli et al., Applications of 2D MXenes in energy conversion and storage systems. Chem. Soc. Rev. 48(1), 72-133 (2019). https://doi. org/10.1039/c8cs00324f

151. J. Zhu, E. Ha, G. Zhao, Y. Zhou, D. Huang et al., Recent advance in MXenes: a promising 2D material for catalysis, sensor and chemical adsorption. Coord. Chem. Rev. 352, 306-327 (2017). https://doi.org/10.1016/j.ccr.2017.09.012

152. S. Chertopalov, V.N. Mochalin, Environment-sensitive photoresponse of spontaneously partially oxidized $\mathrm{Ti}_{3} \mathrm{C}_{2}$ MXene thin films. ACS Nano 12(6), 6109-6116 (2018). https://doi. org/10.1021/acsnano.8b02379 